\title{
Effect of acute phase cytokines on iron uptake in hepatocytes and differential localization of Lipocalin-2 and Transferrin receptors in rat hepatic and extra hepatic organs
}

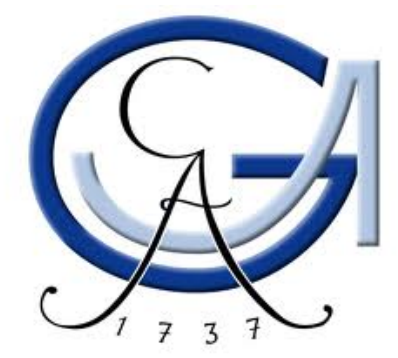

\author{
Dissertation \\ for the award of the degree \\ "Doctor of Philosophy" Ph.D. \\ Division of Mathematics and Natural Sciences \\ of the Georg-August-Universität Göttingen \\ within the doctoral program Biology \\ of the Georg-August University School of Science (GAUSS) \\ submitted by
}

Shakil Ahmad

from Lahore, Pakistan

Göttingen, 2014 


\section{Thesis Committee}

\section{Referent: Prof. Dr. Gregor Eichele}

Deptartment of Genes and Behaviour Max Planck Institute for Biophysical Chemistry,

Korreferent: Prof. Dr. Lutz Walter

Department of Primate Genetics, German Primate Center

\section{Members of the Examination Boards}

1. Prof. Dr. Silvio Rizzoli

STED Microscopy of Synaptic Function, European Neuroscience Institute

2. Prof. Dr. Ernst Wimmer

Department of Developmental Biology, Johann-Friedrich-Blumenbach-Institute of Zoology and Anthropology

3. Prof. Dr. Heidi Hahn

Department of Human Genetics, Section of Developmental Genetics

4. Prof. Dr. Uwe-Karsten Hanisch

Department of Neuropathology, UMG

Date of Oral Examination: 24.03.2014 


\section{Declaration}

I hereby declare that the Ph.D. thesis entitled "Effect of acute phase cytokines on iron uptake in hepatocytes and differential localization of Lipocalin-2 and Transferrin receptors in rat hepatic and extra hepatic organs" is my unaided work, with no other sources than quoted. The material of this thesis has not been submitted elsewhere for any academic qualification. 


\section{TABLE OF CONTENTS}

Abbreviations

1 Introduction _ 1

1.1 Iron an essential element of Life___ 1

1.2 Iron metabolism and liver __ 2

1.3 Mechanisms of iron uptake __ 5

1.3.1 Transferrin bound iron uptake and regulation of $T f R$

1.3.1.1 Transferrin receptor 1 (TfR1) mediated iron uptake __ 5

1.3.1.2 Transferrin receptor 2 (TfR2) mediated iron uptake __ 6

1.3.1.3 Non-Transferrin bound iron uptake (NTBI)___ 8

1.4 Iron storage 10

$1.5 \quad$ Acute phase response (APR) __ 12

1.6 Experimental model of acute phase study (ARP) _ 15

1.6.1 Animal Model of ARP — 15

1.6.2 In vitro Model of ARP

1.7 Aims of study _ 17

2 MATERIALS — 19

2.1 Chemicals__ 19

2.2 Animals and experimental models of acute-phase reaction__ 20

3 METHODS_L 21

3.1 Methods of cell biology ___ 21

3.1.1 Isolation of rat liver cells __ 21

3.1.1.1 Isolation of rat hepatocytes __ 21

3.2 Methods in molecular biology___ 23

3.2.1 RNA isolation _ 23

3.2.2 Reverse transcription (RT) _ 23

3.2.3 Real time quantitative Polymerase chain reaction___ 24

3.2.4 Thermal cycler amplification program _ 24

3.2.5 Standard Curve_ 25

3.2.6 Primers designing _ 25

3.3 Methods of biochemistry __ 25

3.3.1 Protein extraction from liver tissue and cultured hepatocytes __ 25

3.3.1.1 Preparation of tissue homogenates __ 25

3.3.1.2 Preparation of cell lysate___ 26

3.3.2 Proteins isolation and Western Blot _ 26

3.3.3 Immunohistochemistry__ 27

3.4 Methods in clinical chemistry ___ 28 
3.4.1 Iron measurement__ 28

3.4.1.1 Principle__ 28

3.4.1.2 Reagents__ 28

3.4.1.3 Assay Procedure _ 28

3.4.1.4 Calculations__ 29

3.4.1.5 Measuring range __ 29

3.4.1.6 Specificity and sensitivity __ 29

3.5 Statistical analysis _ 29

4 Regulation of iron uptake in primary culture rat hepatocytes: The role of acute phase cytokines 30

5 Regulation and Localization pattern of transferrin receptors and lipocalin-2 in rat hepatic and extra-hepatic organs under physiological and acute phase conditions

6 Ferritin $L$ and ferritin $H$ are differentially located within hepatic and extra hepatic organs under physiological and acute phase conditions 32

7 Discussion 33

7.1 Iron uptake and regulation of iron transport and iron storage proteins in primary culture of rat hepatocytes: Role of $I L-6$ 33

7.2 Kinetic of acute phase cytokines after turpentine oil induced acute phase response 36

7.3 Regulation of iron transport proteins after TO-induced acute phase response in rat and mice hepatic tissue 37

7.4 The cellular localization of iron transport proteins in rat hepatic and extra-hepatic tissues 38 7.5 The cellular localization of iron storage proteins (FTH, FTL) in rat hepatic and extrahepatic tissues 40

8 CONCLUSION__ 42

9 SUMMARY_ 44

10 BIBLIOGRAPHY_ 47

11 AKNOWLEDGEMENTS___ 57

12 CURRICULUM VITAE __ 59 


\section{ABBREVIATIONS}

$\mathrm{Ab}$

APP

APR

BCA

BSA

cDNA

CRP

$\mathrm{Ct}$

dd $\mathrm{H}_{2} \mathrm{O}$

DMSO

dNTP

DTT

Dcytb

DMT1

DTT

EDTA

FCS

FTH

FTL

Fpn1

g

GFP

gp

GRE

HIF

HRP

Нерс
Antibody

Acute phase proteins

Acute phase response

Bicinchoninic acid

Bovine serum albumin

Copy desoxyribonucleic acid

C-reactive protein

Threshold cycle

Double distilled water

Dimethylsulfoxide

Deoxyribonucleoside triphosphate

Dithiothreitol

Duodenal cytochrome B reductase

Divalent metal transporter 1

Dithiothreitol

Ethylendiaminetetraacetic acid

Fetal calf serum

Ferritin heavy chain

Ferritin light chain

Ferroportin 1

Gravity

Green fluorescent protein

Glycoprotein

Glucocorticoid response element

Hypoxia induced factor

Horseradish peroxidase

Hepcidin 


\begin{tabular}{|c|c|}
\hline Heph & Hephaestin \\
\hline HFE & Hemochromatosis gene \\
\hline Hjv & Hemojuvelin \\
\hline IgG & Immunoglobulin G \\
\hline IL & Interleukin \\
\hline IRP & Iron regulatory protein \\
\hline IFN- $\gamma$ & Interferon gamma \\
\hline IL-1 $\beta$ & Interleukin 1 Beta \\
\hline IL-6 & Interleukin 6 \\
\hline IRE & Iron responsive elements \\
\hline IRE-BP1 & Iron responsive element binding protein 1 \\
\hline IRE-BP2 & Iron responsive element binding protein 2 \\
\hline $\mathrm{kDa}$ & Kilodalton \\
\hline LCN-2 & Lipocalin-2 \\
\hline Min & Minutes \\
\hline MOPS & 3-(N-Morpholino)-propanesulfonic acid \\
\hline OD & Optical density \\
\hline PBS & Phosphate buffered saline \\
\hline PCR & Polymerase chain reaction \\
\hline PMSF & Phenylmethyl sulfonylfluoride \\
\hline PBS & Phosphate buffered saline \\
\hline PCR & Polymerase chain reaction \\
\hline PMSF & Phenylmethyl sulfonylfluoride \\
\hline rpm & Revolutions per minute \\
\hline $\mathrm{RT}$ & Room temperature \\
\hline RT-PCR & Reverse transcriptase-PCR \\
\hline RNase & Ribonuclease \\
\hline ROS & Reactive oxygen species \\
\hline
\end{tabular}




$\begin{array}{ll}\text { rpm } & \text { Revolutions per minute } \\ \text { RT-PCR } & \text { Reverse transcriptase-PCR } \\ \text { SDS } & \text { Sodium dodecylsulfate } \\ \text { SDS-PAGE } & \text { SDS-polyacrylamide gel electrophoresis } \\ \text { SEM } & \text { Standard error of the mean } \\ \text { TEMED } & \text { N, N, } \mathrm{N}^{\prime}, \mathrm{N}^{\prime} \text {-tetramethylethylenediamine } \\ \text { TNF- } \alpha & \text { Tumor necrosis factor } \alpha \\ \text { Tris } & \text { Tris-(hydroxymethyl)-aminomethane } \\ \text { TAE } & \text { Tris acetate EDTA buffer } \\ \text { Tf } & \text { Transferrin } \\ \text { TfR1 } & \text { Transferrin receptor 1 } \\ \text { TfR2 } & \text { Transferrin receptor } 2 \\ \text { TO } & \text { Turpentine oil } \\ \text { Tris } & \text { Tris-(hydroxymethyl)-aminomethane } \\ \text { UTR } & \text { Untranslated region } \\ \text { UV } & \text { Ultraviolet }\end{array}$




\section{INTRODUCTION}

\subsection{Iron an essential element of Life}

With few exceptions, almost every cell needs iron as an essential cofactor for biochemical processes, i.e. oxygen transport, energy metabolism, mitochondrial functions, myelin production and DNA synthesis (Camaschella, 2013; Hentze et al, 2004;Napier et al, 2005). Due to redox reactivity of iron it can associate with proteins, couple with oxygen and can also transfer electrons or mediate catalytic reactions (Aisen et al, 2001).

An imbalance of body iron can lead to pathological conditions. The most common disorder of iron metabolism associated with iron depletion is iron deficiency anemia, which affects over $30 \%$ of the world's population and is especially prevalent in developing countries (DeMaeyer and Adiels-Tegman, 1985). Factors such as inadequate iron intake, blood loss, increased iron requirements, and reduced iron absorption contribute to the progression of iron deficiency (Dreyfuss et al., 2000; Lewis et al., 2005; Stoltzfus et al., 2000). At the other extreme are iron overload disorders such as hemochromatosis which is due to excess iron deposition, primarily in the liver (Pietrangelo, 2010). It shows that iron could be potentially toxic because it catalyses the dissemination of ROS (reactive oxygen species) under aerobic conditions which ultimately generate potentially reactive hydroxyl radicals by Fenton pathway (Koppenol, 1993). The

oxidative stress, due to ROS is associated with cellular damage of macromolecules, tissues and certain disease conditions (Galaris et al., 2008; Kell, 2009). However, the acquisition, usage and detoxification of iron is a considerable challenge for cells and organisms, which have evolved various sophisticated mechanisms to comply with their metabolic needs and to 
minimize the risk of toxicity concomitantly (Andrews, 2008; De, I et al., 2008; Hentze et al., 2010).

The amount of iron in the body depends on age, gender, nutrition, and general state of health. In normal conditions, two-thirds of total body iron is incorporated into hemoglobin by erythroid cells, while the remaining third is stored in the liver ( $\sim \mathrm{g}$ iron) or as myoglobin in muscle (300 mg iron) or is found in reticuloendothelial macrophages (600 mg iron) (Andrews, 1999; Olsson and Norrby, 2008). Other tissues contain lower quantities of iron but not negligible.

\subsection{Iron metabolism and liver}

The liver is a major organ for the synthesis of iron regulatory proteins and its output includes several proteins that play critical roles in iron metabolism. These include iron transport proteins [(Tf, TfR1, TfR2, LCN-2)(Johnson et al., 2007; Kaplan, 2002; Lu et al., 1989; Yang et al., 2002)], iron storage proteins [(Ferritin)(Arosio et al., 2009)] ceruloplasmin, haptoglobin, hemopexin, hepcidin and iron export protein ferroportin 1 (Fig. 1b). A major cell population of the liver, hepatocytes (70\% of the cells of liver) is the key cells to regulate iron absorption and reutilization of iron after senescent red cells are phagosytosed and digested by macrophages.

Dietary iron absorption from intestinal lumen (Fig. 1a) and recycling by macrophages (Fig. 1d) is regulated by different physiological factors including iron-load, erythropoiesis and inflammation (De, I et al., 2008). Hepcidin, an antimicrobial peptide secreted by liver, is a key element in the regulation of iron homeostasis (Ganz and Nemeth, 2012; Loreal et al., 2000). Hepcidin is a 25 amino acid peptide secreted by the liver into the circulation (Fig. 1c). In fact, hepcidin synthesis is regulated by iron demand; transcription of hepcidin is increased when iron 
stores are high and, conversely, decreased when iron stores are depleted. In different conditions of chronic inflammation, such as arthritis or cancer-associated inflammation, hepcidin production is increased and decreased iron absorption results in an iron-limited erythropoiesis, known as the anemia of chronic inflammation (De, I et al., 2006).

Almost most of the iron in the circulation is transported by plasma $\mathrm{Tf}$ and the vast majority of Tf is synthesized in the liver (Ponka et al., 1998). Transferrin (Tf)-iron is transported to the reticuloendothelial system (spleen, liver and bone marrow), to liver parenchymal cells and to all proliferating cells in the body. It carries iron through portal blood to the liver by TfR1 mediated iron uptake mechanism (Hentze et al. 2010) or Tf-independent mechanism (Prus and Fibach 2011). Another transferrin-dependent iron uptake route is via TfR2. Although, the role of TfR1 is well defined for transporting iron across the plasma membrane, the role of TfR2 is not yet clearly understood. TfR2 appears to be involved in systemic iron homeostasis (Fig. 1c) rather than in cellular iron uptake and delivery because mutations in the TfR2 gene or its knockout results in hepatic iron overload (Roetto et al. 2010).

However, there has been convincing evidences that, during disrupted iron homeostasis, iron delivery to cells can take place be alternative mechanism i.e. transferrin-independent pathway. This alternative to transferrin-iron is called non-transferrin bound iron (NTBI). This pool has been documented in a variety of iron overload syndromes when transferrin is saturated (Hentze et al., 2004), including hemochromatosis (69\% of patients) and end-stage renal disease (22\% of patients) (Breuer et al., 2000b). Furthermore, NTBI can reduce the uptake of Tf-bound iron and vice versa (Graham et al., 1998; Trinder and Morgan, 1997). A recent study has shown that 
LCN-2 can deliver iron to kidney cells during development (Yang et al., 2003).

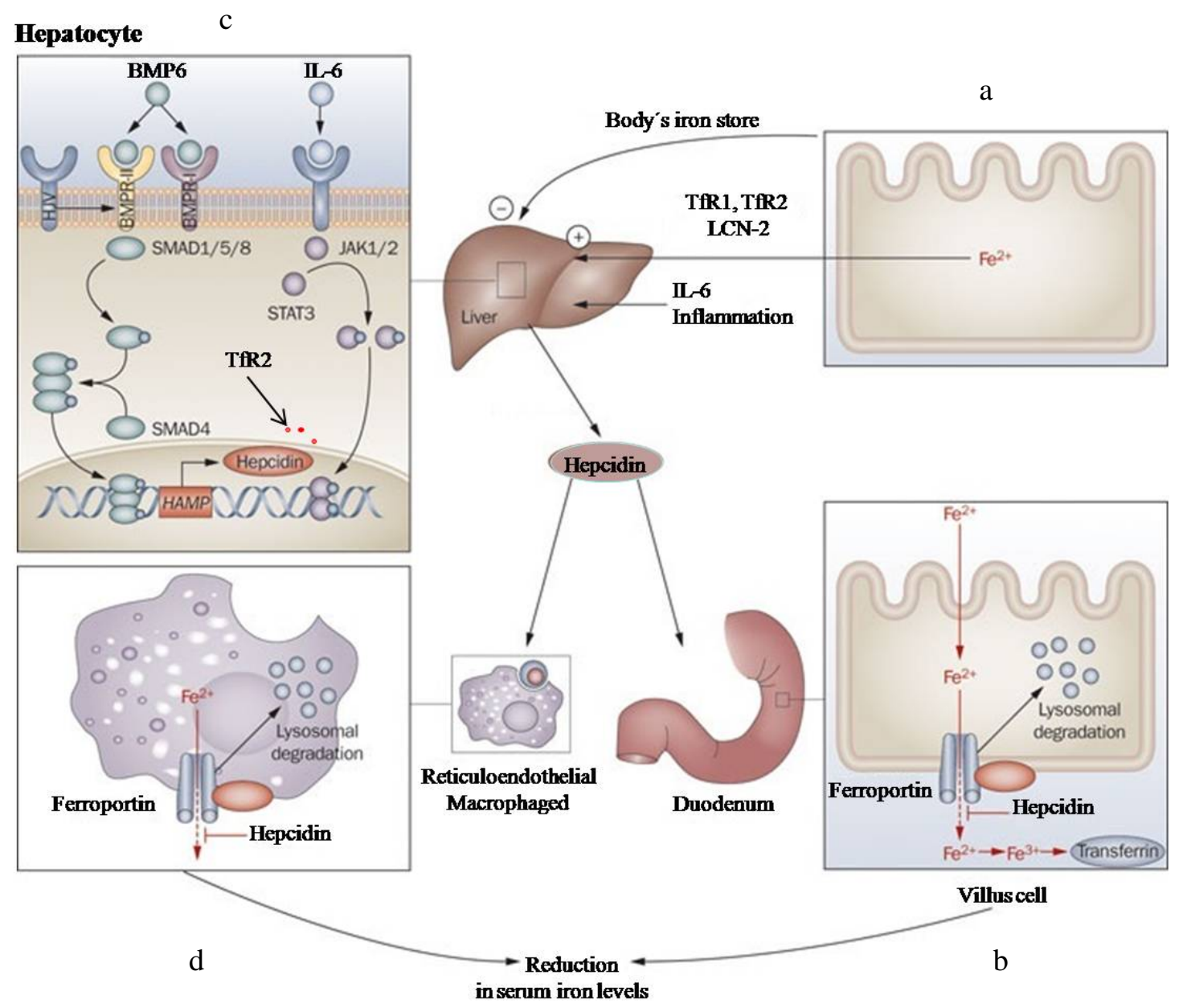

Figure 1: A Schematic overview of iron absorption. From intestinal lumen $\mathrm{Fe}^{+3}$ is reduced to $\mathrm{Fe}^{+2}$ by reductase enzyme and then transported to enterocytes by DMT1 (a). Ferroportin 1 export this iron into the circulation and transferrin bind the free iron which is transported to Liver via Tf-TfR mediated pathway (b). Hepcidin gene expression is up-regulated during inflammation by proinflammatory cytokines mainly IL-6 (involving JAK-dependent activation of STAT3) (c). Hepcidin binds to ferroportin and triggers its lysosomal degradation, leading to a reduction in iron release from enterocytes and macrophages (d). Modified from:Stein et al., 2010. 


\subsection{Mechanisms of iron uptake}

\subsubsection{Transferrin bound iron uptake and regulation of $T f R$}

\subsubsection{Transferrin receptor 1 (TfR1) mediated iron uptake}

Many studies on the uptake of Tf-bound iron by perfused liver, by isolated hepatocytes, or by hepatoma cell lines showed existence of both a high-affinity saturable component and a lowaffinity unsaturable component (Goldenberg et al., 1991; Morgan, 1991; Trinder et al., 1988). The high-affinity uptake of $\mathrm{Tf}$ by hepatic cells is mediated by $\mathrm{Tf}$ receptor 1 [(TfR1, figure 2$)$ (Aisen, 2004; Hentze et al., 2010)]. At physiological pH, TfR1 binds diferric Tf with 10-fold higher affinity than mono-ferric Tf and 2000-fold higher affinity than apo-transferrin (Ponka et al., 1998). After Tf binding to TfR1 on the cell surface, endocytosis of this Tf-TfR1 complex takes place through clathrin-coated pits (Fig. 2). These vesicles are then uncoated to become endosomes and are acidified by a proton pumping ATPas (Watkins et al., 1992). After entering the cytosol, iron is released at a $\mathrm{pH}$ of around 5.5, a process requiring also reduction (Richardson et al., 2010) and takes advantage of a conformational change in Tf that accompanies its binding to TfR1 (Bali et al., 1991). The ferrireductase Steap3 reduces cytosolic Fe3+ to Fe2+ (Ohgami et al, 2005), transported by DMT1 or directly in erythroid cell's mitochondria (Richardson et al., 2010). The affinity of TfR 1 for apotransferrin is much higher at the low $\mathrm{pH}$ of the endosome than at physiological $\mathrm{pH}$ and the two proteins remain bound as the endosome is recycled to the plasma membrane. Apotransferrin is then released into the extracellular milieu where it can again bind iron (Fig. 2). Within the liver, all cell types have Tf receptors as they all need iron to meet their basic metabolic requirements, but quantitatively hepatocytes take up most Tf (Morgan et al., 1986; Sibille et al., 1986). A study demonstrated that hepatocytes expressed three- to fourfold more high-affinity diferric Tf binding sites than nonparenchymal cells which is most likely 
TfR1 (Vogel et al., 1987). TfR1 receptor has also been detected on Kupffer cells (Vogel et al., 1987), endothelial cells (Tavassoli et al., 1986), and activated hepatic stellate cells (Bridle et al., 2003). During iron deficiency conditions, cells require more iron and increase both their total cellular complement of TfR1 and the proportion of TfR1 on the plasma membrane (Aisen, 2004; Hirose-Kumagai and Akamatsu, 1989). Some regulation of the TfR1 gene occurs at the transcriptional level, while most regulation is at the level of mRNA stability via the iron regulatory element (IRE)/iron regulatory protein (IRP) system (Eisenstein, 2000). The TfR1 mRNA contains a series of stem-loop structures (iron responsive elements or IREs) in its 3' untranslated region (UTR) which act as targets for the iron-responsive RNA binding proteins IRP1 and IRP2. When intracellular iron levels decrease, the IRPs bind to the TfR1 3' UTR and protect the TfR1 mRNA from endonuclease degradation. Consequently more TfR1 is synthesized (Mullner and Kuhn, 1988). The opposite response is observed when cells have an excess of iron and a reduction in TfR1 expression serves to protect the cells from accumulating iron (Rouault, 2006; Wallander et al., 2006). TfR1 levels are much higher in fetal liver than in adult liver (Trinder et al., 1986) and in regenerating liver after partial hepatectomy (Cairo et al., 2002; Hirose-Kumagai and Akamatsu, 1989). It reflects the iron requirements of the rapidly growing hepatocyte mass and is likely mediated through the IRE/IRP system. Finally, TfR1 gene expression can also be modulated by cytokines, hypoxia, and nitric oxide, and these factors could play a role in TfR1 synthesis, particularly during disease states (Cairo et al., 2002; Trinder et al., 2002).

\subsubsection{Transferrin receptor 2 (TfR2) mediated iron uptake}

Many studies suggest that the low-affinity iron uptake process may be mediated by the TfR2, TfR1 homolog (Cairo et al., 2002; Kawabata et al., 1999; Lee et al., 2003; Robb et al., 
2004; Trinder et al., 2002). TfR2, like TfR1, is a plasma membrane Tf-binding protein with 25fold lower affinity for diferric Tf than that of TfR1, making it a strong candidate for the lowaffinity binding site. Expression pattern of TfR2 also differs from TfR1. TfR2 has a much more restricted tissue distribution. High expression levels of TfR2 are present on hepatic parenchymal-

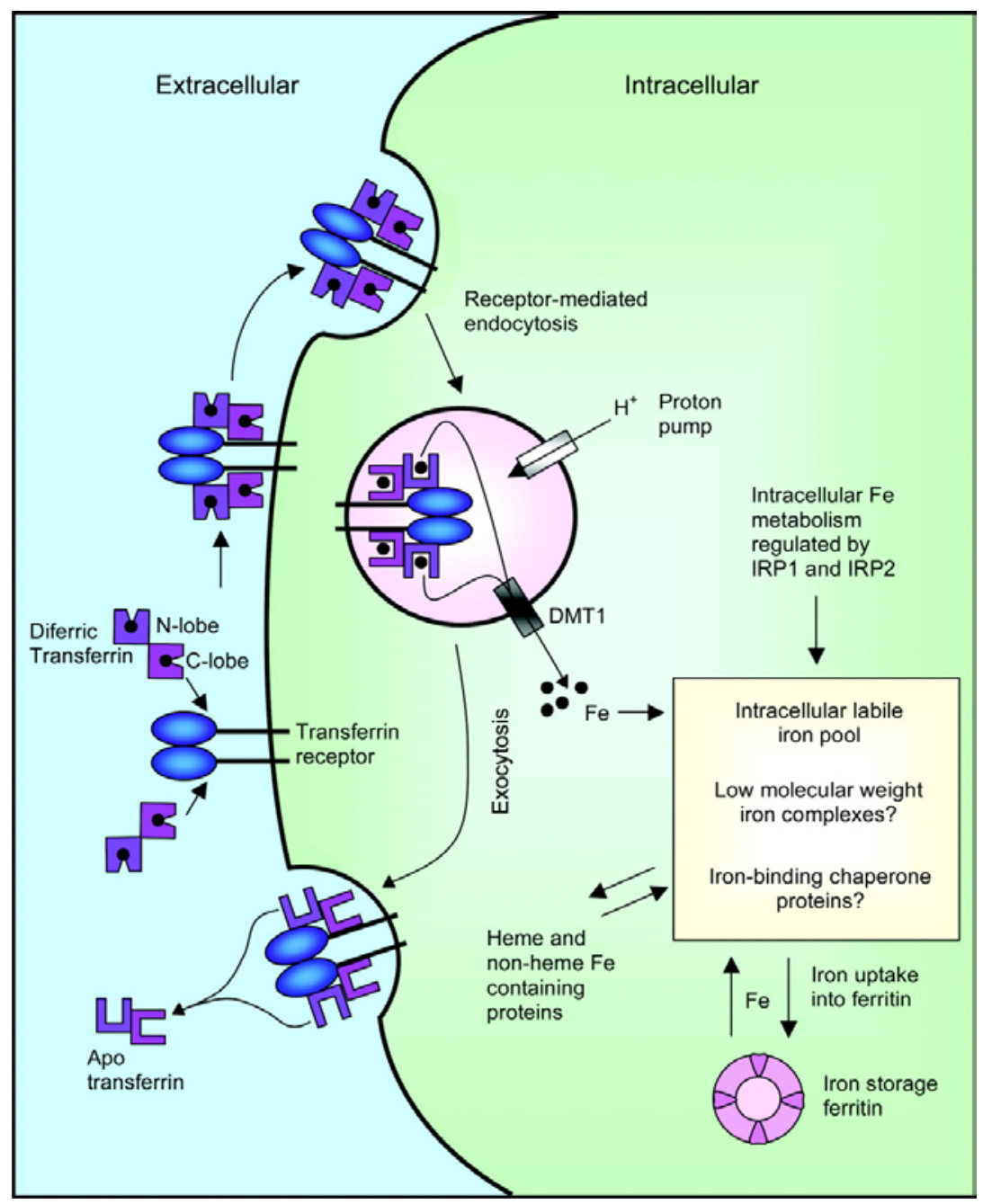

Figure 2: Schematic diagram illustrating the iron uptake mechanisms. After binding to TfR1 the diferric Tf undergoes endocytosis. Iron is released from $\mathrm{Tf}$ by a decrease in $\mathrm{pH}$ and is exported out of the endosome by DMT1, where it enters the LIP. Iron in the LIP can subsequently be incorporated into ferritin for iron storage or into iron-containing proteins. Source:Kalinowski and Richardson, 2005. 
cells, (Deaglio et al., 2002; Fleming et al., 2002) with lower levels in mature erythroid cells, spleen, lung, skeletal muscle, and prostate. Small amounts of TfR2 mRNA have also been found in Kupffer cells, sinusoidal endothelial cells, and stellate cells (Zhang et al., 2004). Many studies have demonstrated the presence of TfR2 on the cell surface, although a considerable fraction is also located at intracellular sites (Deaglio et al., 2002; Robb et al., 2004). TfR2, unlike TfR1, does not contain any IREs in its mRNA and its expression at transcriptional level is not regulated by cellular iron content (Fleming et al., 2000). However, TfR2 protein levels increase with iron loading and decrease with iron depletion (Robb and Wessling-Resnick, 2004). Similarly, treatment of a hepatoma cell line with diferric Tf leads to an increase in TfR2 protein, apparently by increasing protein half-life (Johnson and Enns, 2004; Robb and Wessling-Resnick, 2004). According to different studies, mutations in the TfR2 gene in humans or disruption of the gene in mice lead to systemic body iron loading (Camaschella et al., 2000; Fleming et al., 2002) due to an inability (presumably loss of function) to correctly regulate intestinal iron absorption. Although, it appears that most of Tf-bound iron is taken up by cells via the endocytosis of Tf, there is also evidence that Tf-bound iron can be released at the cell surface. This process has been described for several cell types but is most prominent in hepatocytes (Thorstensen and Romslo, 1990). Membrane impermeant iron chelators can reduce the uptake of iron from Tf, suggesting iron release at the cell surface (Cole and Glass, 1983; Thorstensen and Romslo, 1984), and there is also evidence for a cell surface ferric iron reductase activity that may facilitate iron release from Tf (Thorstensen and Romslo, 1984).

\subsubsection{Non-Transferrin bound iron uptake (NTBI)}

Under normal conditions, $30 \%$ of plasma Tf is hyposaturated and shows high capacity for iron binding to restrain the accumulation of NTBI (non-transferrin bound iron). On the 
contrary, during hereditary haemochromatosis and certain other iron-overload condi-tions, plasma iron levels exceed the saturation capacity of Tf, and NTBI pool builds up contrib-uting significantly to hepatic iron loading (Breuer et al., 2000a). The exact chemical nature of NTBI is still elusive, whereas its redox reactivity and toxicity has been established very well. It may consist of loosely chelated ferric $\left(\mathrm{Fe}^{3+}\right)$ by albumin or small organic molecules, such as citrate (Hider, 2002). The mechanism of NTBI uptake by cells is poorly understood.

Liver can take up NTBI very efficiently. This mechanism is well documented from different studies including rare instances of congenital Tf deficiency in humans (atransferrinemia) and mice (Bernstein, 1987; Hayashi et al., 1993). Affected individuals, despite lacking Tf, absorb iron from their diet very efficiently and large amounts of iron are deposited in the liver. Lipocalin-2 (LCN-2; human ortholog neutrophil gelatinase-associated lipocalin [NGAL], has been proposed as a mediator of transferrin-independent iron transportation (Yang et al., 2002). It belongs to the lipocalin family which is known to be involved in the regulation of im-mune responses, modulation of cell growth and metabolism, prostaglandin synthesis and iron transport (Yang et al., 2002). In fact, it is a bacteriostatic agent and capable of sequestering iron in the form of siderophores (Flo et al., 2004). A recent study has shown that LCN-2 can transport iron during kidney development through siderophore-iron complex (Yang et al., 2003), inju-ry (Mori et al., 2005) and under inflammatory conditions (Devireddy et al., 2005). Iron-loaded LCN-2 is internalized by the $\mathrm{LCN}-2$ receptors (24p3R and megalin) (Devireddy et al, 2005; Hvidberg et al, 2005) (Fig. 3). Siderophores are low-molecular mass iron-chelating metabolites, synthesized by bacteria and fungi for the acquisition of extracellular iron. 


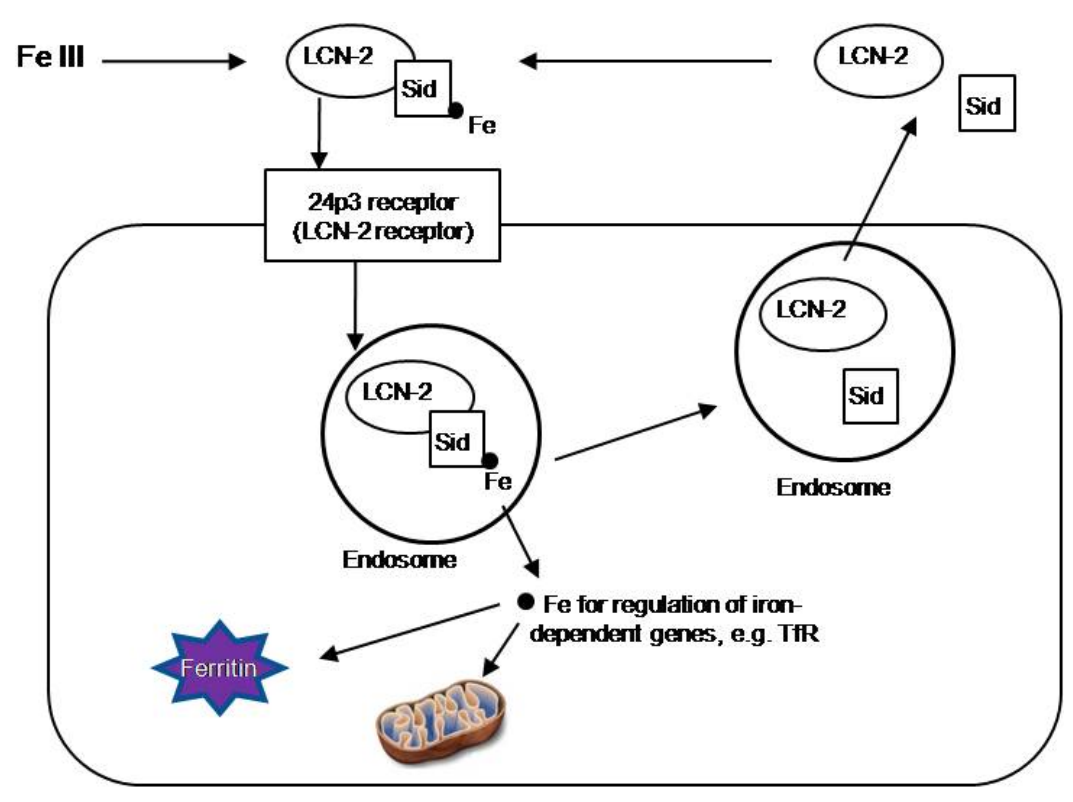

Figure 3: Schematic overview of non-transferrin bound iron uptake through lipocalin-2 (LCN-2). LCN-2 mediates iron uptake through $24 \mathrm{p} 3$ receptor (LCN-2 receptor) endocytosis of a LCN-2 siderophore (Sid)-iron complex. Siderophore-iron-associated LCN-2 (holo-LCN-2) delivers iron into the cell. LCN-2 then traffics in acidic endosomes, which promote the release and cytoplasmic accumulation of iron, resulting in regulation of iron-dependent genes. Source:Haase et al., 2010.

It was recently described that mammals synthesize the siderophore dihydroxybenzoic acid (2,5-DHBA), an isomeric of 2,3-DHBA, the iron-binding component of enterobactin (Devireddy et al., 2010). Most importantly by depletion of 2,5-DHBA iron metabolism was deregulated in mammalian cells and zebrafish embryos, showing the biological importance of the LCN-2dependent mechanisms.

\subsection{Iron storage}

Liver ferritin has a major role in iron storage and iron is stored mainly as ferritin within the cell (Ganz and Nemeth, 2012). Ferritin consits of L and H subunits that are highly conserved (Arosio et al., 2009) nevertheless, these subunits are genetically separate (Caskey et al., 1983; Worwood et al., 1985) and maintain distinct functions (Sammarco et al., 2008). Iron storage is considered to take place in the cytoplasm only, however is also required for the nuclear func- 
tions. $\mathrm{L}$ and $\mathrm{H}$ subunits of ferritin assemble spontaneously to produce a 24-subunit protein “cage” with a variable $\mathrm{H}$ : L ratio. This $\mathrm{H}$ : L ratio can vary between different cell types (Arosio et al., 2009; Sammarco et al., 2008). Hepatocytes have a high proportion of L subunits and relatively fewer $\mathrm{H}$ subunits (ratio 1:10 to 1:20 in human liver ferritin and 1:4 in rat liver ferritin), whereas cells that are involved in rapid iron turn over, such as macrophages, express more $\mathrm{H}$ subunits (Wang et al., 2013). The studies on ferritin proved that the the L gene showed very less tissuespecific regulations whereas the $\mathrm{H}$ ferritin gene is activated by multiple factors or conditions (Briat et al., 2010; Ponka et al., 1998) including changes in the cell proliferation, cytokines and heme. A pre-vious study clearly provided evidence of the association between ferritin expression and cell pro-liferation (Cozzi et al., 2004).

All cell types present within the liver can store iron but during normal physiological conditions hepatocytes are the major storage site and site of ferritin synthesis (Ganz and Nemeth, 2012). During iron-loading disorders characterized by elevated iron absorption, most of excess iron is deposited in parenchymal cells, while with transfusional iron overload Kupffer cells can store considerable amount of iron (Harmatz et al., 2000). There are numerous studies showing positive correlation between ferrtin and body iron store and ferritin level within the cell is determined by the iron content (Arosio et al., 2009). Ferritin subunit synthesis is iron-dependent and is controlled predominantly through a post-transcriptional mechanism by the IRE/IRP system (Eisenstein, 2000; Harrison and Arosio, 1996). Unlike TfR1, which has several IREs in its 3' UTR, the ferritin mRNAs contain only a single IRE in their 5' UTR. When iron contents remain low, the IRPs bind to this IRE present in ferritin transcripts and translation blocked. However, during iron accumulation conditions within the cell, the ferritin translational block is reversed and synthesis of new ferritin subunits is started (Fig. 4). This is not the only one mechanism for 
regulating ferritin synthesis in response to iron status, transcriptional regulation also plays a role in regulation (Cairo et al., 2002). Under normal conditions iron is the major factor influencing expression of ferritin, but it is also an acute phase protein and its synthesis that is regulated differently by different inflammatory stimuli and various acute phase cytokines e.g. IL-1 $\beta$, IL-6, TNF- $\alpha$ (Cairo et al., 2002).

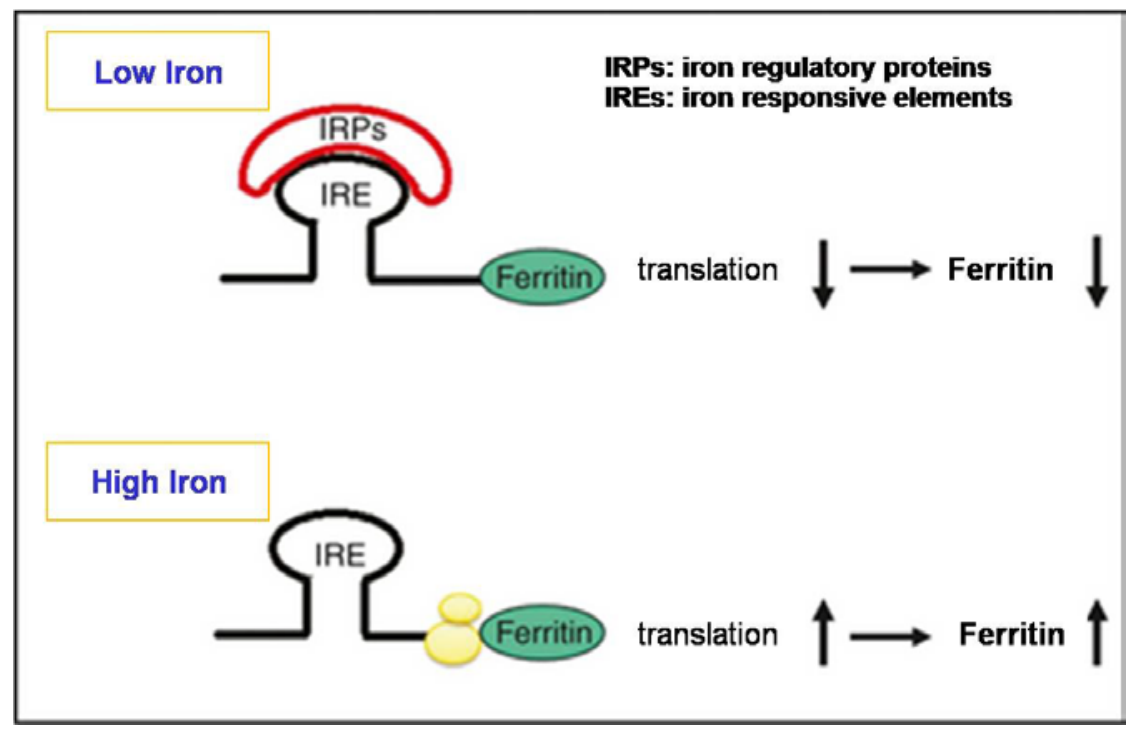

Figure 4: Regulation of ferritin expression by iron at the translational level via the IRE-IRP system. Iron-responsive element (IRE) in ferritin is an mRNA element at the 5'-untranslated region forming a hairpin structure. Iron regulatory proteins (IRPs), including IRP1 and IRP2, bind to IRE and inhibit ferritin mRNA translation. When the iron level is high, IRP2 is degraded, and IRP1 is converted from its active RNA-binding form into an Fe-S cluster-containing aconitase that lacks IRE-binding activity. Thus, IRPs cannot bind to IRE, and ferritin translation increases. Conversely, when the iron level is low, IRPs bind to IRE, and the ferritin level decreases. Source:Wang et al., 2013

\subsection{Acute phase response (APR)}

The acute phase response (ARP) is a key physiological defense mechanism of the organisms in response to any local or systemic insult caused by infection, tissue injury, trauma or surgery and immunological disorders (Gruys et al., 2005; Koj, 1985). The purpose of generating an acute phase response is to recover the damage caused by the injuring noxae and it also ensures the restoration of homeostasis. Acute phase can be characterized clinically by observing different 
signs i.e. fever, drowsiness, weakness, muscular pain, and adynamia. A large group of specific mediators/cytokines including interleukin-6 (IL-6), tumor necrosis factor-alpha (TNF- $\alpha$ ) others is responsible for mediating acute phase reaction (Ramadori and Christ, 1999).

Acute phase proteins are divided into two groups:

1. Type I acute phase proteins include SAA (serum amyloid A), CRP (C-reactive protein; human), complement C3, haptoglobin (rat), and $\alpha 1$-acid glycoprotein. They are induced by interleukin-6 (IL-6), interleukin-1 (IL-1)-like cytokines which comprise IL-1 $\alpha$, IL-1 $\beta$, tumour necrosis factor (TNF)- $\alpha$ and TNF- $\beta$.

2. Type II acute phase proteins are induced by IL-6 cytokine and its family members LIF (leukaemia inhibitory factor), IL-11, OSM (oncostatin M), CNTF (ciliary neurotrophic factor) and CT-1 (cardiotrophin-1). Type II proteins include fibrinogen, haptoglobin (human), $\alpha 1$-antichymotrypsin, $\alpha 1$-antitrypsin, and $\alpha 2$-macroglobulin (rat).

In general, IL-6-like cytokines synergize with IL-1-like cytokines to induce type I acute phase proteins, whereas IL-1-like cytokines do not affect induction of type II acute phase proteins or even have inhibitory effect on it (Moshage, 1997). After injury these cytokines are released or synthesized by different cell types including endothelial cells, fibroblasts, macrophages, granulocytes and lymphocytes, at the site of injury. The systemic circulation brings these floating cytokines to the liver and in response liver starts regulation of different acute phase proteins, differentiated as positive and negative acute phase proteins (APP). Proteins with an increased expression and plasma concentration are classified as positive acute phase proteins (APP), e.g., $\alpha 2$-macroglobulin and LCN2 in rats (Sultan et al., 2012). These APPs phase proteins 
are involved in the process of wound healing to neutralize or recover the tissue damage (Ramadori and Christ, 1999). The other positive APPs include clotting proteins, transport proteins, antiproteases, and complement factors serum amyloid A (SAA) and C-reactive protein (CRP) in humans or in mice its homologue, serum amyloid P component (SAP). Furthermore, the decrease of the serum iron level is also a hallmark of APR (Sheikh et al., 2007). There are some other proteins which are down-regulated and consequently their plasma concentration decreases during APR. These are categorized as negative acute phase proteins and protein such as albumin belongs to this family (Ramadori and Christ, 1999). The major and key source of these APPs is the hepatocytes which become metabolically active during APR (Ramadori et al., 1985; Ramadori and Christ, 1999).

IL-6-like cytokines use the common receptor $\beta$-subunit (gp130) for signal transduction which in some cases requires an $\alpha$-receptor subunit (IL-6, IL-11, CNTF) but in other cases do not (OSM, LIF) (Heinrich et al., 1998). After ligand binding, dimerization of two $\beta$-subunits leads to the activation of the receptor associated Janus kinases (JAKs), which in turn, phosphorylate transcription factors from the signal transducer and activator of transcription (STAT) family, namely STAT1, 3, and 5 (Heinrich et al., 2003). After homo- or heterodimerization, activated STATs are translocated to the nucleus, where they bind to target sequences in the promoters of type II APP genes, stimulating synthesis of corresponding proteins (Fig. 5). Among STAT factors, STAT3 is considered to play a pivotal role in the regulation of the APR, since STAT3 binding sites were shown in the promoters of various APP genes induced by IL-6 (Streetz et al., 2001). 


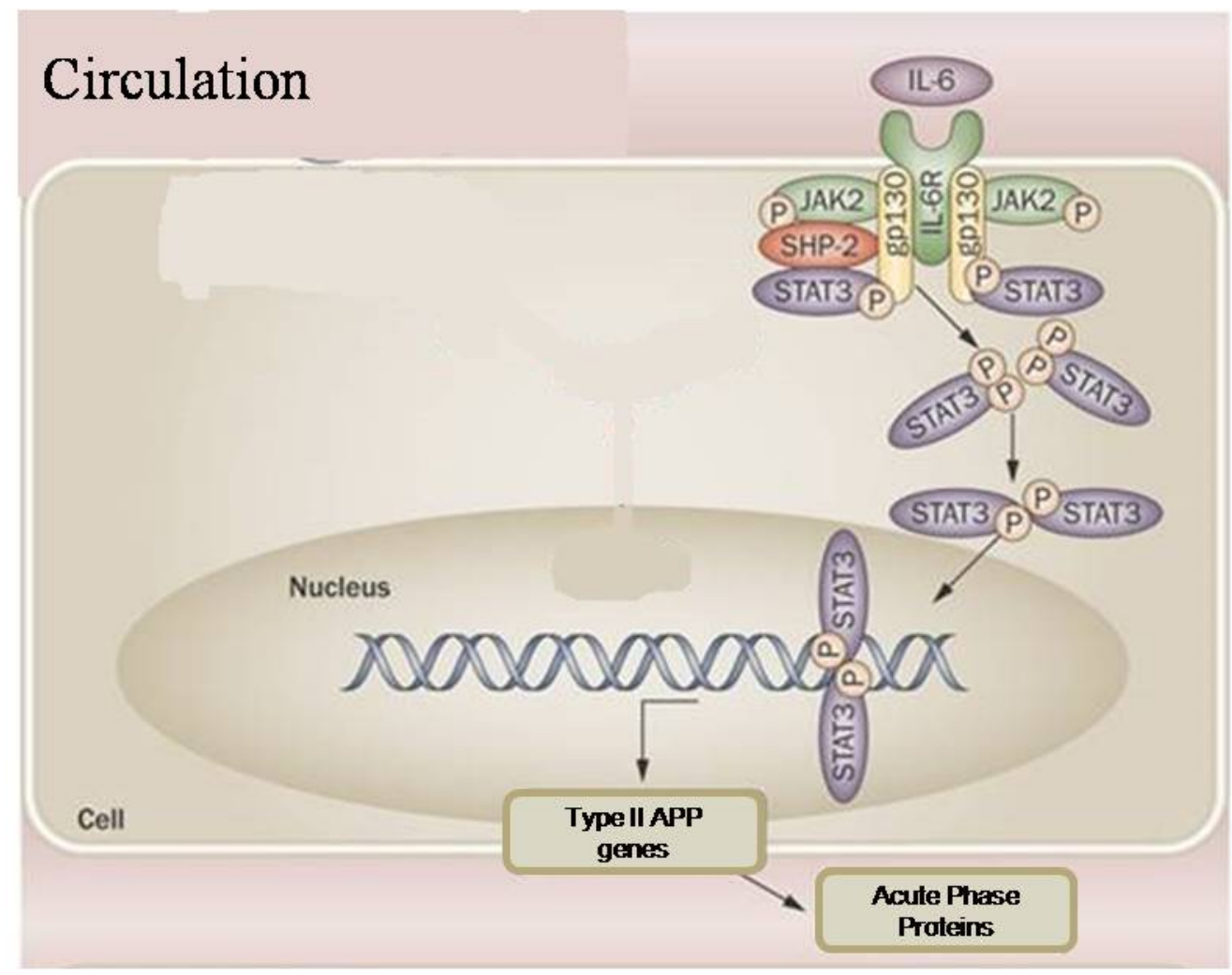

Figure 5: IL-6 stimulation induces the expression of a number of pro-inflammatory genes (Type II APP genes) products via activation of JAK/STAT3 pathway. Modified from:Walters and Griffiths, 2009.

\subsection{Experimental model of acute phase study (ARP)}

\subsubsection{Animal Model of ARP}

There are two well established animal models for the experimental study of the APR and acute phase mediated changes in acute phase proteins. Bacterial endotoxin lipopolysaccharide (LPS) administration leads to induction of APR by inducing systemic APR along with liver damage (Boelen et al. 2005;Ramadori et al. 1985). The other know model of APR, turpentine oil (TO) induced sterile muscle abscess without causing any detectable injury to liver and other tissues (Boelen et al. 2005;Ramadori et al. 1990;Tron et al. 2005;Wusteman et al. 1990). Thus, the TO-induced ARP model allows studying the effect of cytokines on liver produced at distant sites (Fig. 6). This model of ARP reproduces changes observed in human disease states (Basso et al, 
2005; Bodet et al, 2006; Boelen et al, 2005; Gabay and Kushner, 1999; Halter et al, 2005; Kim et al, 2002; Stoeck et al, 2006).

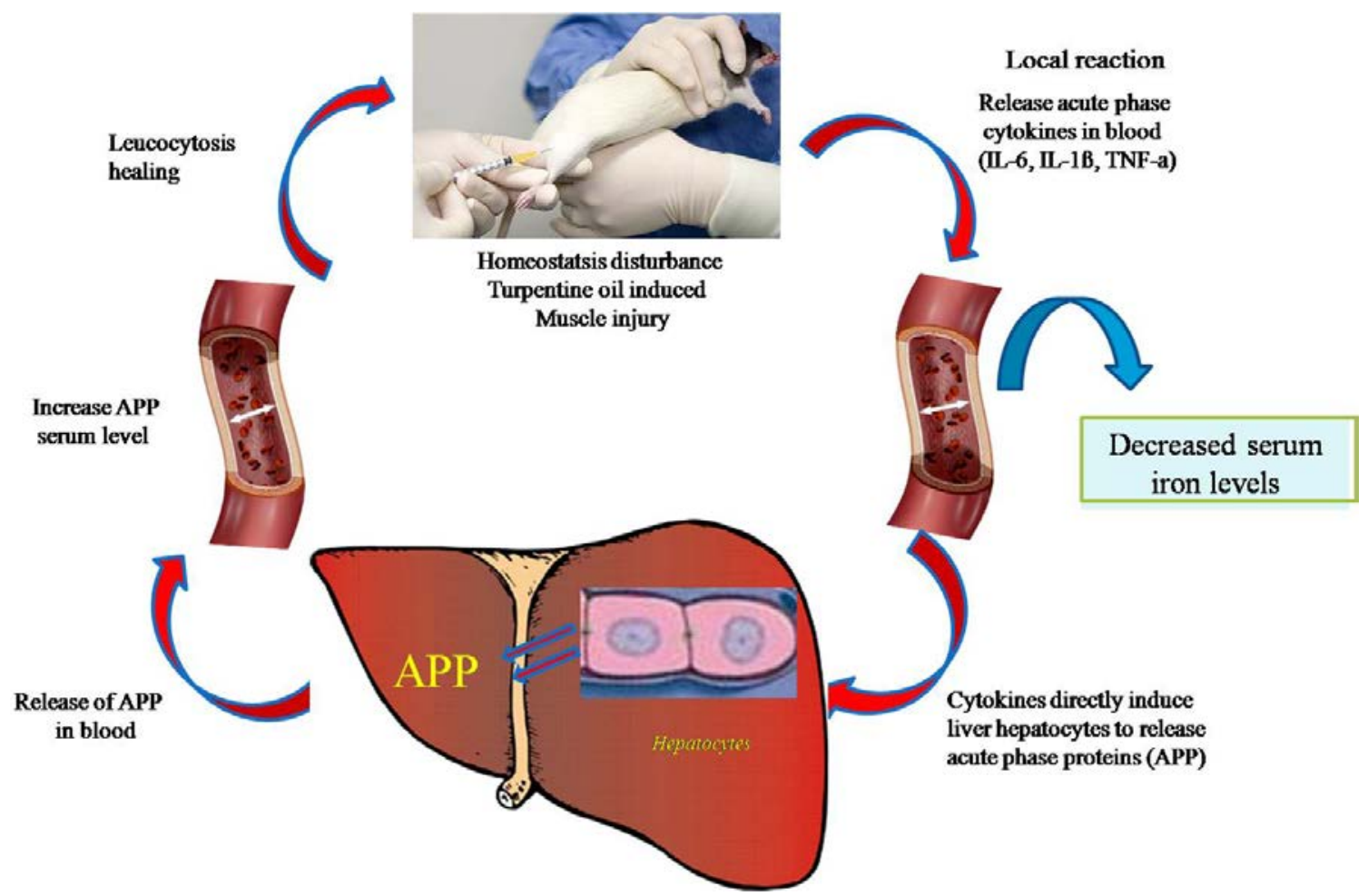

Figure 6: The acute phase model of study. Turpentine injection into the limb muscle results in cytokine production at the site of injury. These cytokines are released into the blood and when they reach the liver, liver becomes metabolically active and release acute phase mediators to trigger the healing process at the site of injury. The decreased iron concentration in serum is the hallmark of APR.

\subsubsection{In vitro Model of ARP}

When it became evident that liver is a primary target organ for the APR, hepatocytes cell culture was used to investigate a hierarchy of the events triggering the full APR in the liver. Besides the ability to respond to the cytokine, different cell types within the liver also express IL$1 \beta$, IL-6 , TNF- $\alpha$, and other modulatory cytokines of the hepatic APR (Ramadori and Christ, 1999). Kupffer cells are the most active intra-hepatic "amplifiers" of the systemic APR in the liver by liberating a second wave of pro-inflammatory cytokines, promoting autocrine stimula- 
tion and paracrine hepatocyte stimulation (Decker, 1990). Hepatocytes express a great variety of receptors for cytokines, growth factors, and prostaglandins and therefore represent the major target for a multiple set of mediators involved in both systemic and local host defense reactions. Hepatocytes also express and secrete cytokines of the APR, which might further stimulate adjacent hepatocytes (Rowell et al., 1997).

\subsection{Aims of study}

Change in hepatic iron status is hall mark of APR. Turpentine oil (TO) induced APR model is well known for studying sterile local inflammation. TO injection leads to local inflammation with a subsequent systemic induction of APR mediated by cytokines (Ramadori and Christ, 1999; Ramadori et al, 1985). Sterile inflammatory processes develop through a cascade of events, char-acterized by a local increase of blood supply, small molecules, and proteins, leakage of fluids, and infiltration of inflammatory cells (Roitt and Delves, 2001). TO induces an aseptic local abscess without any damage caused to other organs (Boelen et al, 2005; Ramadori and Meyer zum Buschenfelde, 1990; Tron et al, 2005; Wusteman et al, 1990). This is clearly differ-ent from agents inducing an acute systemic response, like the administration of bacterial endo-toxin (lipopolysaccharide) (Boelen et al, 2005). Thus, the TO-induced acute-phase response model allows studying the effect of cytokines on the liver produced at distant sites.

Based on the literature and our previous findings it is known that sterile muscle abscess can cause a decrease in serum iron level in parallel to increase in hepatic iron content. Accordingly, it has also been reported that the intramuscular administration of TO induced the changes in gene expression of several proteins involved in iron metabolism in hepatic and extra-hepatic organs (Sheikh et al. 2007). However, the mechanisms governing hepatic iron metabolism under acute 
phase conditions is poorly understood. In addition, previously we also localized several hepatic iron import and export proteins whereas the differential localization of these hepatic iron regulatory proteins in comparison to extra-hepatic organs has not been reported before.

Therefore, the perspective of this study was to compare sub-cellular localization of iron regulatory proteins in hepatic as well as extra-hepatic organs under physiological and acutephase conditions. Further, it was also the aim of the current study to analyze the regulation and signaling pathways of these proteins during APR.

Therefore, following approaches were adopted to address the aims of the current study:

1. Investigate and compare the expression changes in iron transport- (TfR1, TfR2 and LCN2) and iron storage proteins (ferritin) under the influence of acute phase cytokines (IL-6, IL- $\beta$ and TNF- $\alpha$ ) in the presence/absence of iron in primary culture of isolated rat hepatocytes; in vitro.

2. Demonstrate role of cytokines in iron uptake using primary cultures of isolated rat hepatocytes stimulated with acute phase cytokines (IL-6, IL- $\beta$ and TNF- $\alpha$ ) in the presence/absence of iron; in vitro.

3. Evaluate the role of IL-6, the principle mediator of inflammation, in the regulation of expression pattern of iron transport (TfR1, TfR2 and LCN-2) and iron storage proteins (FTH, FTL) in wild type and IL-6 knock-out mice models of acute phase response.

4. Investigate and compare the cellular localization of iron transport- (TfR1, TfR2 and LCN-2) and iron storage proteins (FTH, FTL) in liver, spleen, and heart in rat model of acute phase response. 


\section{MATERIALS}

\subsection{Chemicals}

All the chemicals used in the study were of analytical grade and were purchased from commercial sources as indicated below:

TRIzol reagent (Invitrogen GmbH, Karlsruhe, Germany) for isolation of RNA from the tissues; real-time polymerase chain reaction (PCR) primers, M-MLV reverse transcriptase, reverse transcription buffer and 0.1M DTT, platinum Sybr green qPCRUDG mix from Invitrogen, dNTPs, protector RNase inhibitor, bovine insulin, Klenow enzyme, primer oligo (DT)15 for cDNA synthesis and salmon sperm DNA from Roche (Mannheim, Germany). All other reagents and chemicals were from Sigma-Aldrich (Munich, Germany) or Merck (Darmstadt, Germany). Mouse anti-transferrin receptor-1 from Invitrogen (Darmstadt, Germany), Rabbit anti-transferrin receptor-2 from Abcam (Cambridge, UK), Mouse anti-lipocalin-2 from Novus Biologicals, Goat antilipocalin-2 from R \& D, Rabbit anti-STAT3 from Cell Signaling, Rabbit anti-pSTAT3 from Cell Signaling, FTH from LS Bio and Santa Cruz, Rabbit anti-FTL from Abcam, Mouse anti-betaactin antibody from Sigma Aldrich (Germany) were used in the study. Among secondary antibodies; Horse-reddish-peroxidase-conjugated anti-mouse, anti-rabbit and anti-goat IgGs from DAKO (Germany) and among Fluorescent Dye Conjugates Alexa Fluor-488 Donkey anti-goat, Donkey anti-mouse IgG and Alexa Fluor-555 Donkey anti-rabbit and Donkey anti-mouse IgG from Invitrogen (Darmstadt, Germany), were used in the study. 


\subsection{Animals and experimental models of acute-phase reaction}

Male Wistar rats of about 170-200 g body weight were purchased from Harlan Winkel-

mann (Brochen, Germany). Adult male B6.129S2-Il6 ${ }^{\text {tm1Kopf }}$ (IL6-knockout) mice and control wild type adult male C57BL/6J mice (25-28g) were purchased from Jackson Laboratory. The animals were kept under standard conditions with $12 \mathrm{~h}$ light/dark cycles and had ad libitum access to fresh water and food pellets. All animals were cared for according to the University's guidelines, the German convention for the protection of animals and NIH guidelines.

In rats APR was induced in ether-anesthetized rats by intramuscular administration of 5 $\mathrm{ml} / \mathrm{kg}$ TO in both right and left hind limbs ( $\mathrm{n}=5)$. Control animals did not receive any administration $(\mathrm{n}=4)$. Injected and non-injected control rats were euthanized $1 \mathrm{~h}, 2 \mathrm{~h}, 4 \mathrm{~h}, 6 \mathrm{~h}, 12 \mathrm{~h}, 24 \mathrm{~h}$ and after TO administration under pentobarbital anesthesia. Liver, heart and spleen were excised and minced, rinsed with physiological sodium saline, snap frozen in liquid nitrogen and stored at $80^{\circ} \mathrm{C}$ till further use. Blood samples were collected from the inferior vena cava of the control and treated animals, allowed to clot overnight at $4^{\circ} \mathrm{C}$ and centrifuged for $20 \mathrm{~min}$ at $2000 \mathrm{~g}$. Serum was removed and stored at $-80^{\circ} \mathrm{C}$.

For the mice experiments, a group of animals $(\mathrm{n}=3)$ for each strain, control $(\mathrm{C} 57 \mathrm{BL} / 6 \mathrm{~J})$ and IL6-knockout, was injected intramuscularly with $0.1 \mathrm{ml}$ TO in both right and left hind limbs to induce an aseptic acute phase response. Animals were euthanized 2h, 4h, 6h, $12 \mathrm{~h}$ and $24 \mathrm{~h}$ after the treatments under pentobarbital anesthesia. Liver tissues were excised and minced, rinsed with physiological sodium saline, snap frozen in liquid nitrogen and stored at $-80^{\circ} \mathrm{C}$ till further use. 


\section{METHODS}

\subsection{Methods of cell biology}

\subsubsection{Isolation of rat liver cells}

\subsubsection{Isolation of rat hepatocytes}

Hepatocytes were isolated from male Wistar rats by circulating perfusion with collagenase essentially as described previously (Seglen 1972).

\subsection{Liver perfusion}

After laparotomy, the vena portae was canulated, vena cava inferior was ligated above the diaphragm to prevent flow of the perfusion media into a whole body circulation. Finally, the vena cava inferior was cut beneath the liver and canulated. The liver was perfused in nonrecirculative mode through the portal vein with $150-200 \mathrm{ml} \mathrm{CO}_{2}$-enriched preperfusion medium at a flow rate of 30ml/min until the liver was free from blood. To break down components of extracellular matrix, the liver was perfused in recirculative mode with collagenase perfusion medium until it started to feel soft (about 7-11 min).

\subsection{Preparation of the hepatocytes suspension}

After perfusion, the liver was excised and transferred into a sterile glass beaker filled with culture medium M 199 with additives. Glisson's capsule, i.e. collagen tissue around the liver, was carefully removed and discarded. To obtain a cell suspension, the tissue was disrupted mechanically using sterile forceps. Connective tissue and remainder of the liver capsule as well as big cell aggregates were removed by filtration of the primary cell suspension through a nylon

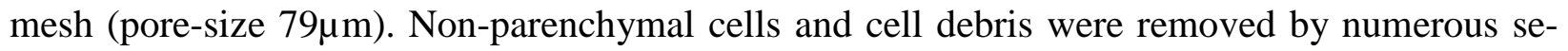
lective sedimentations (20 g, $2 \mathrm{~min}, 4^{\circ} \mathrm{C}$ ) in wash medium. After the last centrifugation, hepato- 
cytes were suspended in medium M 199 with additives. 50ml of M 199 was added per $1 \mathrm{~g}$ of wet weight of the sedimented cells; the cell suspension typically had a density of about 106/2.5 ml.

\subsection{Primary culture treatment and harvesting of rat liver cells}

The cultures of rat hepatocytes were performed on 60mm polystyrol dishes and maintained at $37^{\circ} \mathrm{C}$ in a $95 \%$ air/ $5 \% \mathrm{CO}_{2}$ atmosphere and saturated humidity. Rat hepatocytes were processed further for cytokine stimulation.

\subsection{Primary culture of rat hepatocytes}

Immediately after preparation, fetal calf serum (4 ml/100 ml suspension) was added to the hepatocytes suspension in order to make the efficient cell adhesion to the polystyrol dishes. Furthermore, the antibiotics ( $1 \mathrm{ml}$ of pen/strep stock solution per $100 \mathrm{ml}$ cell suspension) together with 10-7 M dexamethasone and 10-9 $\mathrm{M}$ insulin as permissive hormones were added. Rat hepatocytes were plated onto 60 -mm plastic dishes at a density of $2 \times 10^{6}$ cells per dish. After the initial $4 \mathrm{~h}$ of attachment phase, the medium was changed, and the hepatocytes were further incubated in medium M 199 with the same concentrations of hormones and antibiotics used previously but without fetal calf serum. A volume of $2.5 \mathrm{ml}$ medium per 60mm culture dish was added.

\subsection{Stimulation of hepatocytes with acute phase cytokines and iron}

Primary rat hepatocytes were stimulated with pro-inflammatory cytokines (IL-1 $\beta$ 100ng/ $\mathrm{ml}$, IL-6 500ng/ml, and TNF- $\alpha$ 100ng/ml concentrations) in the presence/absence of iron $(0.1 \mathrm{mM})$ or different concentrations of iron $\left(\mathrm{FeCl}_{3}: 0.01 \mathrm{mM}, 0.1 \mathrm{mM}\right.$ and $\left.0.5 \mathrm{mM}\right)$ alone, on the next day of plating. The medium was changed 6 hours prior to stimulation; the stimuli were diluted to the required concentrations in the culture medium and added directly to the culture dishes by pipetting. An equal volume of the normal culture medium was added to the dishes with 
cells which later served as experimental controls. After addition of the stimuli, cells were incubated in the incubator prior to RNA and protein isolation. The cells were harvested at different time points (0, 6, 12 and 24h), washed with phosphate buffered saline, $\mathrm{pH} 7.4$ and frozen at $80^{\circ} \mathrm{C}$ for subsequent RNA and protein isolation.

\subsection{Methods in molecular biology}

\subsubsection{RNA isolation}

During the whole study, total RNA was isolated from liver, brain, spleen and injured muscle tissue samples with TRIzol reagent according to the manufacturer"es instructions. Briefly, tissue samples were homogenized in $1 \mathrm{ml}$ TRIzol reagent per 100mg of tissue using a power homogenizer. After 5 minutes incubation at room temperature, $0.2 \mathrm{ml}$ chloroform per sample was added and samples were vigorously shaken and incubated at room temperature for 3 minutes. Samples were then centrifuged at 12,000g for 30 minutes and the acqueous phase so obtained in the supernatants was carefully collected. A volume of $0.5 \mathrm{ml}$ of isopropyl alcohol was succevssively added to the collected phase and samples were incubated at room temperature for 10 minutes. The RNA precipitation was favoured centrifuging again at 12,000g for 10 minutes. After a short washing step in ethanol 75\%, RNA was shortly air-dried and resuspended in a volume of approximately $50 \mu \mathrm{l}$ of RNase and Dnase free water. The RNA was then quantified by measuring the absorbance at $260 \mathrm{~nm} / 280 \mathrm{~nm}$.

\subsubsection{Reverse transcription (RT)}

The cDNA was generated by reverse transcription of $3.0 \mathrm{~g}$ of total RNA with $100 \mathrm{nM}$ of dNTPs, 50pM of primer oligo(dT)15, 200U of moloney murine leukemia virus reverse transcrip- 
tase (M-MLV RT), 16U of protector RNase inhibitor, 1X RT buffer and $2.5 \mathrm{ml}$ of 0.1M DTT for $1 \mathrm{~h}$ at $40^{\circ} \mathrm{C}$.

\subsubsection{Real time quantitative Polymerase chain reaction}

The cDNA samples are analyzed by the Real Time PCR using the following ingredients for each PCR reaction:

Volume per reaction

"X” primer-forward (5mM) $1.5 \mu \mathrm{l}$

“X” primer-reverse $(5 \mathrm{mM})$ $1.5 \mu \mathrm{l}$

$\underline{\mathrm{H}}_{2} \underline{\mathrm{O}}$ $6.5 \mu \mathrm{l}$

$\underline{\text { SYBR Green Master Mix Taq Polymerase }}$ $13.0 \mu \mathrm{l}$

$2.5 \mu \mathrm{l}$ of the cDNA sample or $2.5 \mu \mathrm{l}$ of $\mathrm{H}_{2} \mathrm{O}$ for the negative control was added to each PCR reaction.

\subsubsection{Thermal cycler amplification program}

The amplification was performed at $95^{\circ} \mathrm{C}$ for 20 seconds, $95^{\circ} \mathrm{C}$ for 3 seconds to $60^{\circ} \mathrm{C}$ for 30 seconds for 40 thermal cycles in an ABI prism 7000 sequence detection system. All samples were assayed in duplicate. Expression of different genes was analyzed using Platinum SYBR Green qPCR mix UDG. The PCR amplification program was followed by dissociation curve protocol for controlling the specificity of the PCR products. Specific temperature of dissociation of the PCR product was calculated by the Primer Express software. Curves of amplification were analyzed to measure the Ct value in the linear range of the amplification. The results were nor- 
malized to the house keeping gene and fold change expression was calculated using Ct values by Prism Graph Pad 5 software.

\subsubsection{Standard Curve}

Serially diluted PCR products, of the gene of interest are amplified by Real Time PCR and Ct values are calculated. The standard curves were obtained graphically by using the following parameters: Ct values and the logarithm of the number of copies. Standard curve were calculated for the gene of interest and the housekeeping genes. Number of copies of gene in the sample was obtained by extrapolation of the measured Ct value to the relative standard curve. Normalization of gene expression in each sample was performed by calculating the ratio of number of copies of the gene of interest with respect to the number of copies of the housekeeping gene.

\subsubsection{Primers designing}

Primers for different genes were designed using the program "Primer Express” (ABI System) and the gene bank data (http://www.ncbi.nlm.nih.gov).

\subsection{Methods of biochemistry}

\subsubsection{Protein extraction from liver tissue and cultured hepatocytes}

\subsubsection{Preparation of tissue homogenates}

All steps were performed at $4^{\circ} \mathrm{C}$ to prevent proteolytic degradation of the proteins. About 100mg of frozen tissue was homogenized with Ultra-Turrax TP 18/10 model homogenizer 3times for $10 \mathrm{sec}$ each in 10 volumes of $50 \mathrm{mM}$ Tris- $\mathrm{HCl}$ buffer, $\mathrm{pH} 7.4$, containing $150 \mathrm{mM}$ NaCl, 1mM EDTA, 1\% Triton X-100, 1mM PMSF, 1mM benzamidine, $1 \mu \mathrm{g} / \mathrm{ml}$ leupeptin, $10 \mu \mathrm{M}$ chymostatin, $1 \mu \mathrm{g} / \mathrm{ml}$ antipain, $1 \mu \mathrm{g} / \mathrm{ml}$ pepstatin A. Crude homogenates were passed 5 times through a $22 \mathrm{G}$ administration canula connected to a syringe. To pellet the nuclei and particular 
matter, crude homogenates were centrifuged for $5 \mathrm{~min}$ at $10,000 \mathrm{~g}\left(4^{\circ} \mathrm{C}\right)$. Protein concentration of supernatants was determined by the bicinchoninic acid (BCA) method (Smith et al. 1985) using the BCA protein assay reagent kit (Pierce, Bonn, Germany). Prepared homogenates were dispensed in aliquots and stored at $-20^{\circ} \mathrm{C}$ until use.

\subsubsection{Preparation of cell lysate}

All steps of the procedure were performed at $4^{\circ} \mathrm{C}$ to prevent proteolytical degradation of the proteins. The cells frozen on the culture dishes were thawed on ice. $1 \mathrm{X}$ ice-cold lysis buffer, comprised of 150mM NaCl, 1mM EDTA, 1\% Triton X-100, 50mM Tris-HCl, pH 7.4 and supplemented with protease inhibitors, was added to the cells $(500 \mu \mathrm{l}$ per $6 \mathrm{~cm}$ dish) followed by incubation on ice for $10 \mathrm{~min}$. Afterwards, the cells were scraped with a disposable scraper, transferred to new tubes and passed 5 times through a 22G administration canula connected to a syringe. To pellet the nuclei and particular matter, prepared lysates were centrifuged for 5 min at $10,000 \mathrm{~g}\left(4^{\circ} \mathrm{C}\right)$ and the protein concentration of supernatants was determined by BCA method using the kit from Pierce. Prepared lysates were aliquoted and stored at $-20^{\circ} \mathrm{C}$ until use.

\subsubsection{Proteins isolation and Western Blot}

Fifty micrograms from the total protein lysate were loaded in a 4-12\% Nu-PAGE BisTris (Invitrogen) gel and separated after 2 hours electrophoresis at 80V. After the transfer in a semidry apparatus at $26 \mathrm{~V}$ for $1.5 \mathrm{~h}$, the membranes were blocked in 5\% milk, and blotted with primary antibodies overnight at $4^{\circ} \mathrm{C}$. The secondary antibodies were horse reddish peroxidase conjugated goat anti-rabbit, goat anti-mouse and rabbit anti-goat immunoglobulins (DAKO) diluted at 1:2000. Membranes were developed with ECL chemiluminescence Kit (Amersham). 


\subsubsection{Immunohistochemistry}

Immunohistochemical analysis was performed on $4 \mu \mathrm{m}$ thin cryostat sections fixed in methanol/acetone to localize the antigens on the tissues. After blocking non-specific binding with a solution of PBS containing 1\% bovine serum albumin (Serva, Heidelberg, Germany) and 10\% donkey serum (Abcam) for $1 \mathrm{~h}$ at room temperature, the primary antibodies (TfR1, TfR2, LCN-2, FTH and FTL) were incubated overnight at $4^{\circ} \mathrm{C}$ on the sections. The mouse monoclonal (TfR1) and rabbit polyclonal (TfR2) antibodies were detected with an Alexa Fluor-555 conjugated donkey-anti-rabbit/donkey anti-mouse and goat polyclonal (LCN-2), rabbit polyclonal (TfR2) and mouse monoclonal (LCN-2) antibodies with Alexa Fluor-488 conjugated secondary antibody from Invitrogen (Darmstadt, Ger-many). For double-staining, each of the TfR1 and TfR2 primary antibodies was incubated with goat/mouse anti LCN-2 (R \& D) (diluted 1:100) overnight at $4^{\circ} \mathrm{C}$. A mix of Alexa Flour-555-conjugated donkey-antirabbit, donkey-anti-mouse and FITC/ Alexa Fluor-488-conjugated anti-goat Igs from (Invitrogen Darmstadt, Germany) was successively incubated for $1 \mathrm{~h}$ at room temperature in dark. Sections were counter-stained with DAPI (Molecular Probes, Invitrogen) and observed with an epifluorescence microscope (Axiovert 200M, Zeiss, Germany). In peroxidase staining antigens were visualized using HRP-conjugated secondary antibodies. Negative control immunostainings were performed by omission of the primary antibody, by using isotype of matching control immunoglobulins. 


\subsection{Methods in clinical chemistry}

\subsubsection{Iron measurement}

\subsubsection{Principle}

Iron bound to transferrin is released in an acidic medium as ferric iron and is then reduced to ferrous iron in the presence o ascorbic acid. Ferrous iron forms a blue complex with ferene. The absorbance at 595nm is directly proportional to the iron concentration.

$$
\begin{gathered}
\text { Transferrin }\left(\mathrm{Fe}^{3+}\right)_{2} \rightarrow 2 \mathrm{Fe}^{2+}+\text { transferrin } \\
\mathrm{Fe}^{2+}+3 \text { Ferene } \rightarrow \text { Ferrous Ferene (blue complex) }
\end{gathered}
$$

\subsubsection{Reagents}

Final concentration

R1: $\quad$ Acetate buffer $\mathrm{pH} 4.5$

800mM/l

Thiourea

$90 \mathrm{mM} / \mathrm{l}$

R2: Ascorbic acid

45mM/l

Ferene

$0.6 \mathrm{mM} / \mathrm{l}$

Thiourea

20mM/l

Standard

$100 \mu \mathrm{g} / \mathrm{dl}(17.9 \mu \mathrm{M} / \mathrm{l})$

Should be protected from light, reagents are stable at $2-25^{\circ} \mathrm{C}$ until the expiry date.

\subsubsection{Assay Procedure}

To determine the hepatocytes iron level, $100 \mu$ l of the sample along with $1000 \mu 1$ of the reagent 1 was taken in the reaction tube. For blank $100 \mu \mathrm{l}$ of $\mathrm{dd} \mathrm{H}_{2} \mathrm{O}$ was used. The sample and reagent 1 was mixed thoroughly, incubated for 5 minutes and read the absorbance (A1). After that 
$250 \mu 1$ of the Reagent 2 was added, mixed thoroughly and the absorbance (A2) was read after 10 minutes of incubation.

\subsubsection{Calculations}

$$
\Delta \mathrm{A}=[(\mathrm{A} 2-0.82 \mathrm{~A} 1) \text { sample/Std. }]-[(\mathrm{A} 2-0.82 \mathrm{~A} 1) \text { blank }]
$$

The factor 0.82 compensates the decrease of the absorbance by addition of reagent 2 . The factor is calculated as follows:

$$
\text { (Sample +R1)/Total volume. }
$$

This compensation is necessary as a high sample volume is used.

$$
\begin{gathered}
\text { Iron }[\mu \mathrm{g} / \mathrm{dl}]=\Delta \mathrm{A} \text { Sample } / \Delta \mathrm{A} \mathrm{Std} / \mathrm{Cal} \times \text { Conc. Std. } / \mathrm{Cal}[\mu \mathrm{g} / \mathrm{dl}] \\
\text { Conversion factor Iron }[\mu \mathrm{g} / \mathrm{dl}] \times 0.1791[\mu \mathrm{M} / \mathrm{l}]
\end{gathered}
$$

\subsubsection{Measuring range}

The test has been developed to determine iron concentrations within a measuring range from $5-1000 \mu \mathrm{g} / \mathrm{dl}(0.9-179 \mu \mathrm{M} / \mathrm{l})$. When values exceed this value samples should be diluted $1+2$ with $\mathrm{NaCl}$ solution $(9 \mathrm{~g} / \mathrm{l})$ and the results multiplied by 3 .

\subsubsection{Specificity and sensitivity}

The test was specific and no interference was observed by conjugated and free bilirubin up to $60 \mathrm{mg} / \mathrm{dl}$, hemoglobin up to $100 \mathrm{mg} / \mathrm{dl}$, lipemia up to $2000 \mathrm{mg} / \mathrm{dl}$ triglycerides, and copper up to $200 \mu \mathrm{g} / \mathrm{dl}$. The lower limit of detection for the test is $2 \mu \mathrm{g} / \mathrm{dl}(0.4 \mu \mathrm{M} / \mathrm{l})$.

\subsection{Statistical analysis}

The data were analyzed using Prism Graph pad 5 software (San Diego, USA). All experimental errors are shown as SEM. Statistical significance was calculated by Student's t test and one way ANOVA. Significance was accepted at ${ }^{*} P<0.05$ and $* P<0.0125$. 


\title{
CYTES: THE ROLE OF ACUTE PHASE CYTOKINES
}

\author{
Shakil Ahmad, Sadaf Sultan, Naila Naz, Ghayyor Ahmad, Salamah \\ Mohammad Alwahsh, Silke Cameron, Federico Moriconi, Giuliano \\ Ramadori, and Ihtzaz Ahmed Malik
}

Department of Internal Medicine, Division of Gastroenterology and Endocrinology, University Medical Center, Georg-August University, Robert-Koch-Str. 40, 37075 Goettingen, Germany

Authors Contribution: Shakil Ahmad designed and performed experiments (Hepatocytes isolation, RCR, Western blot), data analysis and wrote manuscript

Sadaf Sultan, Naila Naz, Salamah Muhammad Alwahsh and Federico Moriconi participated in hepatocytes isolation

Ghayyor Ahmad and Silke Cameron critical improvement of manuscript

Giuliano Ramadori and Ihtzaz Ahmed Malik designed research and final improvement of the manuscript for publication

Published in SHOCK 2013 Dec 20

PMID: 24365882 


\title{
REGULATION OF IRON UPTAKE IN PRIMARY CULTURE RAT HEPATOCYTES: THE ROLE OF ACUTE-PHASE CYTOKINES
}

\author{
Shakil Ahmad, Sadaf Sultan, Naila Naz, Ghayyor Ahmad, \\ Salamah Mohammad Alwahsh, Silke Cameron, Federico Moriconi, \\ Giuliano Ramadori, and Ihtzaz Ahmed Malik \\ Division of Gastroenterology and Endocrinology, Department of Internal Medicine, University Medical Center, \\ Georg-August University, Goettingen, Germany
}

Received 13 Sep 2013; first review completed 2 Oct 2013; accepted in final form 27 Nov 2013

\begin{abstract}
Decreased serum and increased hepatic iron uptake is the hallmark of acute-phase (AP) response. Iron uptake is controlled by iron transport proteins such as transferrin receptors (TfRs) and lipocalin 2 (LCN-2). The current study aimed to understand the regulation of iron uptake in primary culture hepatocytes in the presence/absence of AP mediators. Rat hepatocytes were stimulated with different concentrations of iron alone $(0.01,0.1,0.5 \mathrm{mM})$ and AP cytokines (IL-1 $\beta, \mathrm{IL}-6, \mathrm{TNF}-\alpha)$ in the presence/absence of iron (FeCl3:0.1 mM). Hepatocytes were harvested at different time points $(0,6,12,24 \mathrm{~h})$. Total mRNA and proteins were extracted for RT-PCR and Western blot. A significant iron uptake was detected with $0.1 \mathrm{mM}$ iron administration with a maximum (133.37 $4.82 \mu \mathrm{g} / \mathrm{g}$ of protein) at $24 \mathrm{~h}$ compared with control and other iron concentrations. This uptake was further enhanced in the presence of APcytokines with a maximum iron uptake ( $481 \pm 25.81 \mu \mathrm{g} / \mathrm{g}$ of protein) after concomitant administration of IL-6+iron to cultured hepatocytes. Concomitantly, gene expression of LCN-2 and ferritin subunits (light- and heavy-chain ferritin subunits) was upregulated by iron or/and AP-cytokines with a maximum at $24 \mathrm{~h}$ both at mRNA and protein levels. In contrast, a decreased TfR1 level was detected by IL-6 and iron alone, whereas combination of iron and AP-cytokines (mainly IL-6) abrogated the downregulation of TfR1. An increase in LCN-2 release into the supernatant of cultured hepatocytes was observed after addition of iron/AP cytokines into the medium. This increase in secretion was further enhanced by combination of IL-6+iron. In conclusion, iron uptake is tightly controlled by already present iron concentration in the culture. This uptake can be further enhanced by AP-cytokines, mainly by IL-6.
\end{abstract}

KEYWORDS-Transferrin receptors, lipocalin 2 (LCN-2), acute-phase cytokines (IL-1 $\beta$, IL-6, TNF- $\alpha$ ), $\mathrm{FeCl}_{3}$

\section{INTRODUCTION}

Despite the abundance of iron in nature and in the human body, iron absorption, transport, storage, and excretion are tightly regulated. Within the cell, iron is mainly stored in the form of ferritin (1). In human, ferritin is composed of two subunits: the light-chain ferritin subunit (FTL; with 125 amino acids, $19 \mathrm{KDa}$ ) and the heavy-chain ferritin subunit (FTH; 183 amino acids, $21 \mathrm{KDa}$ ). Both subunits are highly conserved (2); nevertheless, they are genetically separate (3) and maintain distinct functions (4).

Iron homeostasis is controlled by a large group of iron regulatory proteins including ferroportin 1 (5), transferrin receptors (TfR1, TfR2) (6), hepcidin (7), and hemojuvelin (8). In fact, transferrin (Tf)-bound iron is imported into the reticuloendothelial system, to liver parenchymal cells and to all proliferating cells in the body after binding to TfRs. Interaction of diferric-Tf with TfRs and internalization of the complex by receptormediated endocytosis leads to iron uptake into the cells (9). As a result, Tf efficiently transports the majority of iron into the cells (10). However, there has been convincing evidence that, in situations of disrupted iron homeostasis, iron can also be delivered to cells by alternative, Tf-independent mechanisms. This alternative to $\mathrm{Tf}$ iron is called non-Tf-bound iron (NTBI)

Address reprint requests to IhtzazAhmed Malik,PhD, Department of Gastroenterology and Endocrinology, University Medical Center, Goettingen, Robert-Koch-Strasse 40, D-37099, Goettingen, Germany. E-mail: i.malik@med.uni-goettingen.de. DOI: 10.1097/SHK.0000000000000107

Copyright @ 2013 by the Shock Society
This pool has been documented in a variety of iron overload syndromes when Tf is saturated (11), including hemochromatosis (69\% of patients) and end-stage renal disease (22\% of patients) (12); the identification of the components of NTBI, however, remains elusive.

Lipocalin 2 (LCN-2; human ortholog neutrophil gelatinaseassociated lipocalin) has been proposed to be a mediator of the Tf-independent iron delivery pathway (13). It belongs to the lipocalin family, which is known to be involved in the regulation of immune responses, modulation of cell growth and metabolism, prostaglandin synthesis, and iron transportation (13). In fact, it is a bacteriostatic agent and capable of sequestering iron in the form of siderophores (14). A recent study has shown that LCN-2 siderophore-iron complexes can transport iron into cells during kidney development (10).

Acute-phase response (APR) is the systemic reaction to tissue injury and inflammation. It is clinically characterized by systemic symptoms such as fever, weakness, anemia, somnolence loss of appetite, and cytokines release (15). In the blood, it results in an increase in the plasma levels of a number of positive acute-phase proteins (APPs), including clotting proteins, transport proteins, antiproteases, and complement factors, with a concomitant decrease in negative APPs such as albumin (16). In addition, a decrease in serum iron levels and consecutive increase in hepatic iron levels are also a hallmark of APR. This reaction is mediated by both interleukin 1 (IL-1)-like cytokines (IL-1, tumor necrosis factor $\alpha$ [TNF- $\alpha]$ ) and IL-6-like cytokines (IL-6, oncostatin $\mathrm{M}$, and others), through the activation of different transcription factors. 
The liver is a major site of iron storage, and this iron-storage function is achieved by a tight control of bidirectional exchange of liver iron with plasma iron. Although the effect of cytokines on increased iron uptake has already been reported (17), and there have been several reports on iron regulation and metabolism, the mechanism of iron uptake is still poorly understood in the liver.

Previously, we showed in vivo that expression of acutephase (AP) cytokines (IL-1 $\beta$, IL-6, TNF- $\alpha$ ) increased during inflammation, delivered from the site of injury into the blood, can induce changes in expression of iron-regulatory, including iron-storage proteins (18). Furthermore, a decreased serum and increased hepatic iron content during AP conditions were also observed. This sponge (iron uptake) effect of the liver during AP conditions was supposed to be not only due to a change in gene expression of iron regulatory proteins but also due to AP cytokines.

In the current study, we wanted to explore the role of AP cytokines in iron uptake and the changes in gene expression of iron transport and storage proteins in the absence or presence of AP cytokines in primary culture of rat hepatocytes.

\section{MATERIALS AND METHODS}

\section{Animals}

As sex difference in cytokine secretion has been reported before (19), male Wistar rats (8-12 weeks old, 170-200 g body weight) were purchased from Harlan Winkelmann (Brochen, Germany). The animals were kept under stan- dard conditions with 12:12-h light-dark cycles and were given ad libitum access to water and food. All animals were cared for in accordance with the guidelines of the German Convention for the Protection of Animals and the US National Institutes of Health.

\section{Hepatocytes isolation and treatment}

For each experiment, two to four rats were killed under pentobarbital sodium $(50 \mathrm{mg} / \mathrm{kg})$ anesthesia according to the university's guidelines and German regulations for the protection of animals, and hepatocytes were isolated from these animals as described earlier (20). Isolated cells from different animals were pooled and plated for cytokine and/or iron treatment. Then, these isolated hepatocytes were incubated at $37^{\circ} \mathrm{C}$ in an atmosphere containing 95\% air and 5\% CO, Dulbecco modified Eagle medium supplemented with $10 \%$ fetal calf serum (PAA, Colbe, Germany), $1 \mathrm{nmol} / \mathrm{L}$ insulin, and $100 \mathrm{nmol} / \mathrm{L}$ dexamethasone (Sigma-Aldrich, Munich, Germany) for $48 \mathrm{~h}$ to obtain con- fluence and to reduce the stress of isolation procedure according to established protocol of our laboratory (20). Afterward (48 h), hepatocytes were divided into three groups: one was administrated with different AP cytokines, i.e., IL-6 $(500 \mathrm{ng} / \mathrm{mL})$, IL-1 $\beta$ (100 ng/mL), TNF- $\alpha$ (100 ng/mL) (PeproTech GmbH, Hamburg, Germany). The second group received different concentrations $(0.10 .1,0.5$ $\mathrm{mM}$ ) of $\mathrm{FeCl} 3$ (Sigma-Aldrich) in serum-free medium containing $0.2 \%$ bovine serum albumin up to $24 \mathrm{~h}$. Then, in the third group, cytokines IL-6 $(500 \mathrm{ng} / \mathrm{mL})$, IL-1 $\beta$ (100 ng/mL), and TNF- $\alpha(100 \mathrm{ng} / \mathrm{mL})$ were supplemented concomitantly with $\mathrm{FeCl}_{3}(0.1 \mathrm{mM})(21,22)$ to cultured hepatocytes in serumfree medium containing $0.2 \%$ bovine serum albumin. Each experiment was repeated four times $(n=4)$ in duplicates, cells wereafter treatment, and duplicates were pooled down in one Eppendorf tube for protein and mRNA isolation.

\section{Measurement of hepatocytes iron contents}

The iron contents of the cells at different time points after treatment were measured by colorimetric FerroZine-based assay (23). Iron contents were mea- sured as $\mu \mathrm{g} / \mathrm{g}$ of hepatocytes protein and analyzed using Microsoft Excel 2007.

\section{Isolation of total RNA and PCR analysis}

Total RNA was isolated from the hepatocytes samples with Trizol reagent according to the manufacturer's instructions. RNA was then measured at an absorbance of $260 / 280 \mathrm{~nm}$. The cDNA was generated by reverse transcription of RNA using the superscript kit (Invitrogen, Carlsbad, Calif). Real-time po- lymerase chain reaction (RT-PCR) was performed at $95-60^{\circ} \mathrm{C}$ for 40 thermal cycles using the Step One Plus real-time PCR cycler (Applied Biosystems, Darmstadt, Germany). Quantification of cDNA was done by relative quantification Busing SYBR Green UDG reaction master mix (Invitrogen,Darmstadt, Germany). Table 1 shows the list of primers, which have been gene specifically synthesized (Invitrogen). $\beta$-Actin mRNA is used as a housekeeping gene with every sample. The results in the form of threshold cycle values were normalized to control values and relative to the expression of $\beta$-actin.

\section{Protein extraction and Western blot analysis}

Proteins were isolated from the hepatocytes of different time points as de-scribed previously (24). Protein contents were calculated by the Coomassie protein assay (Pierce, Germany). Cell supernatant (culture medium in which hepatocytes were cultured) as whole and cell lysates were used for Western blot analysis. Western blot was performed with sodium dodecyl sulfate polyacryl-amide under reducing conditions as described (25) with $\beta$-actin as a loading control. The proteins were then transferred onto Hybond ECL nitrocellulose hybridization transfer membranes as described (26). Immunodetection studies have been performed according to the ECL Western blotting protocol of GE Healthcare (Dornstadt, Germany ). The antibodies used are listed in Table 2.

\section{Statistical analysis}

The data were analyzed using GraphPad Prism 4 software (San Diego, Calif). All experimental errors are shown as SEM. Statistical significance was calculated by Student t-test. Significance was accepted at $P \leq 0.05$. Bonferroni correction was applied to iron uptake data set obtained from $\mathrm{FeCl}_{3}$ treatment groups to prevent accumulation of and significance was accepted at $P \leq 0.0125(\alpha / 4, \mathrm{n}=4)$.

\section{RESULTS}

\section{Lactate dehydrogenase measurement}

The cellular damage of iron on hepatocytes was detected by measuring lactate dehydrogenase in the hepatocytes culture medium at all studied time points. All the treatments (iron and cytokines) showed less than 5\% lactate dehydrogenase secretion, indicating no cell damage to control and treated hepatocytes (data not shown).

\section{Iron uptake in hepatocytes}

To find the optimal iron concentration for studying iron uptake, different concentrations of iron $(0.01,0.1$, and $0.5 \mathrm{mM})$ were administered to the culture medium. The $0.1 \mathrm{mM}$ concentrationwas found to be the most efficient for iron uptake in isolated hepatocytes compared with $0.01 \& 0.5 \mathrm{mM}$.

TABLE 1. Primers used in the study

\begin{tabular}{lcc}
\hline Primer & Forward $5^{\prime} \rightarrow 3^{\prime}$ & Reverse $5^{\prime} \rightarrow 3^{\prime}$ \\
\hline LCN-2 & GGA ATA TTC ACA GCT ACC CTC & TTG TTA TCC TTG AGG CCC AG \\
TfR1 & ATA CGT TCC CCG TTG TTG AGG & GGC GGA AAC TGA GTA TGG TTG A \\
TfR2 & AGC TGG GAC GGA GGT GAC TT & TCC AGG CTC ACG TAC ACA ACA G \\
FTH & GCC CTG AAG AAC TTT GCC AAA T & TGC AGG AAG ATT CGT CCA CCT \\
FTL & AAC CAC CTG ACC AAC CTC GCT A & TCA GAG TGA GGA GCT CAA AGA G \\
$\beta$-Actin & TGT CAC CAA CTG GGA CGA TA & AAC ACA GCC TGG ATG GCT AC
\end{tabular}


TA B LE 2. Antibodies used in the study

\begin{tabular}{lccl}
\hline Antibodies & Company & Reference No. & Dilution \\
\hline LCN-2 & R\&D & AF3508 & $1: 300$ \\
TfR1 & Invitrogen & $13-6890$ & $1: 1,000$ \\
FTH & LS Bio & LS-C23537 & $1: 500$ \\
FTL & Abcam & ab69090 & $1: 1,000$ \\
$\beta$-Actin & Sigma & A-2228 & $1: 5,000$
\end{tabular}

Therefore, we used $0.1 \mathrm{mM}$ concentration for costimulatory (AP cytokines+iron) experiments. In iron-treated hepatocytes, the maximum iron uptake was measured $(133.37 \pm 4.82 \mu \mathrm{g} / \mathrm{g}$ of protein) at $24 \mathrm{~h}$ at a concentration of $0.1 \mathrm{mM}$ iron, which was approximately two times higher compared with untreated controls. Other concentrations of iron $(0.01$ and $0.5 \mathrm{mM})$ also showed a significantly increased iron uptake; however, the magnitude of iron uptake using iron concentration $0.1 \mathrm{mM}$ was the maximum among all alone iron-treated hepatocytes (Fig. 1A).

In cytokine-treated hepatocytes (IL-1 $\beta$, IL-6, TNF- $\alpha$ ), no significant uptake of iron was observed (Fig. 1B). However, a significant uptake of iron in hepatocytes was observed when iron was supplemented to the culture medium together with the AP cytokines. The maximum iron uptake was detected by addition of iron and IL-6 together in the culture medium, which was approximately eight times $(481 \pm 25.81 \mu \mathrm{g} / \mathrm{g}$ of protein at 24 h) higher than untreated controls. Similar increase was also found in hepatocytes exposed to IL-1 $\beta+$ iron $(118.91 \pm 10.58 \mu \mathrm{g} /$ $\mathrm{g}$ of protein) and TNF- $\alpha+$ iron $(106.91 \pm 6.91 \mu \mathrm{g} / \mathrm{g}$ of protein) at $24 \mathrm{~h}$, whereas the magnitude of iron uptake was higher in hepatocytes where iron was added together with IL-6 (Fig. 1C).

\section{Changes in amount of LCN-2 in cultured rat hepatocytes}

Cultured rat hepatocytes were exposed to different iron concentrations $(0.01,0.1,0.5 \mathrm{mM})$ to observe the changes in LCN-2 at mRNA and protein levels. Addition of alone iron into the hepatocytes culture medium sign ificantly increased the LCN-2 gene expression at mRNA and protein levels. A significant upregulation for LCN-2 gene expression was detected at $6 \mathrm{~h}$ on mRNA and protein levels (Fig. 2, A and D). However, the max- imum induction of LCN-2 gene expression was found at $12 \mathrm{~h}$ with an iron concentration of 0.1 $\mathrm{mM}(1.95 \pm 0.16$-fold $)$ followed by $0.5 \mathrm{mM}$ (1.71 \pm 0.304 -fold $)$ and $0.01 \mathrm{mM}(1.52 \pm 0.10$-fold $)$.
Similarly, hepatocytes treated with AP cytokines (IL-1 $\beta, I L-6$, and TNF- $\alpha$ ) showed an increase in LCN-2 transcripts (Fig. 2B). Interleukin 6Ytreated hepatocytes showed an early increase in LCN-2 at 6 h $(5.01 \pm 0.24$-fold), which remained upregulated until $24 \mathrm{~h}$ compared with untreated hepatocytes. A late (24 h) but significant induction of LCN-2 was detected after administration of IL- $1 \alpha$ (3.53 \pm 0.14 -fold), whereas TNF- $\alpha$ treated hepatocytes showed a minor change in gene expression of $\mathrm{LCN}-2$ at mRNA level (Fig. 2B).

In the third group (AP cytokines+iron), the upregulating effect of alone iron or AP cytokines was further enhanced by the addition of AP cytokines together with iron into the culture medium. The most pronounced increase was detected at $24 \mathrm{~h}$ by IL-6+iron (11.85 \pm 1.01 -fold) and IL-1 $\beta+$ iron (12.81 \pm 2.13 -fold) (Fig. 2, C and D), whereas TNF- $\alpha+$ iron showed the least pronounced change of LCN-2 gene expression in hepatocytes.

RT-PCR results were further con- firmed by Western blot by using a specific antibody against LCN-2. Reflecting the results at transcript level, an increased protein level of LCN-2 was revealed after administration of iron and/or AP cytokines (Fig. 2D).

\section{Changes in the amount of TfRs in cultured rat hepatocytes}

Alone iron administration to the hepatocytes culture medium decreased the gene expression of TfR1 at mRNA level. The impact of $0.5 \mathrm{mM}$ concentration of iron was stronger than other concentrations in cultured hepatocytes (Fig. 3A) These data were also confirmed at protein level (Fig. 3D).

In group of AP cytokines, IL-1 $\beta+$ treated hepatocytes showed a significant increase in gene expression of TfR1 at $24 \mathrm{~h}$ (7.48 \pm 0.08 -fold) in comparison to untreated controls. In contrast, a reduced expression of TfR1 was detected after IL-6 administration with a minimum ( $0.44 \pm 0.08$-fold) at $6 \mathrm{~h}$. TNF- $\alpha$-treated hepatocytes did not show any considerable change at any studied time point as compared with untreated controls (Fig. 3B). These data were also confirmed at protein level (Fig. 3D).

Contrary to iron treatment alone, the observed downregulating effect of iron on TfR1 transcripts was completely abrogated when iron was administrated together with IL-6 to the culture medium.

However, IL-1 $\beta$ and TNF- $\alpha$ treatment showed a further increase in TfR1 transcripts in the presence of iron (Fig. 3C). By using a specific antibody against TfR1, these results were further confirmed at protein level, although the reduction in TfR1 at protein level was observed with a delay compared with mRNA level (Fig. 3D).
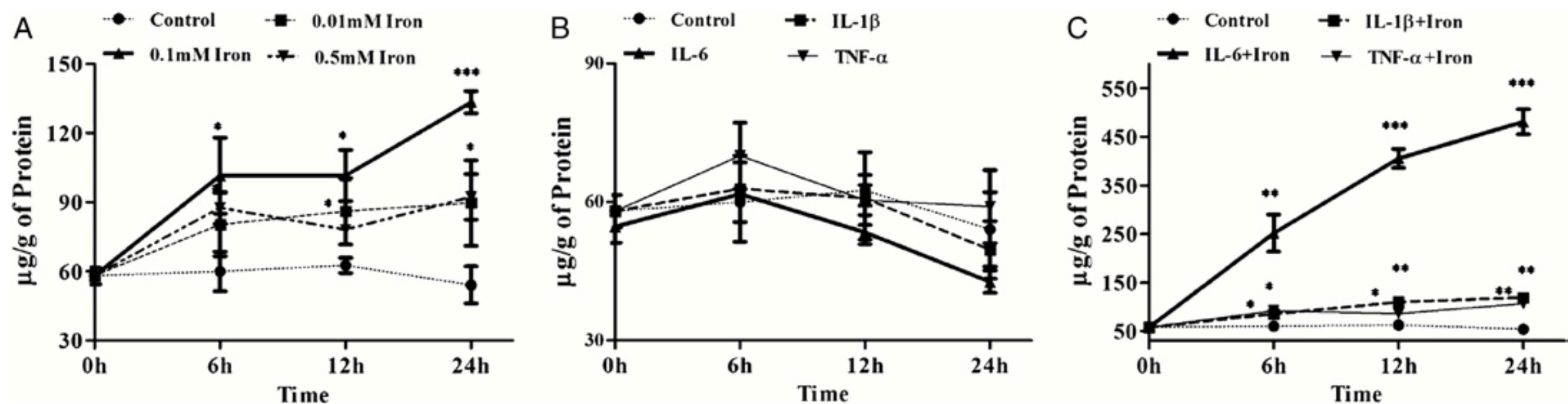

Fig.1. Measurement of iron uptake in hepatocytes: iron-treated hepatocytes (A). Cytokines treated hepatocytes (B). Cytokines+iron-treated hepatocytes (C). Values on $\mathrm{y}$ axis represent the intracellular iron contents of hepatocytes compared with nontreated controls. Results representthe mean value $\pm \mathrm{SEM}$. $* \mathrm{P} \leq 0.0125, * * \mathrm{P} \leq 0.001$, $* * * \mathrm{P} \leq 0.0001$ analyzed by $\mathrm{t}$-test $(\mathrm{n}=4)$. 

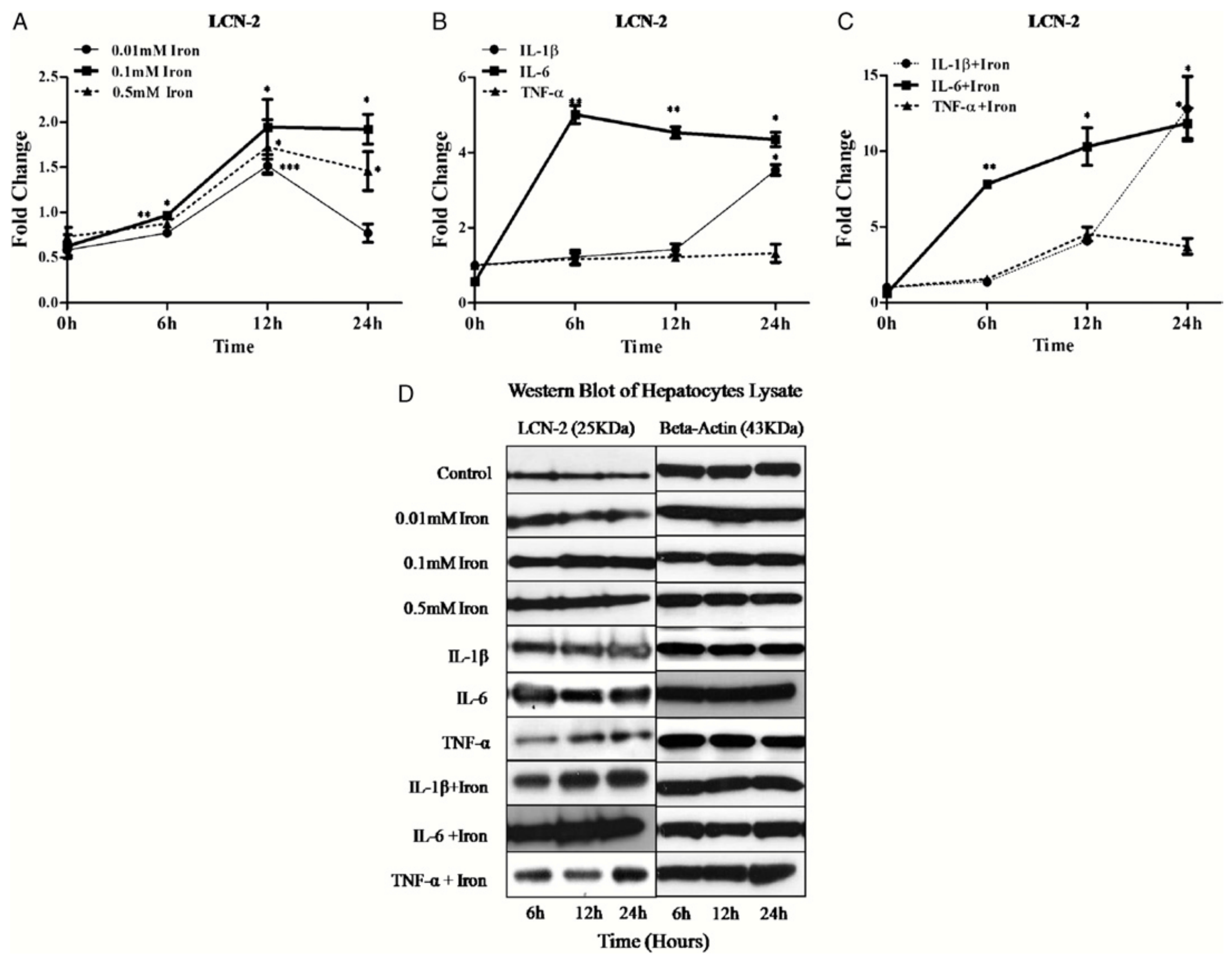

Fig .2. Quantitative RT-PCR analysis of mRNA from rat hepatocytes. Fold changein mRNA expression of LCN-2 gene expression after iron treatment (A), cytokine treatment (B), cytokines+iron treatment $(\mathrm{C})$ at different time points related to nontreated controls for each time point. Quantitative RT-PCR was normalized by using housekeeping gene $\beta$-actin. Results represent mean value \pm SEM. $* \mathrm{P} \leq 0.0125,{ }^{* *} \mathrm{P} \leq 0.001, * * * \mathrm{P} \leq 0.0001$ analyzed by t-test $(\mathrm{n}=4)$. Western blot analysis of LCN-2 (25 KDa) from total protein of rat hepatocytes. $\beta$-Actin (43 KDa) was used as a marker for equal loading (D).

However, IL- $1 \beta$ and TNF- $\alpha$ treatment showed a further increase in TfR1 transcripts in the presence of iron (Fig. 3C). By using a specific antibody against TfR1, these results were further confirmed at protein level, although the reduction in TfR1 at protein level was observed with a delay compared with mRNA level (Fig. 3D).

In contrast to TfR1, TfR2 gene expression was increased by different iron concentrations (Fig. 4A). Interleukin 6 treatment also increased TfR2 gene expression significantly at $6 \mathrm{~h}$, with a maximum expression at $24 \mathrm{~h}$ (7.2 \pm 1.01 -fold), compared with untreated hepatocytes. IL-1 $\beta$ showed a late significant increase (at $24 \mathrm{~h}$ ), whereas minor changes were observed in TfR2 gene expression after TNF- $\alpha$ treatment in hepatocytes (Fig. 4B).

In hepatocytes treated with a combination of iron and AP cytokines together, IL-6 + iron elicited an early increase in TfR2 transcripts $(1.94 \pm 0.31$-fold $)$ with a maximum at $24 \mathrm{~h}(7.32$ \pm 0.61 -fold), which was followed by TNF- $\alpha$ +iron $(7.38 \pm 1.5$ fold) and IL- $1 \beta+$ iron (4.73 \pm 0.1 -fold) (Fig. 4C). Treatment of iron and AP cytokine together showed a synergetic effect on TfR2 gene expression as compared with iron or AP cytokine treatment alone. We could not detect the expression of TfR2 at protein level in control as well as treated hepatocytes. This might be a problem of antibody sensitivity.

\section{Modulation of ferritin subunits in cultured rat hepatocytes after treatment with iron and AP cytokines}

In iron-treated hepatocytes, a time-dependent increase in the FTL was detected both at mRNA and protein levels with a peak at $24 \mathrm{~h}(2.48 \pm 0.195$-fold $)$ after administration of $0.5 \mathrm{mM}$ iron into the culture medium (Fig. 5A).

The effects of AP cytokines (IL-1 $\beta$, IL-6, TNF- $\alpha$ ) on FTL and FTH were examined in the second group. mRNA analysis of ferritin subunits in rat hepatocytes showed a mild increase in FTL gene expression with a maximum at $24 \mathrm{~h}$ upon cytokine (IL-1 $\beta$, IL-6, TNF- $\alpha$ ) treatment (Fig. 5B). This increase was better visible at protein level, where cytokines showed an early increase, which persisted until $24 \mathrm{~h}$ compared with un- treated controls. The most pronounced induction was observed by IL-1 $\beta$ (Fig. 5D). Iron-treated hepatocytes showed a higher induction of FTL than administration of cytokines alone. No significant 


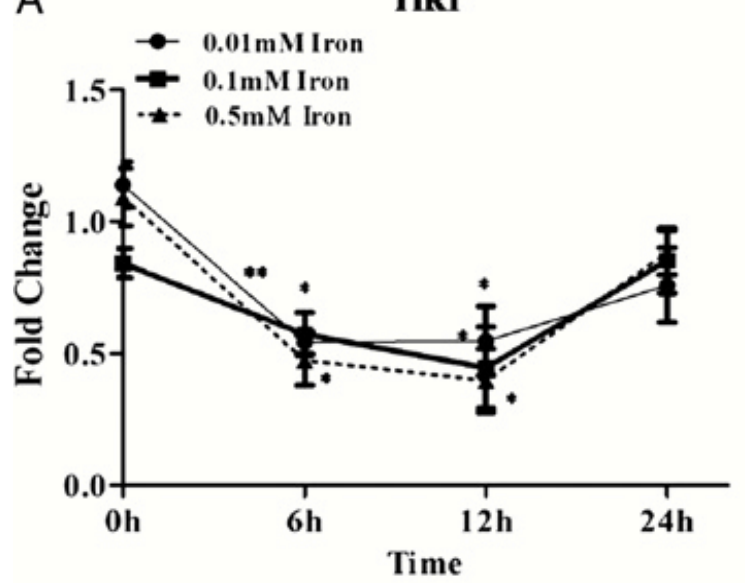

B

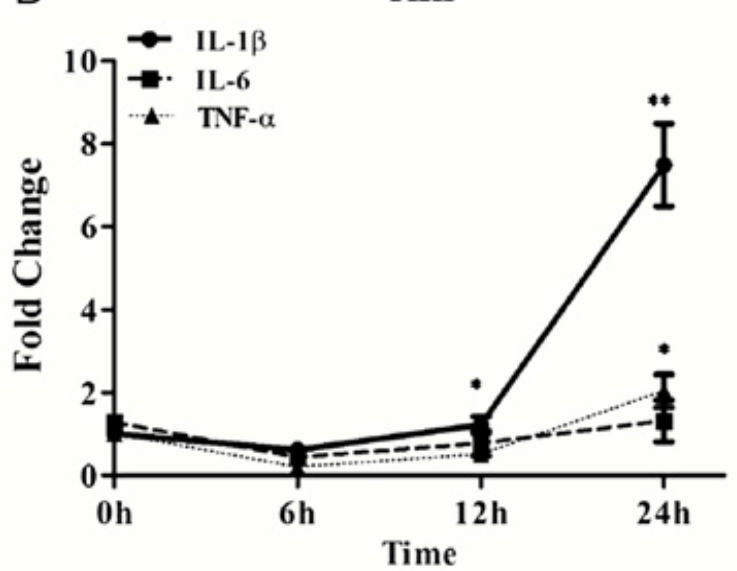

C

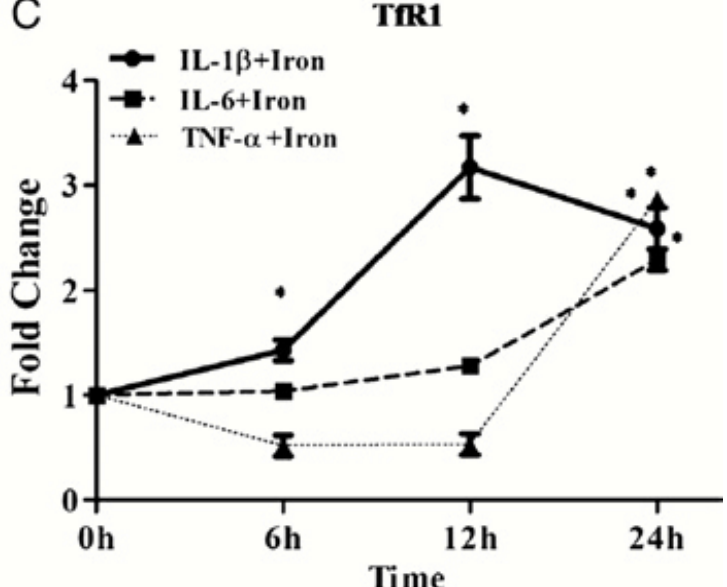

D Western Blot of Hepatocytes Lysate

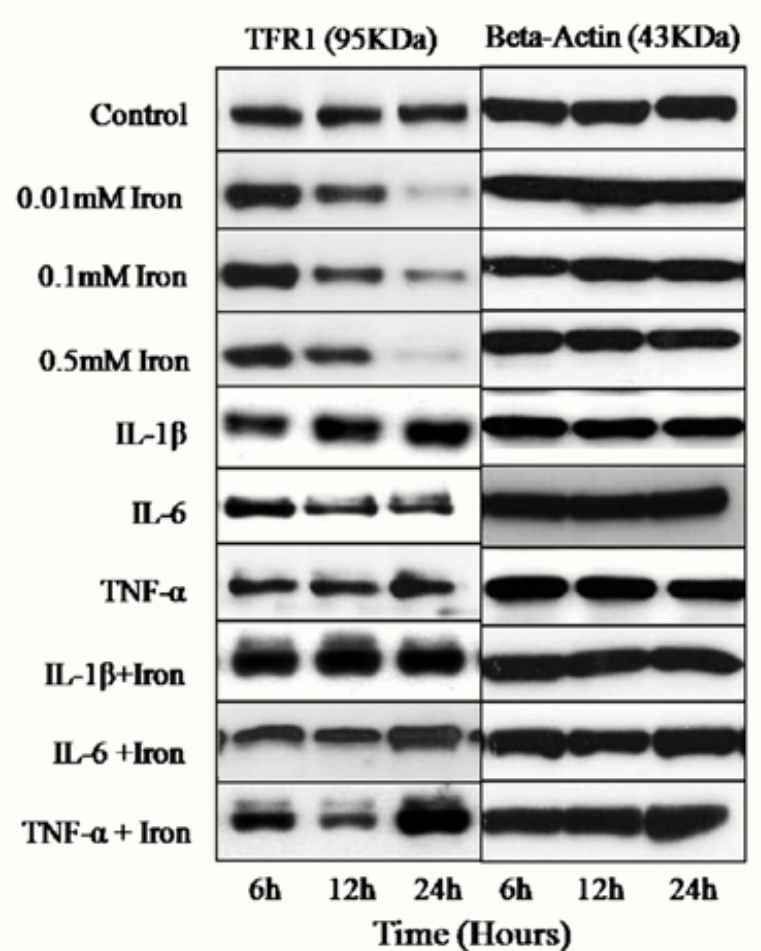

Fig .3. Quantitative RT-PCR analysis of mRNA from rat hepatocytes. Fold change in mRNA expression of TfR1 gene expression after iron treatments (A), cytokine treatment (B), cytokines+iron treatment (C) at different time points related to nont-reated controls for each time point. Quantitative RT-PCR was normalized by using housekeeping gene $\beta$-actin. Results represent mean value \pm SEM. $* \mathrm{P} \leq 0.05$, $* * \mathrm{P} \leq 0.001$ analyzed by $\mathrm{t}$ test $(\mathrm{n}=4)$. Western blot analysis of TfR1 (95 KDa) from total protein of rat hepatocytes. $\beta$-Actin $(43 \mathrm{KDa})$ was used as a marker for equal loading (D).

difference was visible by combination of AP cytokines and iron in comparison to iron or AP cytokine treatment alone (Fig. 5C).

Similar to FTL, a dramatic induction in the gene expression of FTH was detected after iron treatment to hepatocytes both at mRNA and protein levels (Fig. 6, A and D).
Stimulation of hepatocytes with IL-6 showed an early (6h) increase in FTH both at mRNA and protein levels with a peak at $12 \mathrm{~h}$ (3.7 \pm 0.26 -fold). Similarly, a time-dependent increase in FTH was observed after IL- $1 \beta$ and TNF- $\alpha$ treatment, with a maximum at $24 \mathrm{~h}$ (Fig. 6B).
A

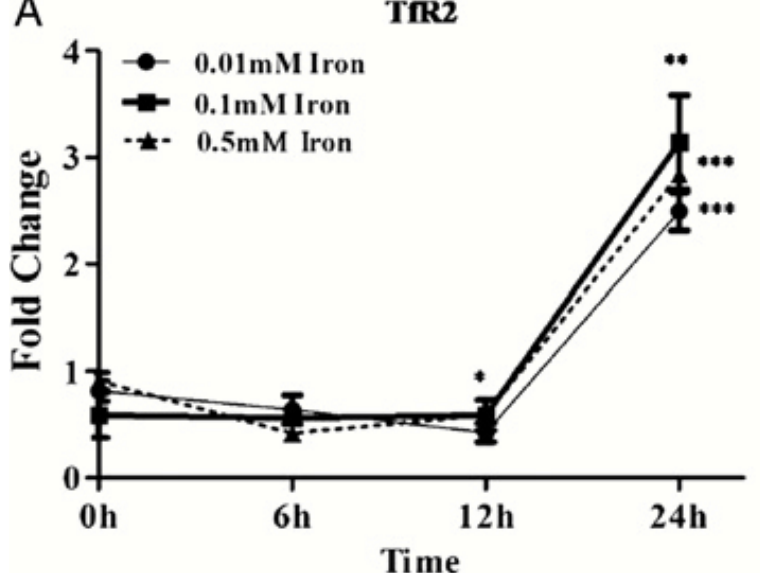

B

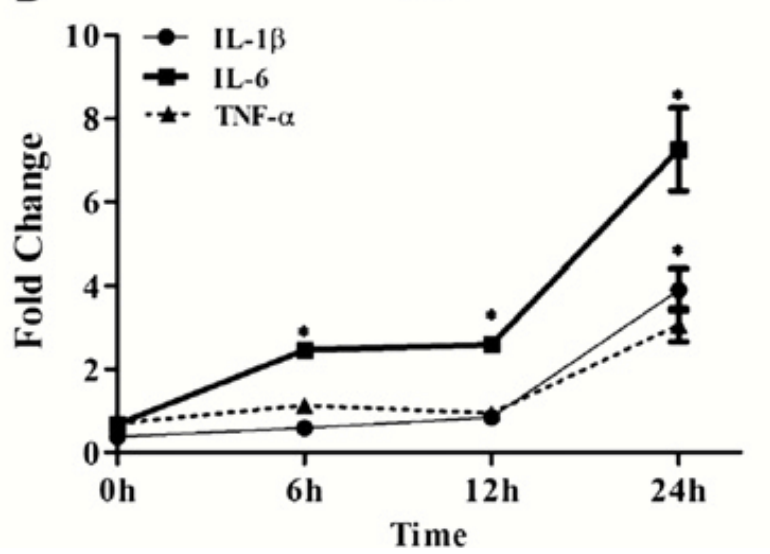

C

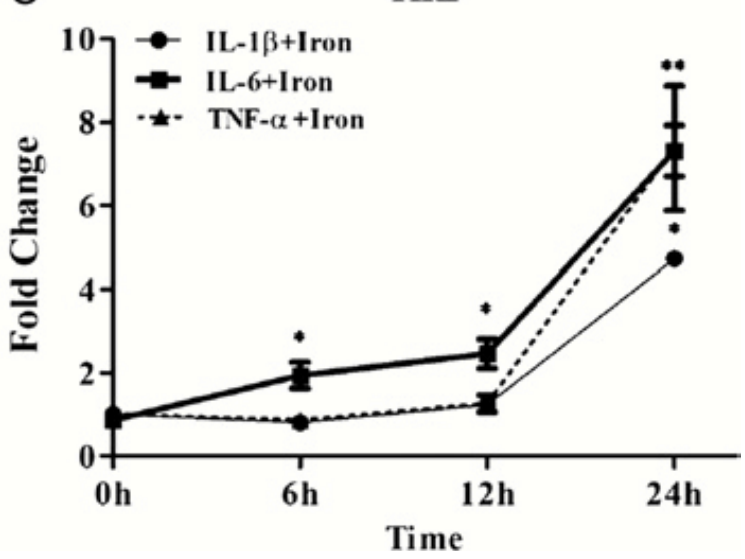

Fig .4. Quantitative RT-PCR analysis of total RNA from rat hepatocytes.Fold change in mRNA expression of TfR2 gene expression after iron treatments (A), cytokine treatment (B), cytokines+iron treatment (C) at different time points related to nontreated controls for each time point. Quantitative RT-PCR was normalized by using housekeeping gene $\beta$-actin. Results represent mean value \pm SEM.*P $\leq 0.0125, * * \mathrm{P} \leq 0.001$, $* * * \mathrm{P} \leq 0.0001$ analyzed by $\mathrm{t}$-test $(\mathrm{n}=4)$. 

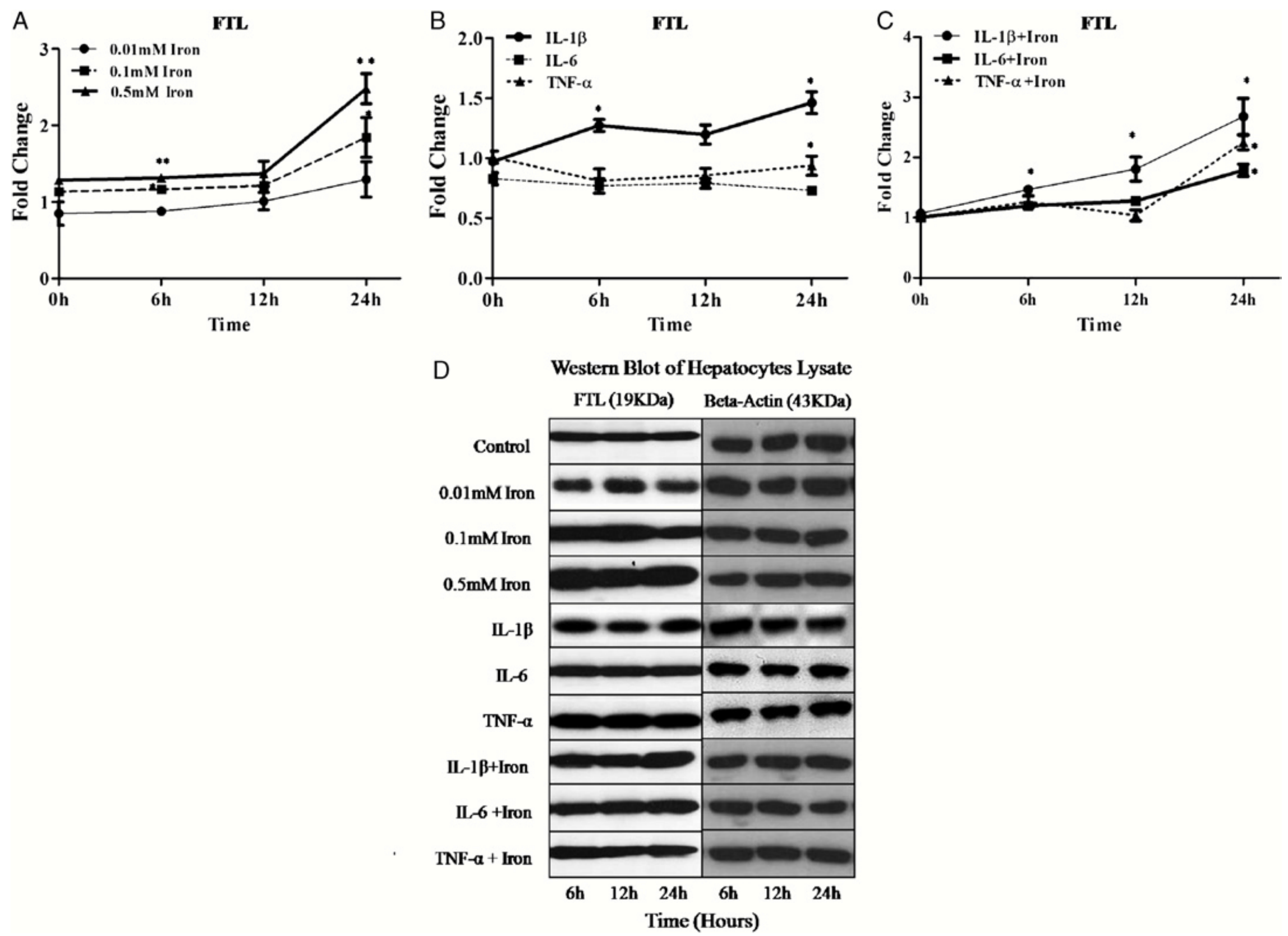

Fig.5. Quantitative RT-PCR analysis of mRNA from rat hepatocytes. Fold change in mRNA expression of FTL gene expression after iron treatments (A), cytokine treatment (B), cytokines+iron treatment (C) at different time points related to nontreated controls for each time point. Quantitative RT-PCR was normalized by using housekeeping gene $\beta$-actin. Results represent mean value $+\mathrm{SEM} * \mathrm{P} \leq 0.05 * * \mathrm{P} \leq 0.001$ analyzed by $\mathrm{t}$-test $(\mathrm{n}=4)$. Western blot analysis of FTL (19 KDa) from total protein of rat hepatocytes. $\beta$-Actin ( $43 \mathrm{KDa}$ ) was used as a marker for equal loading (D)

Furthermore, combination of iron and AP cytokines in comparison to cytokines or iron treatment alone did not show a significant difference (Fig. 6C).

\section{Detection of LCN-2 and FTL in culture media of rat} hepatocytes after treatment with iron and AP cytokines

Light-chain ferritin subunit is known to be a secretory protein with increased release by iron and cytokines into the culture media of hepatocytes (27). Iron is the main inducer of both ferritin subunits (28). To validate the LCN-2 changes in isolated rat hepatocytes, iron was added into the culture medium of hepatocytes. Western blot analysis of total supernatant from rat hepatocytes demonstrated an increase in $\mathrm{LCN}-2$ protein expression after iron or AP cytokine treatment alone with a peak at $24 \mathrm{~h}$, which was comparable to FTL, a positive secretory APP (27). In AP cytokine group, LCN-2 release was most pronounced with IL-6 followed by IL-1 $\beta$ and TNF- $\alpha$ ( Fig. 7) in accordance to hepatocyte lysate.

Moreover, a dramatic synergistic increase in FTL and LCN- 2 at protein level was detected after administration of AP cytokines together with iron in the supernatant of hepatocytes. The protein level of both FTL and LCN-2 remained above the control level throughtout the course of the study (Fig.7). Taken together, LCN-2 can be released from hepatocytes into the supernatant. Similar to FTL, this release can be induced by AP cytokines and further enhanced when iron is provided in the cell culture medium.

\section{DISCUSSION}

In the present study, an increased iron uptake was detected in cultured hepatocytes by the treatment of iron. This iron uptake was dramatically enhanced when AP cytokines, mainly IL-6, were used together with iro $\mathrm{n}$. In parallel to iron uptake, an increase in gene expression of iron transport (LCN-2 and TfR2) and storage proteins (FTL, FTH) was observed. In contrast to TfR2, the amount of TfR1 was decreased by the addition of IL- 6 or iron alone into the culture medium. This reduction was abrogated when IL- 6 was used together with iron at the same time. Another striking finding of the current study was the detection of LCN-2 release from hepatocytes into the supernatant after iron administration, similar to what was observed for FTL. This increase in LCN-2 gene expres- sion caused by iron was further enhanced in the presence of AP cytokines, mainly by IL-6. 
A

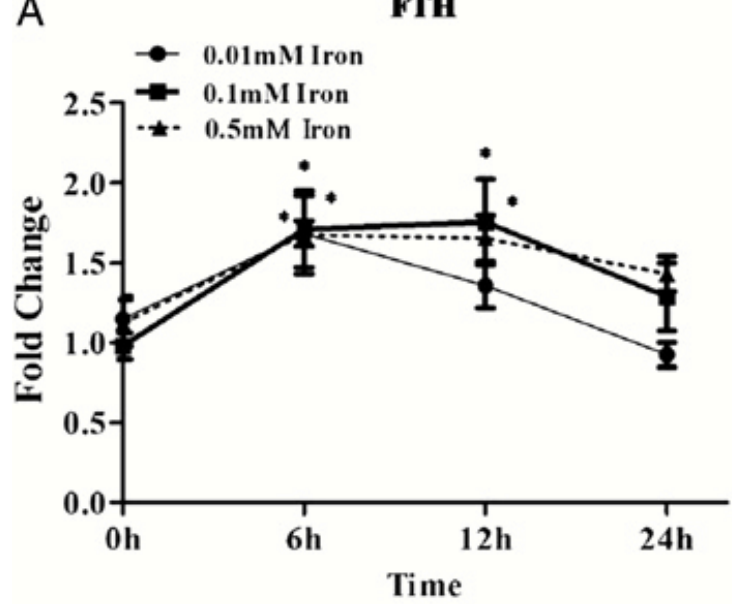

B

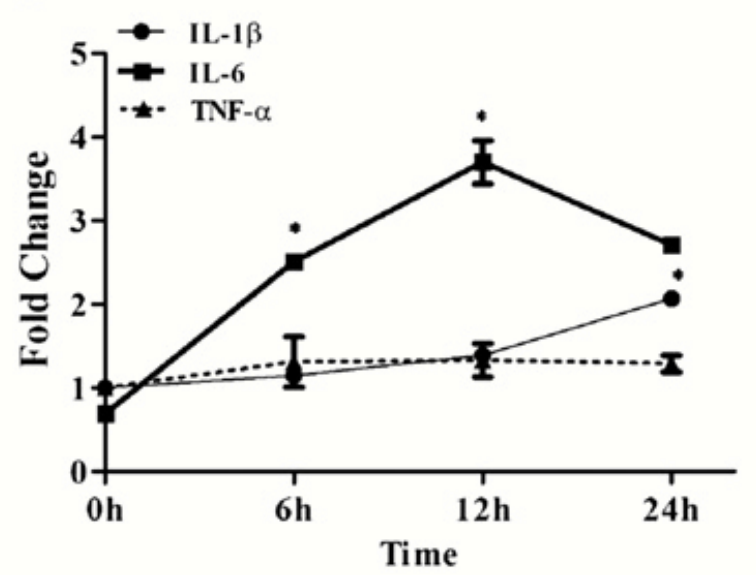

C

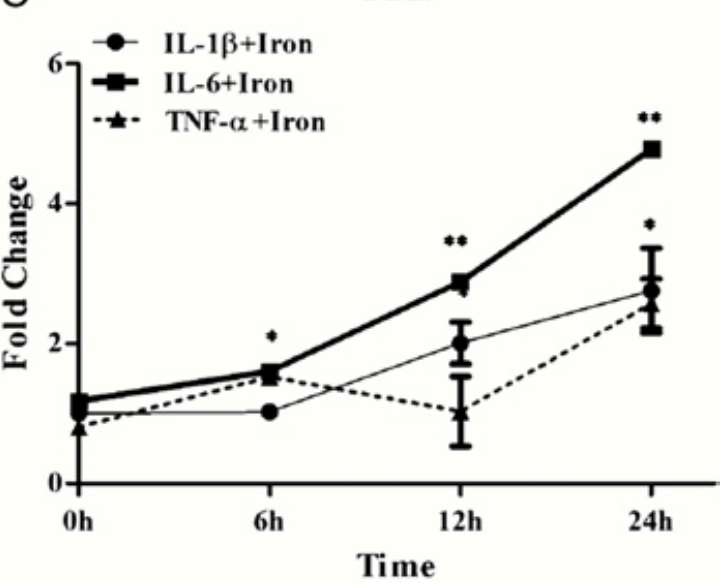

D

Western Blot of Hepatocytes Lysate FTH (21KDa) Beta-Actin (43KDa)

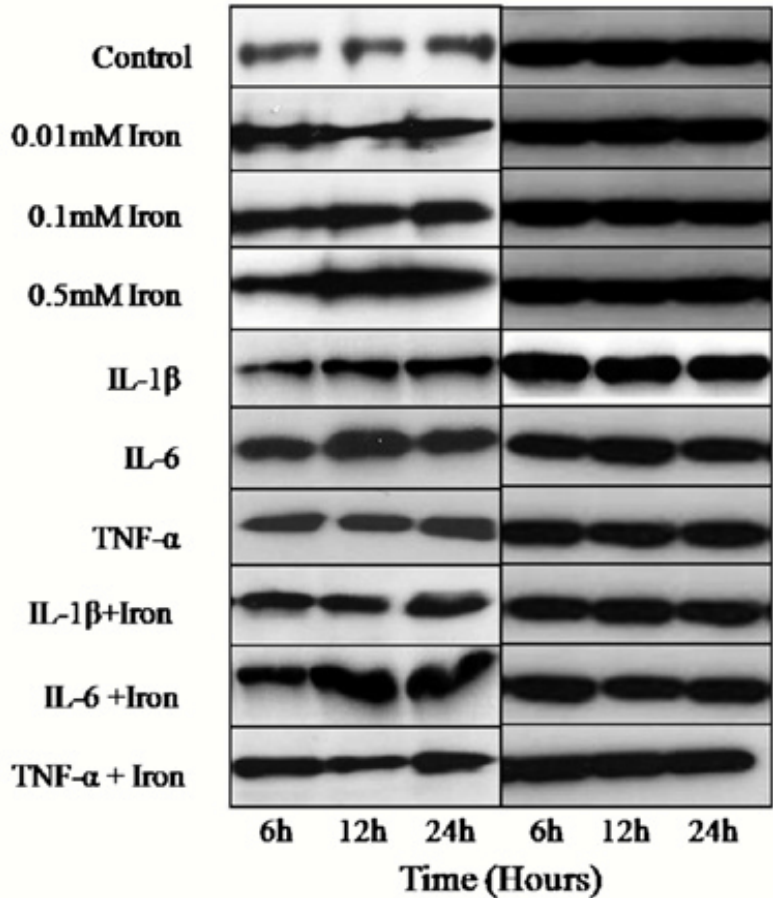

Fig .6. Quantitative RT-PCR analysis of total RNA from rat hepatocytes. Fold change in mRNA expression of FTH gene expression after iron treatments (A), cytokine treatment (B), cytokines+iron treatment (C) at different time points related to nontreated controls for each time point. Quantitative RT-PCR was normalized by using housekeeping gene $\beta$-actin. Results represent mean value $\pm \mathrm{SEM}$. $* \mathrm{P} \leq 0.05, * * \mathrm{P} \leq 0.001$ analyzed by $\mathrm{t}$ test $(\mathrm{n}=4)$. Western blotanalysis of FTH $(21 \mathrm{KDa})$ from total protein of rat hepatocytes. $\beta$-Actin $(43 \mathrm{KDa})$ was used as a marker for equal loading (D).

Indeed, Tf binding maintains iron in a soluble form and serves as a major vehicle of plasma iron delivery into cells via TfRs. TfR2 is positively (29) and TfR1 (30) is known to be negatively regulated by cellular iron status, which is in accordance with our study.

Iron is transported into the cells by two different pathways: Tfdependent and Tf-independent pathway; the latter is acti- vated in iron overload conditions (31). In addition to Tf-bound iron, NTBI uptake mechanisms have also been described in a variety of cell lines (32), including hepatocytes (31). Recent studies have shown that LCN-2 is responsible for transport of iron through this pathway $(33,34)$. Based on previous and our current study, one can propose that iron uptake/transportation into hepatocytes could take place by both Tf-dependent and Tf-independent pathways, and the latter could be regulated by LCN-2. However, the role of LCN-2 pathway in iron uptake could be of minor importance compared with the Tf pathway.

An increase in iron level is associated with increased serum levels of AP cyto kines such as IL-6, IL-1 $\beta$, and TNF- $\alpha$ (35). We and several previous AP studies reported that the liver responded dramatically to elevated levels of IL-6 by releasing APPs (36), which upregulate gene expression of most of iron regulatory proteins in the liver (and isolated hepatocytes). This indicates a strong correlation of these major AP cytokines mainly IL-6 with hepatic expression of iron regulatory proteins. A similar effect can be true in case of LCN-2 in the current study, as our data showed that iron and IL-6 seemed to be the main factors responsible for the dramatically induced LCN-2 gene expression in hepatocytes as has been previously reported (37). Furthermore, a reduced LCN-2 expression was reported in the liver of IL-6 knockout mice during APR (37). In addition, IL-6 is known to cause hypoferremia of inflammation by regulating hepcidin, but a recent study clearly demonstrated hepcidin-independent pathway for hypoferremia (38). In a mouse model of LPS-induced sepsis, LCN-2 has been described to play a key role in causing hypoferremia of inflammation (39). From our experimental data, we can speculate direct increased uptake of iron in hepatocytes stim- ulated by IL-6 can be another mechanism of hypoferremia of inflammation.

Another important aspect of current study showed that LCN-2 is a secretory hepatocellular protein. $\mathrm{LCN}-2$ releases into the supernatants of isolated hepatocytes was detected not only by AP- 
Western Blot of Hepatocytes Culture Medium

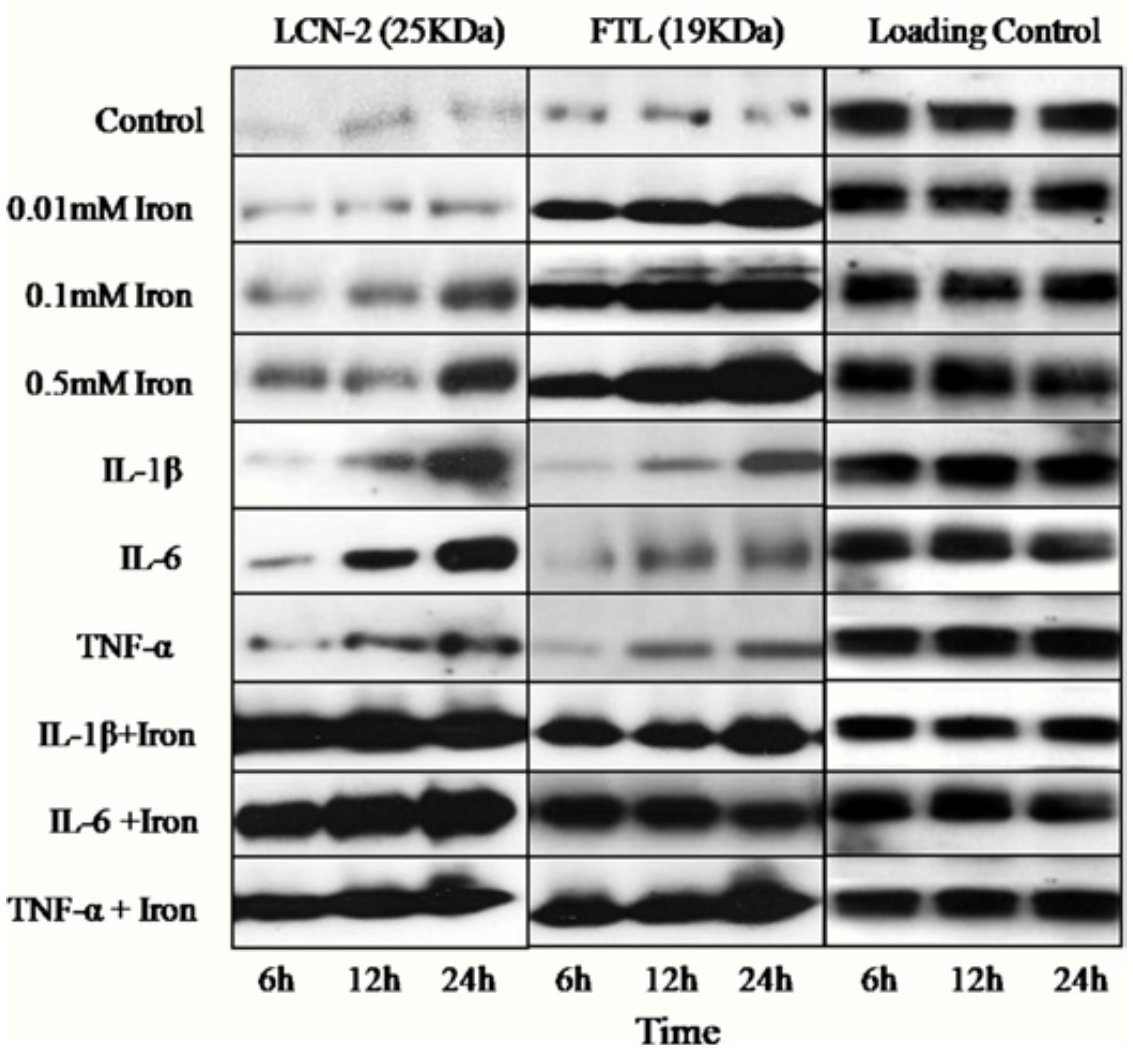

Fig.7. Western blot analysis of LCN-2 (25 KDa) and FTL (19 KDa) from total protein of rat hepatocytes supernatant. Ponceau S staining was used for equal loading.

ernatants of isolated hepatocytes was detected not only by AP cytokines (mainly IL-6) administration but also by iron, and this release was comparable to that of FTL (iron-storage and AP secretory protein). This finding indicates that AP cytokines and iron increase the release of LCN-2 probably in a similar way to FTL or another classic AP secretory protein (e.g., $\alpha-2 \mathrm{M}$ ) as has been previously shown in same setting (27).

In fact, hepatocytes are the main source of most of the serum proteins, and they have a pivotal role in iron metabolism $(2,40)$. This work emphasizes the importance of iron uptake in hepatocytes during AP reaction. Hepatocytes need more iron to respond to the massive increase in protein synthesis under such stress conditions. This information contradicts the usual assumption that iron is just sequestrated in the macrophages to reduce bacterial growth (41). In conclusion, the disappearance of iron from the circulation has a very important functional meaning also in conditions (acute damage) where AP reaction is not caused by bacterial infections.

The results of the current and our previous studies (36) show the change in expression of hepatic iron regulatory genes including LCN-2 is not only due to the increase in hepatic iron concentration but is also due to the effect of AP cytokines (mainly IL-6) produced in hepatocytes during AP conditions.

\section{REFERENCES}

1.Ganz T, Nemeth E: Iron metabolism: interactions with normal and disordered erythropoiesis. Cold Spring Harb Perspect Med 2(5):a011668, 2012.

2. Arosio P, Ingrassia R, Cavadini P: Ferritins: a family of molecules for iron storage, antioxidation and more. Biochim Biophys Acta 1790(7):589-599, 2009.

3. Worwood M, Brook JD, Cragg SJ, Hellkuhl B, Jones BM, Perera P, Roberts SH, Shaw DJ: Assignment of human ferritin genes to chromosomes 11 and 19q13.3V-19qter. Hum Genet 69(4):371-374, 1985.

4.Sammarco MC, Ditch S, Banerjee A, Grabczyk E: Ferritin L and H subunits are differentially regulated on a post-transcriptional level. J Biol Chem 283(8): 4578-4587, 2008.
5. McKie AT, Marciani P, Rolfs A, Brennan K, Wehr K, Barrow D, Miret S, Bomford A, Peters TJ, Farzaneh F, et al.: A novel duodenal iron-regulated transporter, IREG1, implicated in the basolateral transfer of iron to the circu-lation. Mol Cell 5(2):299-309, 2000.

6. Chen J, Chloupkova M, Gao J, Chapman-Arvedson TL, Enns CA: HFE modulatestransferrin receptor 2 levels in hepatoma cells via interactions that differ from transferrin receptor 1-HFE interactions. J Biol Chem282(51):36862-36870, 2007.

7. Pigeon C, Ilyin G, Courselaud B, Leroyer P, Turlin B, Brissot P, Loreal O: A new mouse liver-specific gene, encoding a protein homologous to human antimicrobial peptide hepcidin, is overexpressed during iron overload. J Biol Chem 276(11):7811Y7819, 2001.

8. Lanzara C, Roetto A, Daraio F, Rivard S, Ficarella R, Simard H, Cox TM, Cazzola M, Piperno A, Gimenez-Roqueplo AP, et al.: Spectrum of hemojuvelin gene mu-tations in 1q-linked juvenile hemochromatosis. Blood 103(11):4317Y4321, 2004.

9. Conner SD, Schmid SL: Differential requirements for AP-2 in clathrin-mediated endocytosis. J Cell Biol 162(5):773Y779, 2003.

10. Yang J, Mori K, Li JY, Barasch J: Iron, lipocalin, and kidney epithelia. Am J Physiol Renal Physiol 285(1):F9YF18, 2003.

11. Hentze MW, Muckenthaler MU, Andrews NC: Balancing acts: molecular control of mammalian iron metabolism. Cell 117(3):285Y297, 2004.

12. Breuer W, Ronson A, Slotki IN, Abramov A, Hershko C, Cabantchik ZI The assessment of serum nontransferrin-bound iron in chelation therapy and iron supplementation. Blood 95(9):2975-2982, 2000.

13. Yang J, Goetz D, Li JY, Wang W, Mori K, Setlik D, Du T, ErdjumentBromage $\mathrm{H}$, TempstP, Strong $\mathrm{R}$, et al.:An iron delivery pathway mediated by a lipocalin. Mol Cell 10(5):1045-1056, 2002.

14. Flo TH, Smith KD, Sato S, Rodriguez DJ, Holmes MA, Strong RK, Akira S, Aderem A: Lipocalin 2 mediates an innate immune response to bacterial in-fection by sequestrating iron. Nature 432(7019):917-921, 2004.

15. Solan PD, Piraino G, Hake PW, Denenberg A, O’Connor M, Lentsch A, Zingarelli B: Liver $\mathrm{X}$ receptor alpha activation with the synthetic ligand T0901317 reduces lung injury and inflammation after hemorrhage and resuscitation via inhi- bition of the nuclear factor kappaB pathway. Shock 35(4):367-374, 2011

16. Ramadori G, Christ B: Cytokines and the hepatic acute-phase response. Semin Liver Dis 19(2):141-155, 1999.

17. Telfer JF, Brock JH: Proinflammatory cytokines increase iron uptake into human monocytes and synovial fibroblasts from patients with rheumatoid arthritis. Med Sci Monit 10(4):BR91-BR95, 2004.

18. Malik IA, Naz N, Sheikh N, Khan S, Moriconi F, Blaschke M, Ramadori $\mathrm{G}$ :Comparison of changes in gene expression of transferrin receptor-1 and other iron-regulatory proteins in rat liver and brain during acute-phase response. Cell Tissue Res 344(2):299-312, 2011.

19. Lefevre N, Corazza F, Duchateau J, Desir J, Casimir G: Sex differences in inflammatory cytokines and CD99 expression following in vitro lipopolysac- charide stimulation. Shock 38(1):37Y42, 2012.

20. Ramadori G, Moebius U, Dienes HP, Meuer S, Meyer zum Buschenfelde $\mathrm{KH}:$ Lymphocytes from hepatic inflammatory infiltrate kill rat hepatocytes in pri- mary culture. Comparison with peripheral blood lymphocytes. Virchows Arch B Cell Pathol Incl Mol Pathol 59(5):263-270, 1990

21. Jego P, Chenoufi N, Loreal O, Morel I, Pasdeloup N, Abdallah MA, Brissot P,Lescoat G: Inhibition of iron toxicity in human hepatocyte cultures by pyoverdins $\mathrm{Pa} \mathrm{A}$ and $\mathrm{Pf}$, the peptidic siderophores of Pseudomonas aeruginosa and fluorescens. Liver 17(2):70-75, 1997.

22. Liu Q, Wang H, Hu D, Ding C, Xu H, Tao D: Effects of trace elements on the elomere lengths of hepatocytes L-02 and hepatoma cells SMMC-7721. Biol Trace Elem Res 100(3):215-227, 2004.

23. Riemer J, Hoepken HH, Czerwinska H, Robinson SR, Dringen R Colorimetric FerroZine-based assay for the quantitation of iron in cultured cells. Anal Biochem 331(2):370-375, 2004 
24.Tron K, Novosyadlyy R, Dudas J, Samoylenko A, Kietzmann T, Ramadori G:Upregulation of heme oxygenase-1 gene by turpentine oil-induced localized inflammation: involvement of interleukin-6. Lab Invest 85 (3).376-387, 2005

25. Laemmli UK: Cleavage of atructural proteins of the head of bacteriophage T4. Nature 227(5259):680-685, 1970.

26.Towbin H, Staehelin T, Gordon J: Electrophoretic transfer of proteins from polyacrylamide gels to nitrocellulose sheets: procedure and some applications. Proc Natl Acad Sci USA 76(9):4350-4354, 1979.

27.Naz N, Moriconi F, Ahmad S, Amanzada A, Khan S, Mihm S, Ramadori G, Malik IA: Ferritin L is the sole serum ferritin constituent and a positive hepatic acute phase protein. Shock 39(6):520-6, 2013

28.Eisenstein RS, Garcia-Mayol D, Pettingell W, Munro HN: Regulation of ferritin and heme oxygenase synthesis in rat fibroblasts by different forms of iron. Proc Natl Acad Sci USA 88(3):688-692, 1991.

29 Calzolari A, Oliviero I, Deaglio S, Mariani G, Biffoni M, Sposi NM,

- Malavasi F, Peschle C, Testa U: Transferrin receptor 2 is frequently expressed in human cancer cell lines. Blood Cells Mol Dis 39(1):82-91, 2007.

30.Lu JP, Hayashi K, Awai M: Transferrin receptor expression in normal, iron-deficient and iron-overloaded rats. Acta Pathol Jpn 39(12):759-764, 1989.

31. Chua AC, Olynyk JK, Leedman PJ, Trinder D: Nontransferrin-bound iron uptake by hepatocytes is increased in the Hfe knockout mouse model of hereditary hemochromatosis. Blood 104(5):1519Y1525, 2004.

32. Prus E, Fibach E: Uptake of non-transferrin iron by erythroid cells. Anemia 2011:945289, 2011.

33.Kaplan J: Mechanisms of cellular iron acquisition: another iron in the fire. Cell 111(5):603Y606, 2002
34. Schmidt-Ott KM, Mori K, Li JY, Kalandadze A, Cohen DJ, Devarajan P,Barasch J: Dual action of neutrophil gelatinase-associated lipocalin. $J$ Am Soc Nephrol 18(2):407Y413, 2007.

35. Sheikh N, Batusic DS, Dudas J, Tron K, Neubauer K, Saile B, Ramadori G:Hepcidin and hemojuvelin gene expression in rat liverdamage: in vivo and in vitro studies. Am $J$ Physiol Gastrointest Liver Physiol 291(3):G482YG490, 2006.

36. Naz N, Malik IA, Sheikh N, Ahmad S, Khan S, Blaschke M, Schultze F,Ramadori G: Ferroportin-1 is a nuclear-negative acute-phase protein in rat liver: a comparison with other iron-transport proteins. Lab Invest 92(6):842Y856, 2012

37. Sultan S, Pascucci M, Ahmad S, Malik IA, Bianchi A, Ramadori P, Ahmad G, Ramadori G: lipocalin-2 is a major acute-phase protein in a rat and mouse model of sterile abscess. Shock 37(2):191Y196, 2012.

38. Deschemin JC, Vaulont S: Role of hepcidin in the setting of hypoferremia during acute inflammation. PLoS One 8(4):e61050, 2013.

39. Srinivasan G, Aitken JD, Zhang B, Carvalho FA, Chassaing B,Shashidharamurthy R, Borregaard N, Jones DP, Gewirtz AT, VijayKumar M: Lipocalin 2 deficiency dysregulates iron homeostasis and exacerbates endotoxin-induced sepsis. J Immunol 189(4):1911Y1919, 2012.

40.Tran TN, Eubanks SK, Schaffer KJ, Zhou CY, Linder MC: Secretion of ferritin by rat hepatoma cells and its regulation by inflammatory cytokines and iron. Blood 90(12):4979Y4986, 1997.

41.Nairz M, Theurl I, Ludwiczek S, Theurl M, Mair SM, Fritsche G, Weiss G: The coordinated regulation of iron homeostasis in murine macrophages limits the availability of iron for intracellular Salmonella typhimurium. Cell Microbiol 9(9):2126Y2140, 2007. 
TORS AND LIPOCALIN-2 IN RAT HEPATIC AND EXTRA-HEPATIC ORGANS UN-

DER PHYSIOLOGICAL AND ACUTE PHASE CONDITIONS

\author{
Shakil Ahmad, Naila Naz, Gesa Martius, Ihtzaz Ahmed Malik \\ Department of Gastroenterology and Endocrinology, University Medical Center, \\ Georg-August University, Robert-Koch-Str. 40, D-37075 Goettingen, Germany
}

\begin{abstract}
Authors Contribution: Shakil Ahmad designed project, performed experiments (Immunostainings, Western blot), data analysis and wrote manuscript

Naila Naz and Gesa Martius paricipated in experimental animal model development

Ihtzaz Ahmed Malik designed research, critical review and final improvement of the manuscript for publication
\end{abstract}

Submitted in Progress in Histochemistry and Cytochemistry 
Regulation and localization pattern of transferrin receptors and lipocalin- 2 in rat hepatic and extra-hepatic organs under physiological and acute phase conditions

Shakil Ahmad, Naila Naz, Gesa Martius, Ihtzaz Ahmed Malik

Department of Gastroenterology and Endocrinology, University Medical Center, Georg-August University, Robert-Koch-Str. 40, D-37075 Goettingen, Germany

\section{Address for Correspondence}

Dr. rer. nat. Ihtzaz Ahmed Malik

Department of Gastroenterology and Endocrinology,

University medical center Goettingen,

Robert-Koch-Strasse 40, D-37099

Goettingen, Germany.

E-mail:_ i.malik@med.uni-goettingen.de

Phone: 0049-551-39-8902

Fax: $\quad$ 0049-551-39-6921 


\begin{abstract}
Iron is crucial for tissue functions, DNA synthesis and repair. Iron uptake is controlled by iron transport proteins like transferrin receptors (TfRs) and lipocalin 2 (LCN-2). We previously reported hepatic nuclear detection of iron storage protein subunit, FTH, along with increasing amount of nuclear iron in liver during acute phase response (APR). We now aimed to compare the expression and subcellular localization of iron transport proteins, (TfR1, TfR2 and LCN-2) in the same model of study. Rat, mice wild type (WT) and IL-6 knock-out (KO) mice were injected turpentine oil to generate APR. Total protein was used for Western blot analysis and $4 \mu \mathrm{m}$ thick sections were evaluated with immunohistochemistry. Immunohistochemistry of hepatic and extra hepatic tissues indicated organ dependent localization of TfR1 and TfR2. TfR1 was primarily localized in the membrane and cytoplasm of liver, and spleen cells whereas, in both organs, TfR2 showed nuclear expression mostly. However, in heart, both TfR1 and TfR2 were detected to be surplus in membrane, cytoplasm and nucleus. In all the organs studied, TfR1, TfR2 and LCN-2 were colocalized. Western-blot analysis showed an increased hepatic protein level of TfR1, TfR2 and LCN-2 in rat and WT mice during APR whereas such an increase was not detected for TfR2 and LCN-2 in IL6-KO mice. In parallel to induction of iron transporters, a phosphorylation of STAT3 was also observed in WT mice however such a change was not noticed in IL-6-KO mice. LCN-2 interaction with TfRs suggests its role in iron uptake during APR. Moreover, the differential localization of iron transport proteins in different organs may be due to their diverse role in these organs under physiological and pathological conditions. Furthermore, our results demonstrate that these iron import proteins (TfR2 and LCN-2) mediated mainly but not exclusively by IL-6 induced STAT3 pathway.
\end{abstract}

Key words: Interleukin 6, lipocalin-2, STAT3, transferrin receptor 1, transferrin receptor 2, 


\section{Introduction}

Iron is an important co-factor for oxygen transport, heme and nonheme iron proteins, electron transfer, neurotransmitter synthesis, myelin production energy, metabolism and mitochondrial function in the different organs (Wang et al, 2011). Iron homeostasis is controlled by a number of iron-regulatory proteins. After entering enterocytes, iron is used for essential metabolic purposes, stored in ferritin, or translocated to the portal blood by ferroportin-1 (Fpn-1). The plasma protein, transferrin ( $\mathrm{Tf}$ ) binds to diferric iron $\left(\mathrm{Fe}_{2} \mathrm{Tf}\right)$ and transfers it through portal blood to the liver where either the transferrin receptor-1 (TfR1)(Hentze et al, 2010) or Tfindependent mechanism mediates hepatic uptake of iron (Prus and Fibach, 2011) Interaction of iron bound to Tf with the TfR- 1 and internalization of the resultant complex leads to iron uptake in the cells as a result of receptor-mediated endocytosis (Frazer and Anderson, 2005). A second alternative transferrin-mediated route of iron uptake exists via TfR-2. Although the role of TfR-1 in transporting iron across the hepatocyte membrane is well defined, the role of TfR-2 is not yet fully understood. TfR-2 knock-out mice fail to reproduce as a result of embryonic lethality due to severe anemia (Levy et al, 1999). Because TfR-2 mutations result in hepatic iron overload, TfR2 appears to function, not principally in cellular iron uptake and delivery, but rather in iron storage (Roetto et al, 2010). Several other genes involved in iron homeostasis have been characterized including hepcidin (Pigeon et al, 2001), hemojuvelin [Hjv (Lanzara et al, 2004)] and lipocalin-2 [LCN-2 (Srinivasan et al, 2012)].

LCN-2 (25kDa) also known as NGAL (neutrophil gelatinase associated lipocalin) belongs to lipocalin family which is known to be involved in regulation of immune responses, modulation of cell growth and metabolism, and prostaglandin synthesis (Flower, 1996;Yang et al, 2002). Apart from its function as bacteriostatic agent and capable of sequestering iron in the form of siderophores (Flo et al, 2004), its role in apoptosis, inflammation, angiogenesis, adiposis 
has been reported (Borkham-Kamphorst et al, 2011;Devireddy et al, 2001;Zhang et al, 2008). Under physiologic conditions LCN-2 is also known to be involved in iron transportation and iron homeostasis (Bao et al, 2010;Srinivasan et al, 2012). It has also been shown that LCN-2 has a role in stabilizing the labile iron/siderophore complex (Cherayil, 2011;Correnti and Strong, 2012). LCN-2 is an upregulated host protein during the acute phase response, not only during infection but also in sterile inflammation and aseptic diseases (Sultan et al, 2012). In addition, by chelating bacterial siderophores, LCN-2 showed a consistent correlation in driving or dampening an inflammatory response, the known bioactivities of LCN-2 led one to hypothesize that it might play a role in hypoferremia of inflammation and, thereby, the resolution of severe inflammation. Furthermore, several in vitro studies have demonstrated that LCN-2 protects against cellular stress and over-expression of LCN-2 allows cells to tolerate super-physiological iron concentrations (Hu et al, 2009; Roudkenar et al, 2011). LCN-2 is known not only to chelate iron limiting iron available to pathogens but also regulates intracellular iron concentration thus loss of LCN-2 may disrupt iron transport/homeostasis (Nairz et al, 2007;Srinivasan et al, 2012). In LCN-2 knockout mice model of LPS-induced sepsis delayed hypoferremia of inflammation has been described (Srinivasan et al, 2012).

A characteristic response to tissue damage is a change in iron metabolism, beginning with an acute decline in serum iron thought to be due to the sequestration of iron in organs of the reticuloendothelial system, the liver and spleen (Cairo et al, 2011). Macrophages sequester iron to prevent its availability to pathogens and its subsequent use for tissue repair and cell regeneration. This acute reduction of serum iron level is not only observed in cases of bacterial infections, but in all conditions associated with tissue damage (Cairo et al, 2011). 
Indeed, APR produced by turpentine-oil (TO) induced muscle damage, changes in gene expression of several iron regulatory proteins in hepatic and non-hepatic organs including the brain have already been described by our group in rat model of APR (Malik et al, 2011; Sheikh et al, 2006; Sheikh et al, 2007). Moreover, a significant increase in the hepatic cytoplamic and nuclear content of iron associated with a reduction of the serum concentration was also reported in same model (Naz et al, 2012). In parallel to heaptic iron increase, an elevatation in the proteins involved in serum iron-uptake and transport with a receprocal reduction in iron export proteins (Fpn-1, and hephastin) occurs (Naz et al, 2012). However, the mechanisms governing hepatic iron metabolism under acute phase conditions is poorly understood. In addition, previously we also localized several hepatic iron import and export proteins whereas the differential localization of these hepatic iron regulatory proteins in comparison to extra-hepatic organs has not been reported before.

Therefore, the perspective of this study was to compare sub-cellular localization of iron transport proteins (TfR1, TfR2, LCN-2) in hepatic as well as extra-hepatic organs under physiological and acute-phase conditions. Further, it was also the aim of the current study to analyze the regulation and signaling pathway of these proteins during APR induced by TOinjection.

\section{Materials and Method}

\section{Animals}

Male Wistar rats of about 170-200 gram body weight were purchased from HarlanWinkelmann (Brochen, Germany). Adult male B6.129S2-Il6 ${ }^{\text {tm1Kopf }}$ (IL-6-KO) mice and control wild-type adult male C57BL/6J mice (25-28g body weight) were purchased from Jackson Laboratory. Animals were kept under standard conditions with 12h light/ dark cycles and had ad 
libitum access to fresh water and food pellets. All animals were cared according to the University’s guidelines, German regulations for the protection of animals, and NIH guidelines.

\section{Materials}

All chemicals used, were of analytical grade and purchased from commercial sources as followed: Hybond N nylon membranes were from Amersham Pharmacia Biotech (Germany), 4,6-diamidino-2-phenylindole (DAPI) from Southern Biotech (Germany), donkey serum from Abcam (Germany), Alexa fluor-488 and Alexa fluor-555 from Invitrogen (Germany). All other reagents and chemicals were from Sigma-Aldrich (Germany) or Merck (Germany).

\section{Induction of acute phase and removal of hepatic and extra-hepatic organs}

APR was induced by injecting turpentine oil (TO) at a dose of $5 \mathrm{ml} / \mathrm{kg}$ body weight of rat and $10 \mathrm{ml} / \mathrm{kg}$ body weight of mice. TO was injected into each of the right and left hind limb gluteal muscles of ether-anesthetized animals. Control animals for each time point received a saline injection. All animals were killed at different time points ranging from 1 to 36 hours (rats), 2 to 24 hours (mice) after TO administration under pentobarbital anesthesia (Tron et al, 2005). The liver, spleen and heart were taken, frozen in liquid nitrogen, and stored at $-80^{\circ} \mathrm{C}$.

\section{Preparation of tissue lysate}

About 50mg frozen tissue was homogenized with an Ultra-turrax TP 18/10, three times for 10 s each, in 10 vol 50mM TRIS-HCl buffer, $\mathrm{pH}$ 7.4, containing 150mM sodium chloride, 1mM EDTA, 1\% Triton X-100, 1mM phenylmethane sulfonyl-fluoride (PMSF), 1mM benzamidine, $1 \mathrm{mg} / \mathrm{ml}$ leupeptin, $10 \mathrm{mM}$ chymostatin, $1 \mathrm{mg} / \mathrm{ml}$ antipain, and $1 \mathrm{mg} / \mathrm{ml}$ pepstatin A. The entire procedure was carried out at $4^{\circ} \mathrm{C}$. Crude homogenates were passed five times through a 22-G needle attached to a syringe and centrifuged for $5 \mathrm{~min}$ at $10,000 \mathrm{~g}$, at $4^{\circ} \mathrm{C}$. The protein concentration was determined in supernatants by using the BCA (bicinchoninic acid) protein 
assay reagent kit (Pierce, Bonn, Germany). Aliquots of the homogenates were stored at $-20^{\circ} \mathrm{C}$ until further use for Western blot analysis.

\section{Immunohistochemistry}

Liver sections were cut in a cryostat at a thickness of $4 \mu \mathrm{m}$, air-dried, fixed with acetone $\left(-20^{\circ} \mathrm{C}, 10 \mathrm{~min}\right)$ and used for immunohistochemical studies. The antibodies and respective dilutions used are listed in table. Blocking of non-specific proteins was performed using donkey serum for 1 hour at room temperature in a humidified chamber. After 3 times 5 min washing with phosphate buffer saline (PBS) slides were incubated with primary antibodies diluted in 0.3\% Triton-X PBS overnight at $4^{\circ} \mathrm{C}$. On the next day slides were rinsed 3 times in PBS for 10 min each. To visualize antigens, slides were incubated in immunoflourescence conjugated secondary antibodies (donkey anti-rabbit/donkey anti-goat/donkey anti-mouse Alexa fluor-488 and donkey anti-rabbit/donkey anti-mouse Alexa Fluor-555) at room temperature for $1 \mathrm{~h}$, and washed 5 times for 5 min in PBS. Finally, the nuclei were stained with 4,6-diamidino-2phenylindole (DAPI) $5 \mu \mathrm{l} / 100 \mathrm{ml}$ of PBS for $5 \mathrm{~min}$, sections were washed and mounted with Fluoromount-G.

\section{Western blot analysis}

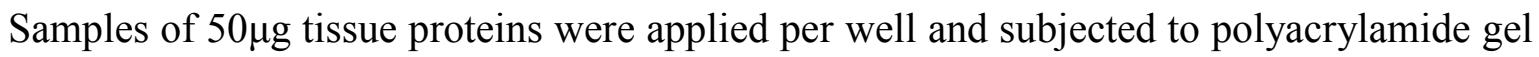
electrophoresis using NuPAGE (4\%-12\% Bis-Tris Gel; Invitrogen) under reducing conditions (Laemmli, 1970). After electrophoresis, the proteins were transferred to Hybond-ECL (enhanced chemiluminescence) nitrocellulose membranes (Towbin et al, 1979). Immunodetection was performed according to the ECL Western blotting protocol. The antibodies used are listed in table. 


\section{Results}

\section{Hepatic expression and localization of transferrin receptors (TfR1, TfR2)}

Immunohistochemical analysis of normal rat liver showed membranous and cytoplasmic expression of TfR1 in hepatic cells which increased (6h) after TO-induced APR. The intensity of expression was found to be increased in hepatocytes. In contrast, TfR2 was mainly localized in the nuclei of hepatic cells and dispersed cytoplasmic dots were also observed in normal rat liver. An increase intensity of nuclear dots (TfR2) was noticed after TO-administration as compared to normal rat liver (Fig: 1A).

\section{Localization of transferrin receptors (TfR1, TfR2) in extra-hepatic organs}

Immunodetection of TfR1 in heart tissues showed exclusively membranous and cytoplasmic expression in heart of both normal and of TO-administrated rat. However, in contrast to liver tissue some nuclei of heart cells showed TfR1 positivity. Similar pattern of immuno-expression was observed for TfR2. Both transferrin receptors showed a different expression pattern in heart tissue of normal and of TO-administrated rat compared to liver tissue. The intensity of expression of both transferrin receptors (TfR1, TfR2) increased and a strong immuno-reactivity was also present in cardiac muscle fibers after TO-administration (6h). TfR1 and TfR2 interaction was also noticed in the nuclei and membranes of heart cells (fig. 1B).

In spleen of normal and of TO-administrated rat immunohistochemical analysis of transferrin receptors showed TfR1 localized to membranes of spleen cells and TfR2 in the nuclei mostly but membranous expression was also observed for TfR2. In spleen cells of both red and white pulp area partial colocalization of TfR1 and TfR2 was also observed (fig. 1C). 


\section{Lipocalin-2 (LCN-2) interaction with transferrin receptors in hepatic tissue}

In the previous few years LCN-2 emerged as a iron transport protein, playing a vital role in iron regulation under different pathological conditions. We and others showed that LCN-2 played a pivotal role in iron transport through transferrin receptor mediated and non-transferrin bound iron (NTBI) pathway. Therefore, we performed double immunostaining of LCN-2 along with TfR1 and TfR2 in control and TO-administrated rat liver. LCN-2 showed no interaction with TfR1 under physiological conditions in hepatic tissue (fig. 2A). However, in control rat hepatic tissues, a slight interaction between LCN-2 and TfR2 was detected (fig. 2B). After TOadministration LCN-2 expression increased and a co-expression of LCN-2 protein with TfR1 in membranes and cytoplasm of hepatic cells was observed (fig. 15A). Parallel to the interaction of LCN-2 and TfR1 proteins, TfR2 was also colocalized with LCN-2 within the cytoplasm and few nuclei of hepatic cells during APR (Fig: 2C).

\section{Lipocalin-2 (LCN-2) interaction with transferrin receptors in extra-hepatic tissues}

Immunohistochemical analyses of extra-hepatic tissues showed no interaction of LCN-2 protein with TfR1 and TfR2, in hearts from control rat (fig. 3A, 3B). However after the onset of acute phase LCN-2 was expressed in heart tissue interacting with TfR1 protein in cardiomyocytes and a strong expression of LCN-2 and TfR2 was present in edothelial cells of the myocardial vessel, with partial interaction. In spleen both from control and acute-phase response rats LCN-2 colocalization with TfR1 and TfR2 was detected. The expression of LCN-2 interaction with both transferrin receptors was stronger in red pulp cells of the spleen (fig. 4A, 4B). 


\section{Changes in iron transport proteins in rat hepatic tissue during APR}

Liver of TO-injected rats demonstrated an increase in both, transferrin receptors (TfR1, TfR2) and LCN-2 with the onset of APR at protein level by Western blot analysis. TfR1 protein

was found elevated from 1-24h after TO-injection (Fig. 18). A gradual but less increase in TfR2 protein was observed with a maximum expression at 6h after APR (Fig. 5). Likewise, LCN-2 protein revealed a progressive increase in the liver which became clearly evident at $12 \mathrm{~h}$ by immunoblotting with a further increase till 36h after TO-injection (Fig. 5).

\section{Modulation of iron transport proteins in mice hepatic tissue during APR}

To validate the role of IL-6 in iron regulatory proteins expression, we generated acute phase model in wild type (WT) and IL-6 Knockout (KO) mice. Similar to what was observed in rat liver after TO-injection, Western blot analysis of WT-mice showed an increase in hepatic TfR1, TfR2 and LCN-2 protein level after TO-injection. However such an increase for TfR2 and LCN-2 was not found in IL-6-KO-mice after TO-injection. In contrast, TfR1 showed a time dependent increase at protein level in IL-6 KO mice similar to WT-mice with the onset of APR with a maximum expression at 24h (Fig. 6).

\section{Phosphorylation of STAT3 in mice hepatic tissue during ARP}

IL-6 is potent pro-inflammatory cytokine and it activates transcription protein signal transducer and activator of transcription 3 (STAT3). Phosphorylation of STAT3 in turn activates many target downstream genes. By means of Western blot using specific antibody against STAT, it was possible to detect the STAT-3 at protein level both in WT and IL-6-Ko-mice. Phosphorylation of STAT3 was only detectable in WT-mice after TO-injection. The protein expression of p-STAT3 started to increase at $2 \mathrm{~h}$ with a maximum at $4 \mathrm{~h}$ with the onset of APR. In 
contrast, such an increase was not observed in IL-6-KO mice after TO-injection apart from a slight increase at $12 \mathrm{~h}$ (fig. 6).

\section{Discussion}

In this current study we compared sub-cellular interaction between iron transport proteins (TfR1, TfR2 and LCN-2) and their expression pattern under physiological and acute phase conditions. Immunhistochemical analysis showed no interaction between transferrin receptors (TfR1, TfR2) in hepatic tissue suggesting their own independent iron transfer route in hepatic cells. However, interestingly TfR1 and TfR2 co-expression was detected in extra-hepatic tissues (heart, spleen) suggesting co-transportation of both receptors into the cell through a common route. In nuclei of some cardiomyocytes TfR1 and TfR2 positivity was observed and to some extent co-expression of TfRs can also be seen in these nuclei. In a study colocalization of TfR1 and TfR2 has been reported in HepG2 and Hep3B cell lines (Johnson et al, 2007).

Furthermore, LCN-2 colocalization with TfR1 and TfR2 was detected in liver during physiological and AP-conditions, however after ARP co-expression of LCN-2 and TfRs increased which suggests that, LCN-2 transports iron during acute phase conditions. In extrahepatic tissues (heart, spleen), LCN-2 interaction with transferrin receptors (TfR1, TfR2) was also observed in spleen of control and of TO-rat, however, in heart LCN-2 expression was detected only after AP reaction, appearance of LCN-2 protein in heart only after the generation of AP reaction can be due to stress conditions. We previously reported LCN-2 expression in heart at mRNA level in the same settings and a different study reported LCN-2 production by isolated neonatal cardiomyocytes (Yndestad et al, 2009). To the best of our knowledge the current study is first of a kind to exclusively report colocalization of TfRs in extra-hepatic tissues. Our this study also suggests that differential localization of transferrin receptors (TfR1, 
TfR2) in hepatic and extra-hepatic tissues is due to diverse role of these proteins in different tissues under physiological and pathological conditions (AP-conditions).

Although nuclear expression of iron proteins in different organs has already been reported, we and others showed TfR1 nuclear expression in rat brain (Malik et al, 2011), LCN-2 nuclear expression in mice brain (Ip et al, 2011), FTL (Ahmad et al, 2013a), Fpn1 and DMT-1 nuclear expression in rat liver (Naz et al, 2012), PC12 cells (Roth et al, 2000) and in mice glioblastoma cell lines respectively (Calzolari et al, 2010). However, colocalization and differential localization of iron importer proteins (TfRs, LCN-2) in hepatic and extra-hepatic tissues (heart and spleen) has never been reported before.

These findings support not only the presence of iron transport proteins within the nuclei to transport more iron in the hepatic cell nuclei under stress conditions but suggests that increased level of nuclear iron may be necessary for the increased activity of nuclear enzymes involved in DNA synthesis, repair and the regulation of transcription (Roth et al, 2000).

Western blot analysis and immunohistochemical findings support an intense increase of iron importer proteins (TfRs and LCN2) within liver under AP conditions studied. Under iron overload conditions, level of these proteins increase resulting in cellular iron retention (CanonneHergaux et al, 2006). However, the early upregulation of these transporter proteins could be controlled by the acute-phase cytokines (mainly IL-6) which is released at the site of injury resulting in an APR (Sheikh et al, 2007). Moreover, the upregulation of IL-6 gene expression during an APR (Malik et al, 2011;Sheikh et al, 2007) can account for the intense induction of these importer proteins expression, indicating a direct effect of the acute phase cytokine, IL-6, in regulating iron importer proteins. 
To answer this question, same APR model was established in wild type (WT) and IL-6KO mice after TO-injection. Similar to what was observed in rat APR model, a pattern of increase in TfR1, TfR2 and LCN-2 protein level was observed in the liver of WT-mice with the onset of APR, such a increase was not observed for TfR2 and LCN-2 in the liver tissue of IL-6 KO mice. Moreover, IL-6 stimulation leads to the activation and phosphorylation of STAT3 pathway. A striking finding of the current study is to detect STAT3 phosphorylation in WT-mice liver after TO-injection which was not observed in IL-6-KO mice liver, indicating a regulative function of this important acute-phase cytokine on TfR2 and LCN-2 during APR.

In contrast, an increase in TfR1 protein level, similar in both WT and IL-6 KO mice during APR suggest the effects of the other acute phase cytokines such as IL-1 $\beta$ and, to a lesser extent TNF- $\alpha$, which are produced also at the site of tissue injury to control this protein (Ramadori et al, 2010). In fact, the upregulation of IL-1 $\beta$ and TNF- $\alpha$ gene expression is more intense in the injured muscle of IL-6 KO mice than in their wild type (Ramadori et al, 2010) indicating that in the absence of IL-6 other cytokines may replace its functional role.

By summarizing our previous and current study, the upregulation of DMT-1, Tf, TfR1, TfR2 and LCN-2 at the mRNA and protein levels supports an increased iron uptake by liver cells during the APR. Although TfR1 is thought to be inversely regulated by the cellular iron stores via posttranscriptional IRE-iron regulatory protein mechanism, (Levy et al, 1999) the upregulation of TfR1 in the present study consisting of the effect of an APR might be attributable to either an activation of IRP-1(Caltagirone et al, 2001) or hypoxia-inducible factor-1 $\alpha$ (HIF-1 $\alpha$ ), both of which bind to a conserved binding site within the TfR1 promoter (Tacchini et al, 2002). It should be noted that an induction of hepatic HIF-1 $\alpha$ has been reported in the APR model utilized in the present experiments (Ramadori et al, 2010). The upregulation of iron transport molecules 
(TfR2 and LCN-2) may be due to an action of the major acute phase cytokine (IL-6) through STAT3 pathway suggested by our current study or the increased iron concentration may induce an upregulation of gene expression of iron regulaotry proteins as has also been shown previously in our in vitro study (Ahmad et al, 2013b).

In conclusion, we propose that under normal conditions, portal blood iron is taken up by liver cells mostly through a TfRs and by LCN-2 mediated iron uptake pathway. Furthermore, during APR, IL-6 induced changes in iron transporter genes (TfR2 and LCN-2) could be regulated through STAT3 pathway. 
Reference List

Ahmad S, Moriconi F, Naz N, Sultan S, Sheikh N, Ramadori G, and Malik IA (2013a). Ferritin L and Ferritin $\mathrm{H}$ are differentially located within hepatic and extra hepatic organs under physiological and acute phase conditions. Int J Clin Exp Pathol 6:622-629.

Ahmad S, Sultan S, Naz N, Ahmad G, Alwahsh SM, Cameron S, Moriconi F, Ramadori G, and Malik IA (2013b). Regulation of Iron Uptake in Primary Culture Rat Hepatocytes: The Role of Acute Phase Cytokines. Shock.

Bao G, Clifton M, Hoette TM, Mori K, Deng SX, Qiu A, Viltard M, Williams D, Paragas N, Leete T, Kulkarni R, Li X, Lee B, Kalandadze A, Ratner AJ, Pizarro JC, Schmidt-Ott KM, Landry DW, Raymond KN, Strong RK, and Barasch J (2010). Iron traffics in circulation bound to a siderocalin (Ngal)-catechol complex. Nat Chem Biol 6:602-609.

Borkham-Kamphorst E, Drews F, and Weiskirchen R (2011). Induction of lipocalin-2 expression in acute and chronic experimental liver injury moderated by pro-inflammatory cytokines interleukin-1beta through nuclear factor-kappaB activation. Liver Int 31:656-665.

Cairo G, Recalcati S, Mantovani A, and Locati M (2011). Iron trafficking and metabolism in macrophages: contribution to the polarized phenotype. Trends Immunol 32:241-247.

Caltagirone A, Weiss G, and Pantopoulos K (2001). Modulation of cellular iron metabolism by hydrogen peroxide. Effects of $\mathrm{H} 2 \mathrm{O} 2$ on the expression and function of iron-responsive element-containing mRNAs in B6 fibroblasts. J Biol Chem 276:19738-19745.

Calzolari A, Larocca LM, Deaglio S, Finisguerra V, Boe A, Raggi C, Ricci-Vitani L, Pierconti F, Malavasi F, De MR, Testa $U$, and Pallini R (2010). Transferrin receptor 2 is frequently and highly expressed in glioblastomas. Transl Oncol 3:123-134.

Canonne-Hergaux F, Donovan A, Delaby C, Wang HJ, and Gros P (2006). Comparative studies of duodenal and macrophage ferroportin proteins. Am J Physiol Gastrointest Liver Physiol 290:G156-G163.

Cherayil BJ (2011). The role of iron in the immune response to bacterial infection. Immunol Res 50:1-9.

Correnti C and Strong RK (2012). Mammalian siderophores, siderophore-binding lipocalins, and the labile iron pool. J Biol Chem 287:13524-13531.

Devireddy LR, Teodoro JG, Richard FA, and Green MR (2001). Induction of apoptosis by a secreted lipocalin that is transcriptionally regulated by IL-3 deprivation. Science 293:829-834.

Flo TH, Smith KD, Sato S, Rodriguez DJ, Holmes MA, Strong RK, Akira S, and Aderem A (2004). Lipocalin 2 mediates an innate immune response to bacterial infection by sequestrating iron. Nature 432:917-921.

Flower DR (1996). The lipocalin protein family: structure and function. Biochem J 318 ( Pt 1):1-14. 
Frazer DM and Anderson GJ (2005). Iron imports. I. Intestinal iron absorption and its regulation. Am J Physiol Gastrointest Liver Physiol 289:G631-G635.

Hentze MW, Muckenthaler MU, Galy B, and Camaschella C (2010). Two to tango: regulation of Mammalian iron metabolism. Cell 142:24-38.

Hu L, Hittelman W, Lu T, Ji P, Arlinghaus R, Shmulevich I, Hamilton SR, and Zhang W (2009). NGAL decreases E-cadherin-mediated cell-cell adhesion and increases cell motility and invasion through Rac1 in colon carcinoma cells. Lab Invest 89:531-548.

Ip JP, Nocon AL, Hofer MJ, Lim SL, Muller M, and Campbell IL (2011). Lipocalin 2 in the central nervous system host response to systemic lipopolysaccharide administration. J Neuroinflammation 8:124.

Johnson MB, Chen J, Murchison N, Green FA, and Enns CA (2007). Transferrin receptor 2: evidence for ligand-induced stabilization and redirection to a recycling pathway. Mol Biol Cell 18:743-754.

Laemmli UK (1970). Cleavage of structural proteins during the assembly of the head of bacteriophage T4. Nature 227:680-685.

Lanzara C, Roetto A, Daraio F, Rivard S, Ficarella R, Simard H, Cox TM, Cazzola M, Piperno A, GimenezRoqueplo AP, Grammatico P, Volinia S, Gasparini P, and Camaschella C (2004). Spectrum of hemojuvelin gene mutations in 1q-linked juvenile hemochromatosis. Blood 103:4317-4321.

Levy JE, Jin O, Fujiwara Y, Kuo F, and Andrews NC (1999). Transferrin receptor is necessary for development of erythrocytes and the nervous system. Nat Genet 21:396-399.

Malik IA, Naz N, Sheikh N, Khan S, Moriconi F, Blaschke M, and Ramadori G (2011). Comparison of changes in gene expression of transferrin receptor-1 and other iron-regulatory proteins in rat liver and brain during acute-phase response. Cell Tissue Res 344:299-312.

Nairz M, Theurl I, Ludwiczek S, Theurl M, Mair SM, Fritsche G, and Weiss G (2007). The co-ordinated regulation of iron homeostasis in murine macrophages limits the availability of iron for intracellular Salmonella typhimurium. Cell Microbiol 9:2126-2140.

Naz N, Malik IA, Sheikh N, Ahmad S, Khan S, Blaschke M, Schultze F, and Ramadori G (2012). Ferroportin1 is a 'nuclear'-negative acute-phase protein in rat liver: a comparison with other iron-transport proteins. Lab Invest 92:842-856.

Pigeon C, Ilyin G, Courselaud B, Leroyer P, Turlin B, Brissot P, and Loreal O (2001). A new mouse liverspecific gene, encoding a protein homologous to human antimicrobial peptide hepcidin, is overexpressed during iron overload. J Biol Chem 276:7811-7819.

Prus E and Fibach E (2011). Uptake of non-transferrin iron by erythroid cells. Anemia 2011:945289.

Ramadori P, Ahmad G, and Ramadori G (2010). Cellular and molecular mechanisms regulating the hepatic erythropoietin expression during acute-phase response: a role for IL-6. Lab Invest 90:1306-1324.

Roetto A, Di CF, Pellegrino RM, Hirsch E, Azzolino O, Bondi A, Defilippi I, Carturan S, Miniscalco B, Riondato F, Cilloni D, Silengo L, Altruda F, Camaschella C, and Saglio G (2010). Comparison of 3 Tfr2- 
deficient murine models suggests distinct functions for Tfr2-alpha and Tfr2-beta isoforms in different tissues. Blood 115:3382-3389.

Roth JA, Horbinski C, Feng L, Dolan KG, Higgins D, and Garrick MD (2000). Differential localization of divalent metal transporter 1 with and without iron response element in rat PC12 and sympathetic neuronal cells. J Neurosci 20:7595-7601.

Roudkenar MH, Halabian R, Bahmani P, Roushandeh AM, Kuwahara Y, and Fukumoto M (2011). Neutrophil gelatinase-associated lipocalin: a new antioxidant that exerts its cytoprotective effect independent on Heme Oxygenase-1. Free Radic Res 45:810-819.

Sheikh N, Batusic DS, Dudas J, Tron K, Neubauer K, Saile B, and Ramadori G (2006). Hepcidin and hemojuvelin gene expression in rat liver damage: in vivo and in vitro studies. Am J Physiol Gastrointest Liver Physiol 291:G482-G490.

Sheikh N, Dudas J, and Ramadori G (2007). Changes of gene expression of iron regulatory proteins during turpentine oil-induced acute-phase response in the rat. Lab Invest 87:713-725.

Srinivasan G, Aitken JD, Zhang B, Carvalho FA, Chassaing B, Shashidharamurthy R, Borregaard N, Jones DP, Gewirtz AT, and Vijay-Kumar M (2012). Lipocalin 2 deficiency dysregulates iron homeostasis and exacerbates endotoxin-induced sepsis. J Immunol 189:1911-1919.

Sultan S, Pascucci M, Ahmad S, Malik IA, Bianchi A, Ramadori P, Ahmad G, and Ramadori G (2012). LIPOCALIN-2 is a major acute-phase protein in a rat and mouse model of sterile abscess. Shock 37:191196.

Tacchini L, Fusar PD, Bernelli-Zazzera A, and Cairo G (2002). Transferrin receptor gene expression and transferrin-bound iron uptake are increased during postischemic rat liver reperfusion. Hepatology 36:103-111.

Towbin H, Staehelin T, and Gordon J (1979). Electrophoretic transfer of proteins from polyacrylamide gels to nitrocellulose sheets: procedure and some applications. Proc Natl Acad Sci U S A 76:4350-4354.

Tron K, Novosyadlyy R, Dudas J, Samoylenko A, Kietzmann T, and Ramadori G (2005). Upregulation of heme oxygenase-1 gene by turpentine oil-induced localized inflammation: involvement of interleukin-6. Lab Invest 85:376-387.

Wang H, Lafdil F, Kong X, and Gao B (2011). Signal transducer and activator of transcription 3 in liver diseases: a novel therapeutic target. Int J Biol Sci 7:536-550.

Yang J, Goetz D, Li JY, Wang W, Mori K, Setlik D, Du T, Erdjument-Bromage H, Tempst P, Strong R, and Barasch J (2002). An iron delivery pathway mediated by a lipocalin. Mol Cell 10:1045-1056.

Yndestad A, Landro L, Ueland T, Dahl CP, Flo TH, Vinge LE, Espevik T, Froland SS, Husberg C, Christensen G, Dickstein K, Kjekshus J, Oie E, Gullestad L, and Aukrust P (2009). Increased systemic and myocardial expression of neutrophil gelatinase-associated lipocalin in clinical and experimental heart failure. Eur Heart J 30:1229-1236. 
Zhang J, Wu Y, Zhang Y, Leroith D, Bernlohr DA, and Chen X (2008). The role of lipocalin 2 in the regulation of inflammation in adipocytes and macrophages. Mol Endocrinol 22:1416-1426. 


\section{Legends}

Figure 1: Double Immunofluorescence detection of TfR1 and TfR2 positivity in liver, heart and

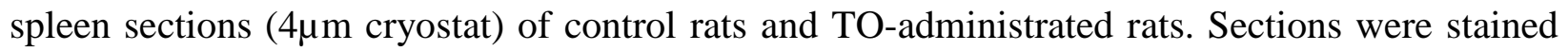
with TfR1 and TfR2 in liver (A), heart: white arrows showing cytoplasmic and blue arrows indicating nuclear co-localization (B), spleen: white arrows showing cytoplasmic co-localization and blue arrows indicating TfR2 nuclear expression (C) followed by fluorescence immunodetection using Alexa fluor-488 and Alexa fluor-555 (original magnification 200X, Bar $20 \mu \mathrm{m})$. Nuclear counterstaining was done with DAPI.

Figure 2: Double Immunofluorescence detection of TfR1, TfR2 and LCN2 positivity in liver section (4 $4 \mathrm{~m}$ cryostat) of control rats and TO-administrated rats. Sections were stained with antibodies against neutrophil gelatinase associated LCN2 and TfR1, blue arrows indicating LCN2+TfR1 cytoplasmic interation (A), LCN2 and TfR2, blue arrows indicating cytoplasmic and white arrows showing nuclear co-expression of LCN-2+TfR2 (B) followed by fluorescence immunodetection using Alexa fluor-488 and Alexa fluor-555 (original magnification 200X, Bar $20 \mu \mathrm{m})$. Nuclear counterstaining was done with DAPI

Figure 3: Double Immunofluorescence detection of TfR1, TfR2 and LCN2 positivity in heart section ( $4 \mu \mathrm{m}$ cryostat) of control rats and TO-administrated rats. Sections were stained with antibodies against neutrophil gelatinase associated LCN2 and TfR1: yellow arrows indicating TfR1 nuclear positivity, white arrows showing nuclear colocalization of LCN-2 and TfR1 (A), LCN2 and TfR2 (B) followed by fluorescence immunodetection using Alexa fluor-488 and

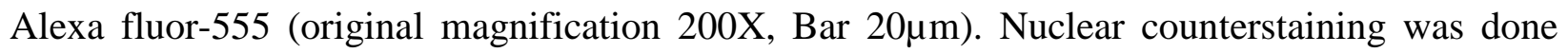
with DAPI.

Figure 4: Double Immunofluorescence detection of TfR1, TfR2 and LCN2 positivity in spleen section ( $4 \mu \mathrm{m}$ cryostat) of control rats and TO-administrated rats. Sections were stained with antibodies against neutrophil gelatinase associated LCN2 and TfR1 (A), LCN2 and TfR2 (B) followed by fluorescence immunodetection using Alexa fluor-488 and Alexa fluor-555 (original

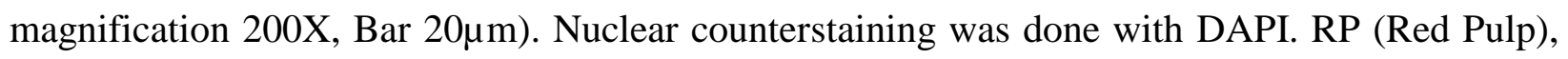
WP (White pulp) 


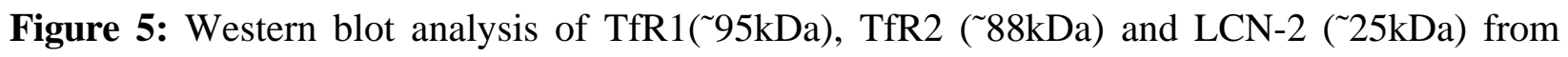
total protein of rat liver. $\beta$-actin $(43 \mathrm{kDa})$ was used as a marker for equal loading.

Figure 6: Western blot analysis of TfR1 ( 95kDa), TfR2 ( 88kDa), LCN-2 ( 25kDa), p-STAT3 $(\sim 80 \mathrm{kDa})$, and STAT3 $(\sim 80 \mathrm{kDa})$, from total protein of WT and IL-6 KO mice. Beta-actin (43kDa) was used as a marker for equal loading. 
Figure 1
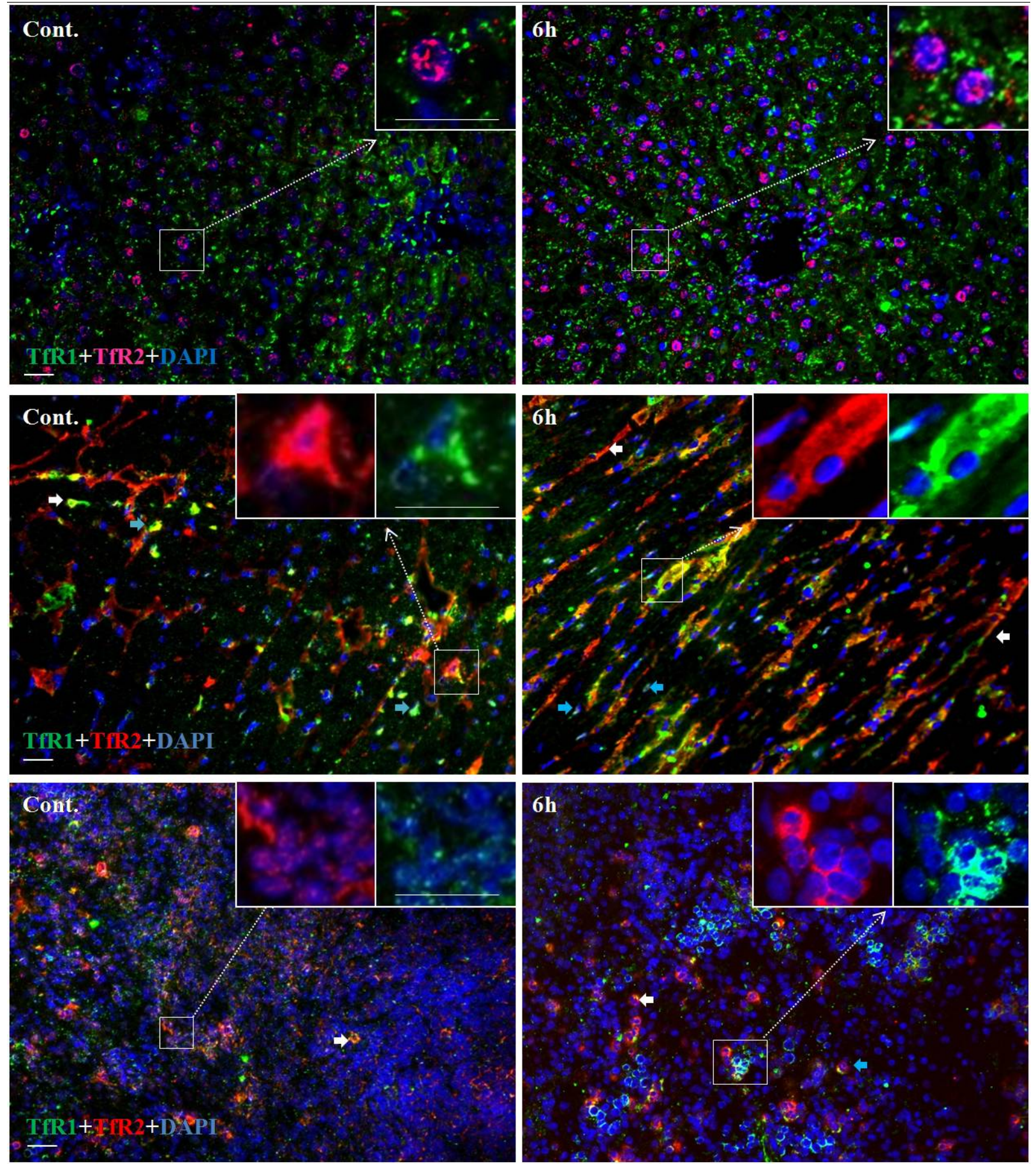
Figure 2

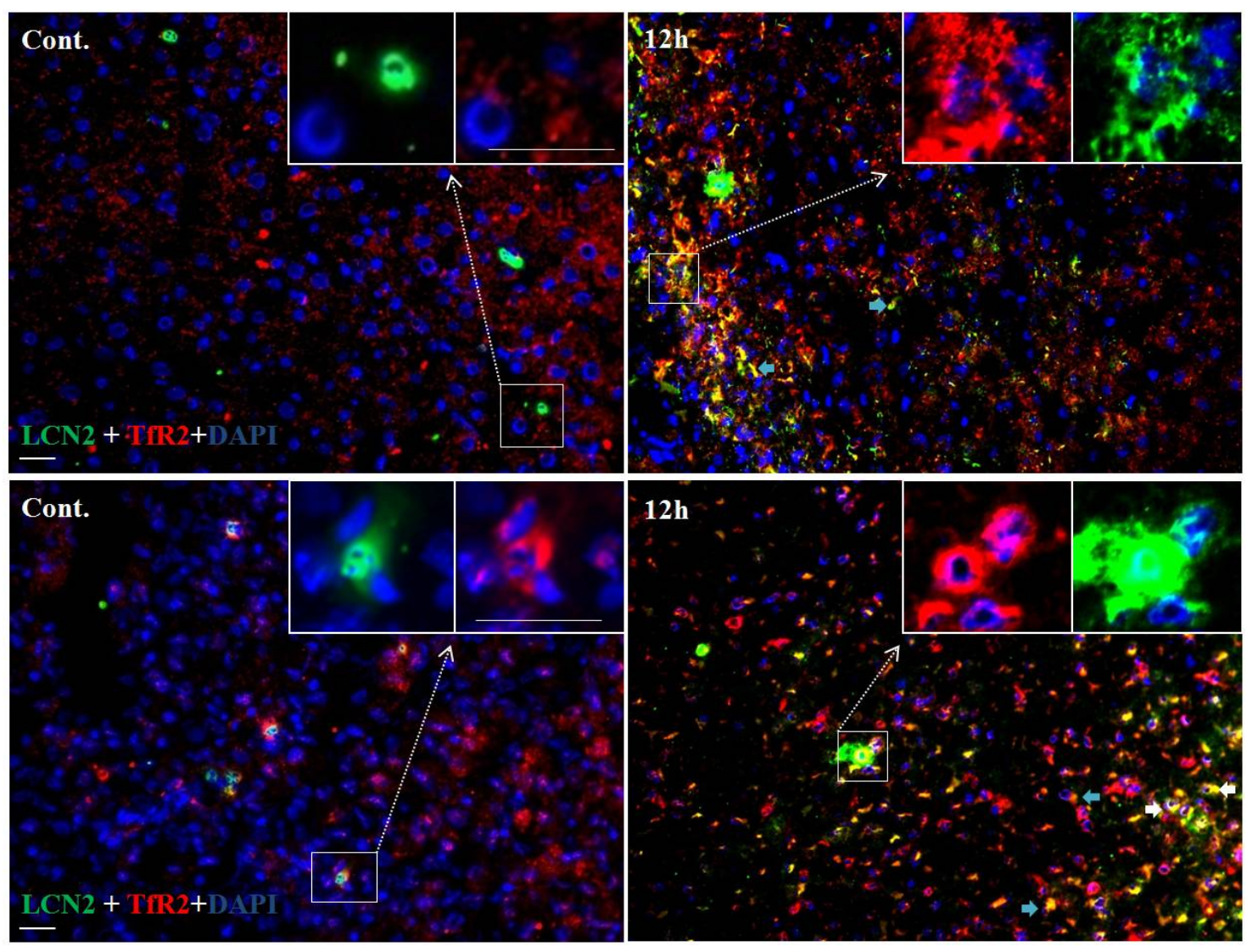


Figure 3

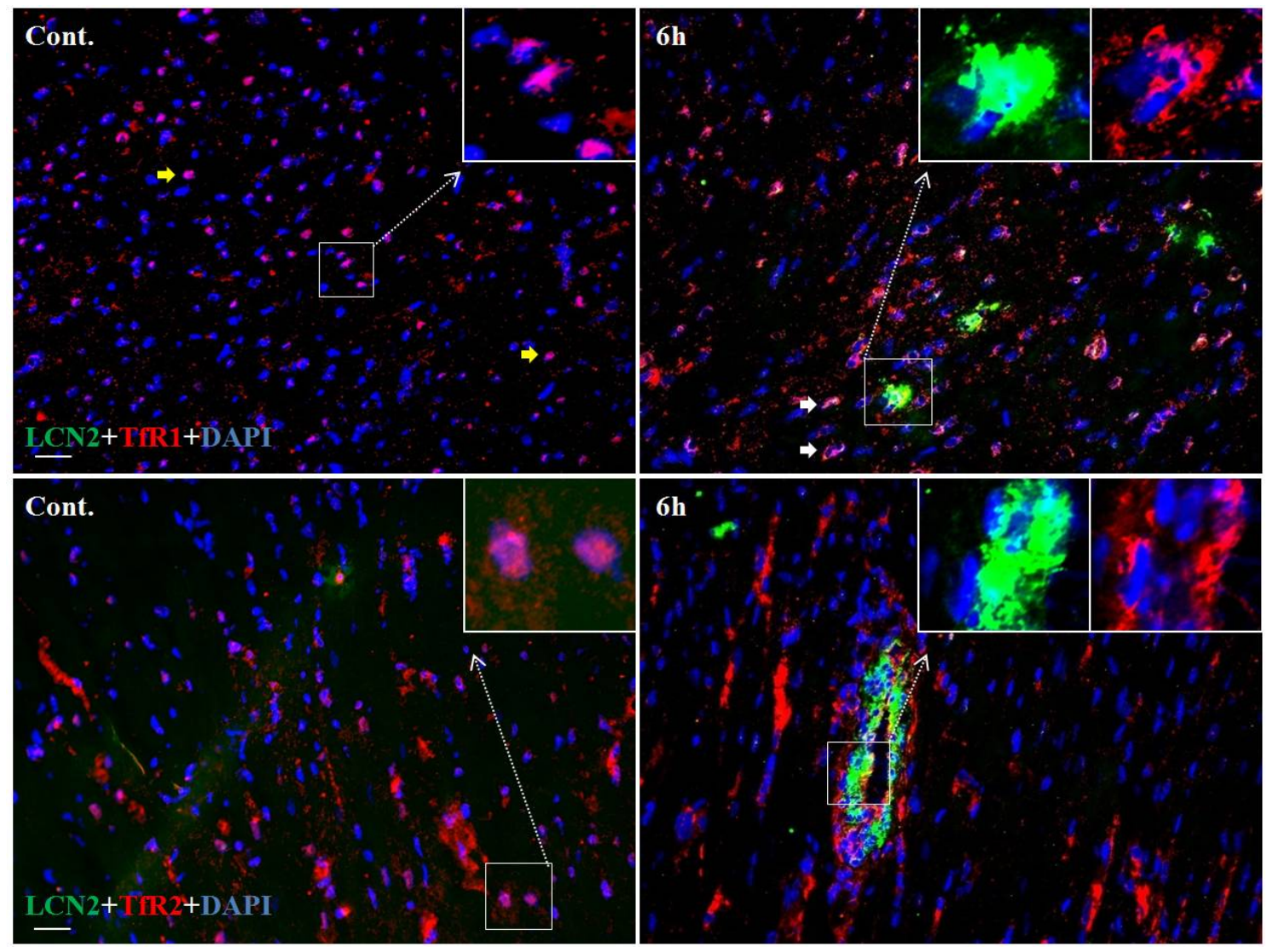


Figue 4
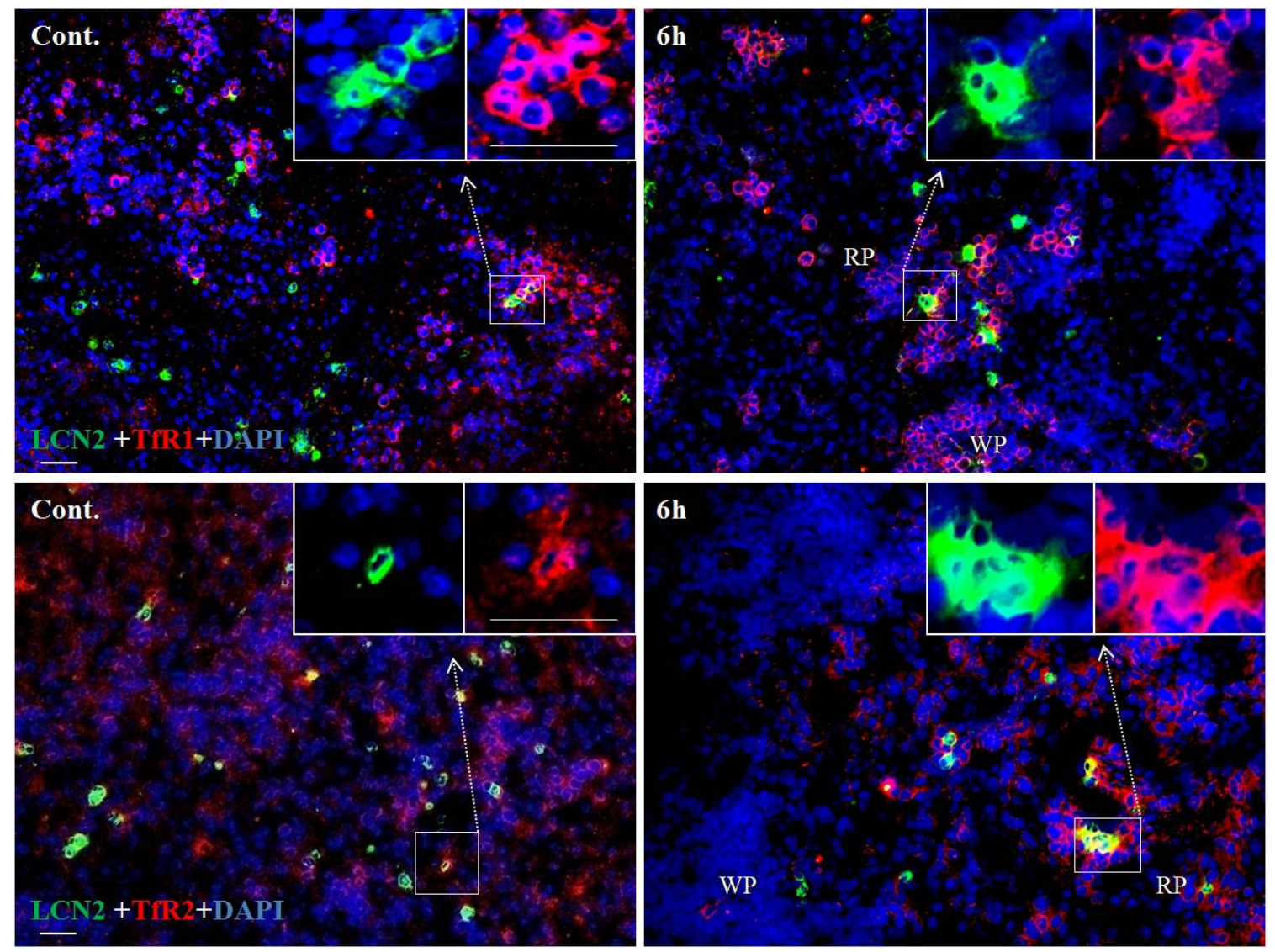
Figure 5

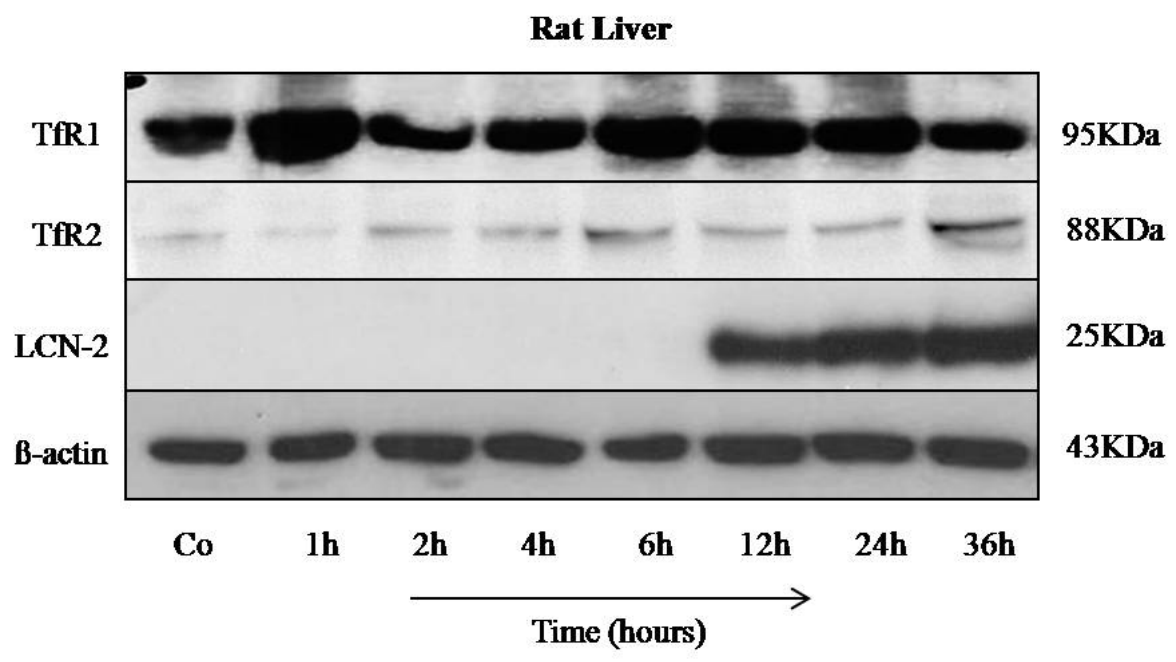

Figure 6

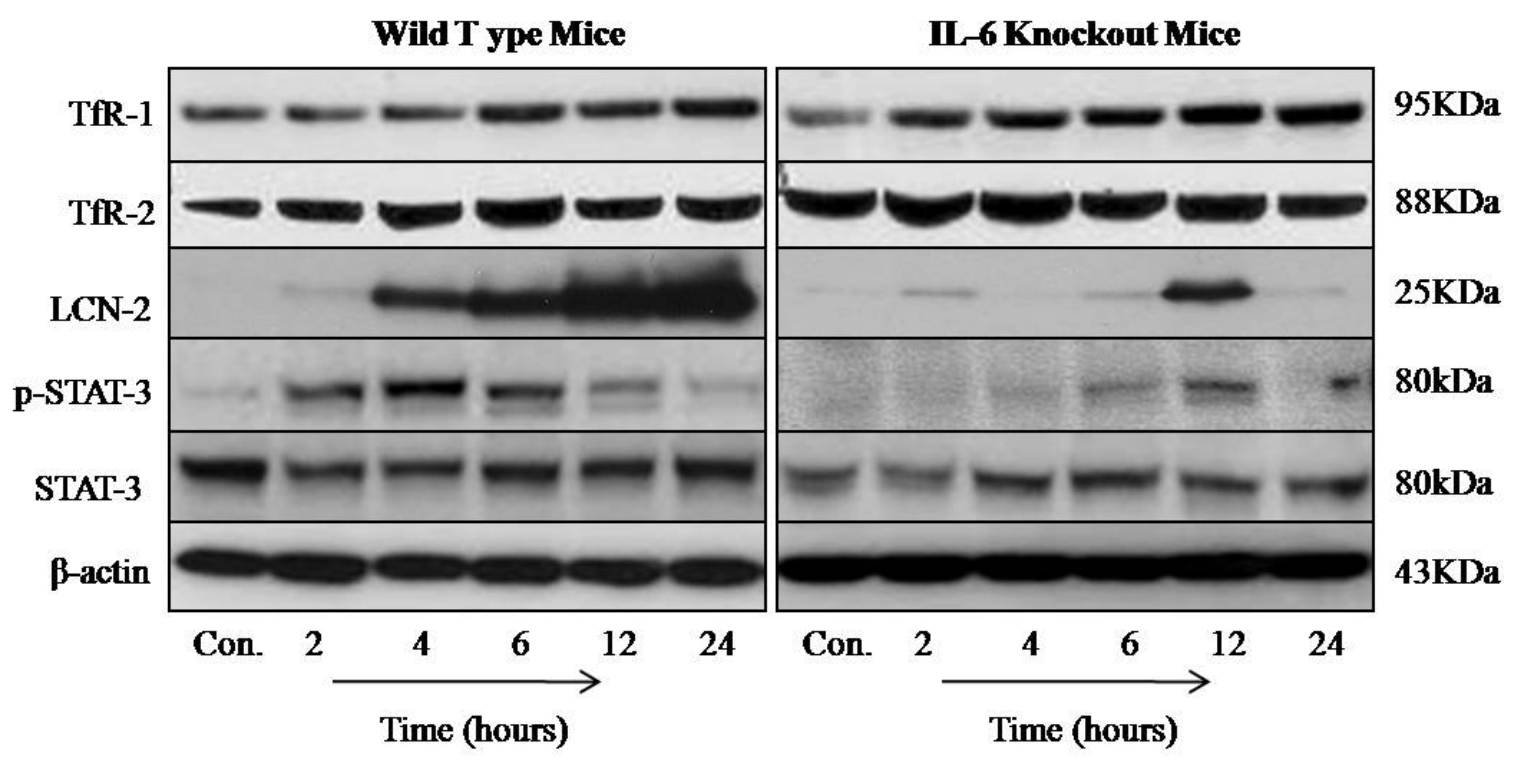


Table: Antibodies used in this study

\begin{tabular}{|c|c|c|c|c|}
\hline Antibodies & Company & $\begin{array}{c}\text { Reference } \\
\text { Number }\end{array}$ & WB & $\mathrm{IHC}$ \\
\hline $\begin{array}{l}\text { Lipocalin-2 (LCN-2) } \\
\text { Polyclonal Goat IgG }\end{array}$ & $R \& D$ & AF3508 & $1: 300$ & 1:100 \\
\hline $\begin{array}{l}\text { Lipocalin2 (LCN2) } \\
\text { Monoclonal Mouse IgG }\end{array}$ & Novus biological & NBPI-05182 & $1: 100$ & $1: 100$ \\
\hline $\begin{array}{c}\text { Transferrin Receptor1 (TfR1) } \\
\text { Monoclonal Mouse IgG }\end{array}$ & Invitrogen & $13-6890$ & 1:1000 & $1: 200$ \\
\hline $\begin{array}{c}\text { Transferrin Receptor2 (TfR2) } \\
\text { Polyclonal Rabbit IgG }\end{array}$ & Abcam & ab80194 & 1:1000 & $1: 200$ \\
\hline $\begin{array}{c}\text { STAT3 } \\
\text { Polyclonal Rabbit IgG }\end{array}$ & Cell Signaling & 9132 & $1: 1000$ & \\
\hline $\begin{array}{c}\text { Phospho-STAT3 } \\
\text { Polyclonal Rabbit IgG }\end{array}$ & Cell Signaling & 9131 & 1:1000 & \\
\hline $\begin{array}{c}\text { Beta-actin ( } \beta \text {-actin) } \\
\text { Monoclonal Mouse IgG }\end{array}$ & Sigma & A-2228 & $1: 5000$ & - \\
\hline
\end{tabular}


HEPATIC AND EXTRA HEPATIC ORGANS UNDER PHYSIOLOGICAL AND ACUTE

\title{
PHASE CONDITIONS
}

\author{
Shakil Ahmad, Federico Moriconi, Naila Naz, Sadaf Sultan, Nadeem Sheikh, \\ Giuliano Ramadori, Ihtzaz Ahmed Malik
}

Department of Internal Medicine, Division of Gastroenterology and Endocrinology, University Medical Center, Georg-August University, Robert-Koch-Str. 40, 37075 Goettingen, Germany

Authors Contribution: Shakil Ahmad designed and performed experiments (Immunostainings, Western blot), data analysis and wrote manuscript

Federico Moriconi participated in experimental model development and helped for critical improvement of manuscript

Naila Naz, Sadaf Sultan and Nadeem Sheikh paricipated in experimental animal model development

Giuliano Ramadori and Ihtzaz Ahmed Malik designed research, critical review and final improvement of the manuscript for publication

Published in International Journal of Clinical and Experimental Pathology 2013;6(4):622-629.

PMID: 23573308 


\title{
Original Article Ferritin $\mathrm{L}$ and ferritin $\mathrm{H}$ are differentially located within hepatic and extra hepatic organs under physiological and acute phase conditions
}

\author{
Shakil Ahmad*, Federico Moriconi*, Naila Naz, Sadaf Sultan, Nadeem Sheikh, Giuliano Ramadori, Ihtzaz \\ Ahmed Malik
}

Department of Internal Medicine, Division of Gastroenterology and Endocrinology, University Hospital, GeorgAugust-University, Robert-Koch-Str. 40, 37075 Göttingen, Germany. *These author contributed equally in the work.

Received January 23, 2013; Accepted February 21, 2013; Epub March 15, 2013; Published April 1, 2013

\begin{abstract}
Ferritin L (FTL) and Ferritin H (FTH) subunits are responsible for intercellular iron storage. We previously reported increasing amounts of liver cytoplasmic and nuclear iron content during acute phase response (APR). Aim of the present study is to demonstrate intracellular localization of ferritin subunits in liver compared with extra hepatic organs of rat under physiological and acute phase conditions. Rats were administered turpentine-oil (TO) intramuscularly to induce a sterile abscess (acute-phase-model) and sacrificed at different time points. Immunohistochemistry was performed utilizing horse-reddish-peroxidise conjugated secondary antibody on $4 \mu \mathrm{m}$ thick section. Liver cytoplasmic and nuclear protein were used for Western blot analysis. By means of immunohistology, FTL was detected in cytoplasm while a strong nuclear positivity for FTH was evident in the liver. Similarly, in heart, spleen and brain FTL was detected mainly in the cytoplasm while FTH demonstrated intense nuclear and a weak cytoplasmic expression. Western blot analysis of cytoplasmic and nuclear fractions from liver, heart, spleen and brain further confirmed mainly cytoplasmic expression of FTL in contrast to the nuclear and cytoplasmic expression of FTH. The data presented demonstrate the differential localization of FTL and FTH within hepatic and extra hepatic organs being FTL predominantly in the cytoplasm while FTH predominantly in nucleus.
\end{abstract}

Keywords: Ferritin, nuclear localization, liver, acute phase, iron regulation

\section{Introduction}

Liver is key organ for iron homeostasis and storage under physiological as well as acute phase conditions. Within the cell, iron is stored mainly as ferritin [1]. Ferritin is composed of $L$ and $\mathrm{H}$ subunits that are highly conserved [2] nevertheless, genetically separate [3, 4] and maintain distinct functions [5]. The storage of iron is considered to take place in the cytoplasm, however iron is required for the nuclear functions as well. $\mathrm{L}$ and $\mathrm{H}$ subunits spontaneously assemble in a 24-subunit protein "cage" with a flexible $\mathrm{H}$ : $\mathrm{L}$ ratio. The $\mathrm{H}$ : $\mathrm{L}$ ratio can vary between different cell types $[2,5]$. The $L$ gene has very little tissue-specific regulations whereas multiple conditions activate $\mathrm{H}$ ferritin gene transcription [6, 7] including cell differentiation, changes in the cell proliferation status, oncogenes, cytokines, and heme. Infact, a pre- vious study has showed an association between ferritin expression and cell proliferation [8].

Acute-phase response (APR) is a major physiological defence reaction of the body aimed to eliminate the injuring noxae and to re-establish homeostasis. Clinically, it is characterized by fever, somnolence, weakness, muscular joint pain, adinamia and increased liver activity. Moreover, decrease of serum iron level is also a hallmark of acute-phase reaction [9, 10]. This decrease is considered to be due to the sequestration of iron by the reticuloendothelial system [11].

In previous work, we demonstrated that under acute phase conditions the liver takes up serum iron $[12,13]$ and increased hepatic iron level is demonstrable in the nuclear fraction of the liver tissue as well [13]. The increased nuclear iron content was further supported by the nuclear 


\section{Differential localization of ferritin subunits during APR}
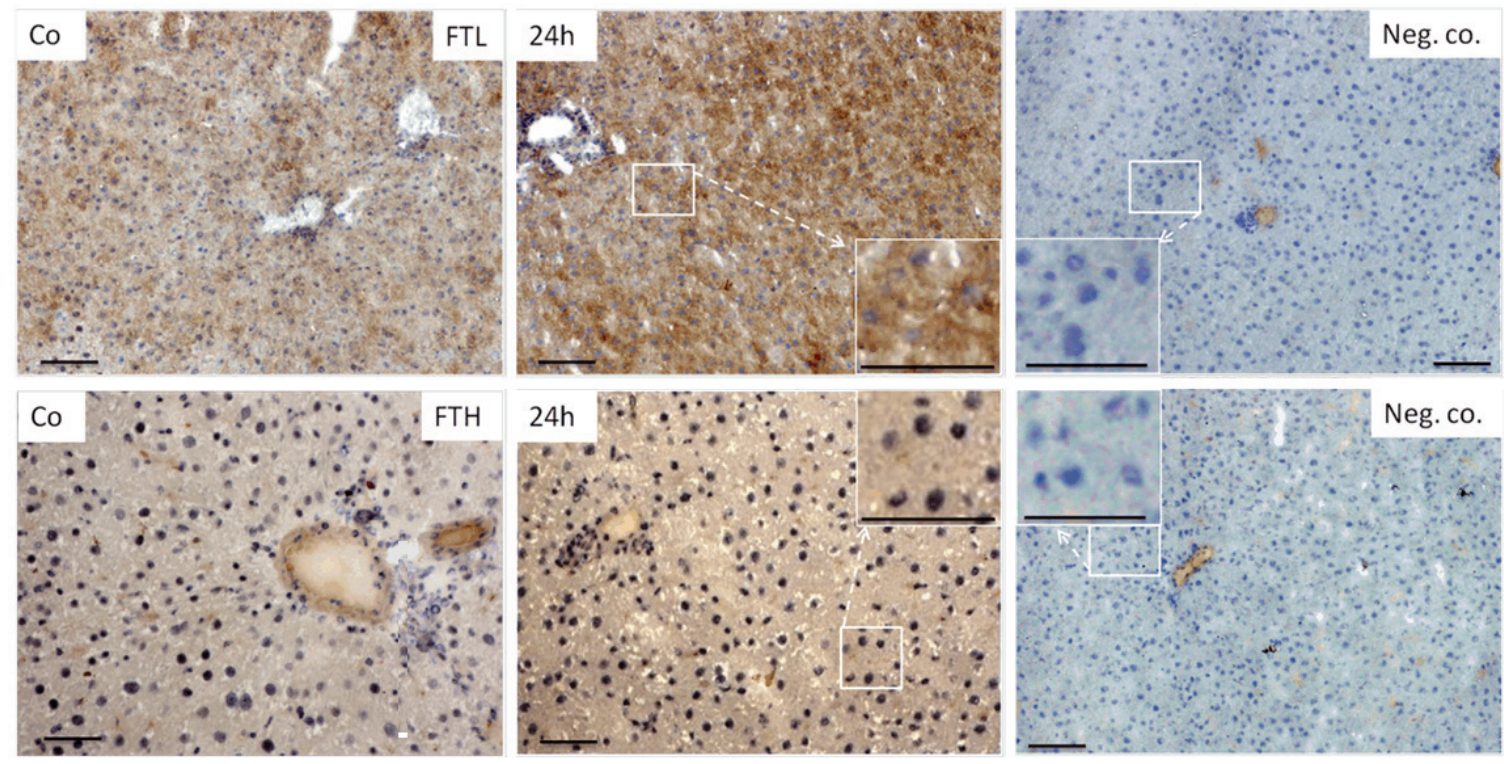

Figure 1. Immunodetection of FTL (upper panel) and FTH (lower panel) on cryostat sections of rat liver from control and TO-injected animals utilizing horse reddish peroxidase conjugated secondary antibody. Negative control represents immunostaining when primary antibody was omitted. Insets show the enlarged magnification of selected box. Original magnification 200x bar 50um.

detection of iron import proteins including TfR2 and DMT-1 along with nuclear Fpn-1; the iron export protein under physiological and acute phase conditions [13]. The aim of our prospective study was to determine the intracellular localization of major iron storage proteins; FTH and FTL in hepatic as well as extra hepatic organs.

\section{Methods}

\section{Materials}

Animals: Rats (170-200 g body weight), were purchased from HarlanWinkelmann (Brochen, Germany). The animals were kept under standard conditions with 12:12-h light dark cycles, and were given ad libitum access to water and food. All animals were cared for in accordance with the guidelines of our institution, the German Convention for the Protection of Animals, and the National Institutes of Health (USA).

\section{Induction of acute phase and harvesting the liver, heart, spleen and brain}

APR was induced and organs were removed as described previously [14]. Briefly, tissue damage was induced by injecting $5 \mathrm{ml} / \mathrm{kg}$-TO in both right and left hind limbs of animals. Control animals were treated in the same way for each time point with saline injection. Liver, heart, spleen and brain tissue was harvested, cut into pieces and snapped frozen for further used.

\section{Immunohistochemistry and immunocytology}

Four to five micrometer thick cryostat sections (Reichert Jung, Wetzlar, Germany) from rat liver, heart, spleen and brain were used for immunodetection of FTL and FTH. The slides were airdried, fixed with ice cold methanol $\left(-20^{\circ} \mathrm{C}, 10\right.$ min) and ice cold acetone $\left(-20^{\circ} \mathrm{C}, 10 \mathrm{sec}\right)$ and stored at $-20^{\circ} \mathrm{C}$. After inhibition of endogenous peroxidase by incubating the slides with phosphate-buffered saline (PBS) containing glucose/glucose oxidase/sodium azide, the sections were treated with FCS for $30 \mathrm{~min}$ to minimize nonspecific staining. Peroxidase immunostaining was performed utilizing two different commercially available antibodies for FTL (abcam; UK and Santa Cruz; USA) and FTH (LS Bio and Santa Cruz from USA). The primary antibodies were diluted FTH (1:10), FTL (1:50). Negative controls were incubated with isotypespecific IgGs, instead of the specific primary antibody. After washing, the slides were covered with peroxidase-conjugated anti-rabbit/ anti-mouse immunoglobulins pre-absorbed with normal rat serum to avoid cross-reactivity. Slides were washed and incubated with PBS containing 3,3-diaminobenzidine $(0.5 \mathrm{mg} / \mathrm{ml})$ 

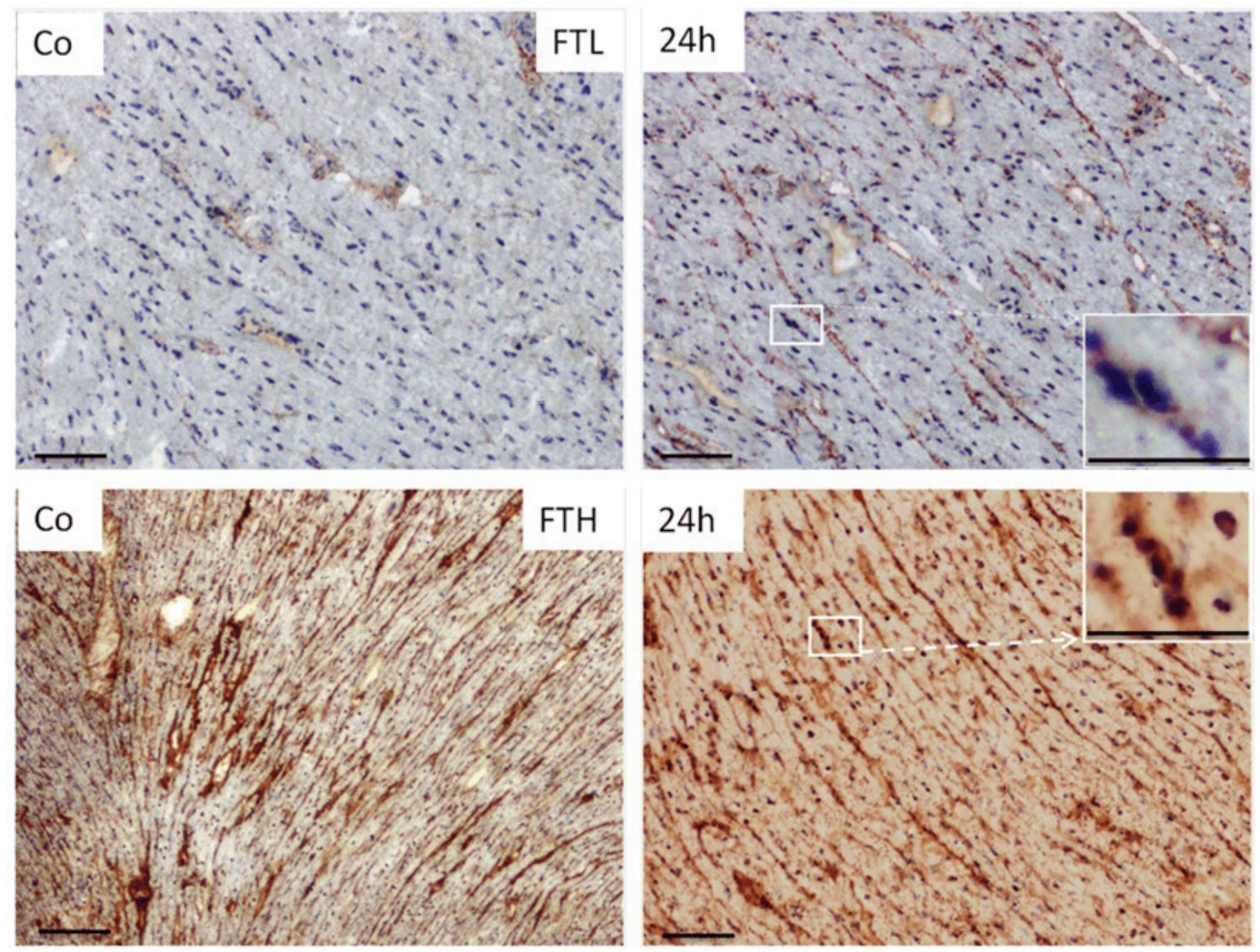

Figure 2. Immunodetection of FTL (upper panel) and FTH (lower panel) on cryostat sections of rat heart from control and TO-injected animals utilizing horse reddish peroxidase conjugated secondary antibody. Insets show the enlarged magnification of selected box. Original magnification 100x bar $25 \mu \mathrm{m}$.

and $\mathrm{H}_{2} \mathrm{O}_{2}(0.01 \%)$ for 10 min to visualize immune complexes. Nuclei were counterstained with Meyer's hemalaun solution before the slides were mounted with cover slips.

\section{Cellular fractionation for protein isolation}

Liver, heart, spleen and brain cytoplasmic and nuclear proteins were isolated using NucBuster Protein Extraction kit (Novagen USA) as described by manufacturer, with some modifications. Briefly, $100 \mathrm{mg}$ of tissue sample was homogenized in $300 \mu \mathrm{l}$ of NucBuster reagent 1 followed by collection of supernatant as cytoplasmic fraction. Pellet was washed thrice with sterile ice-cold PBS and dissolved in $50 \mu$ of NucBuster reagent $2.1 \mu \mathrm{l}$ of $100 \mathrm{mMDTT}$ and Protease Inhibitor Cocktail Set I was added to each sample to inhibit proteases activity. Samples were stored at $-20^{\circ} \mathrm{C}$ for further use.

\section{Western blot analysis}

$30 \mu \mathrm{g}$ of protein from tissue fraction was applied per well and were subjected to electrophoresis using NuPAGEÒ (4-12\% Bis-Tris Gel; Invitrogen) under reducing conditions [15]. After electrophoresis the proteins were transferred to Hybond-ECL nitrocellulose membranes [16]. Immunodetection was performed according to the ECL Western blotting protocol. The anti-Ferritin $L$ (abcam and Santa cruz) and anti-Ferritin H (LSBio, Santa cruz) were used in the study.

\section{Results}

Hepatic expression and localization of FTL and FTH

Immunohistochemical analysis of normal liver showed FTL granular positivity mainly in the 

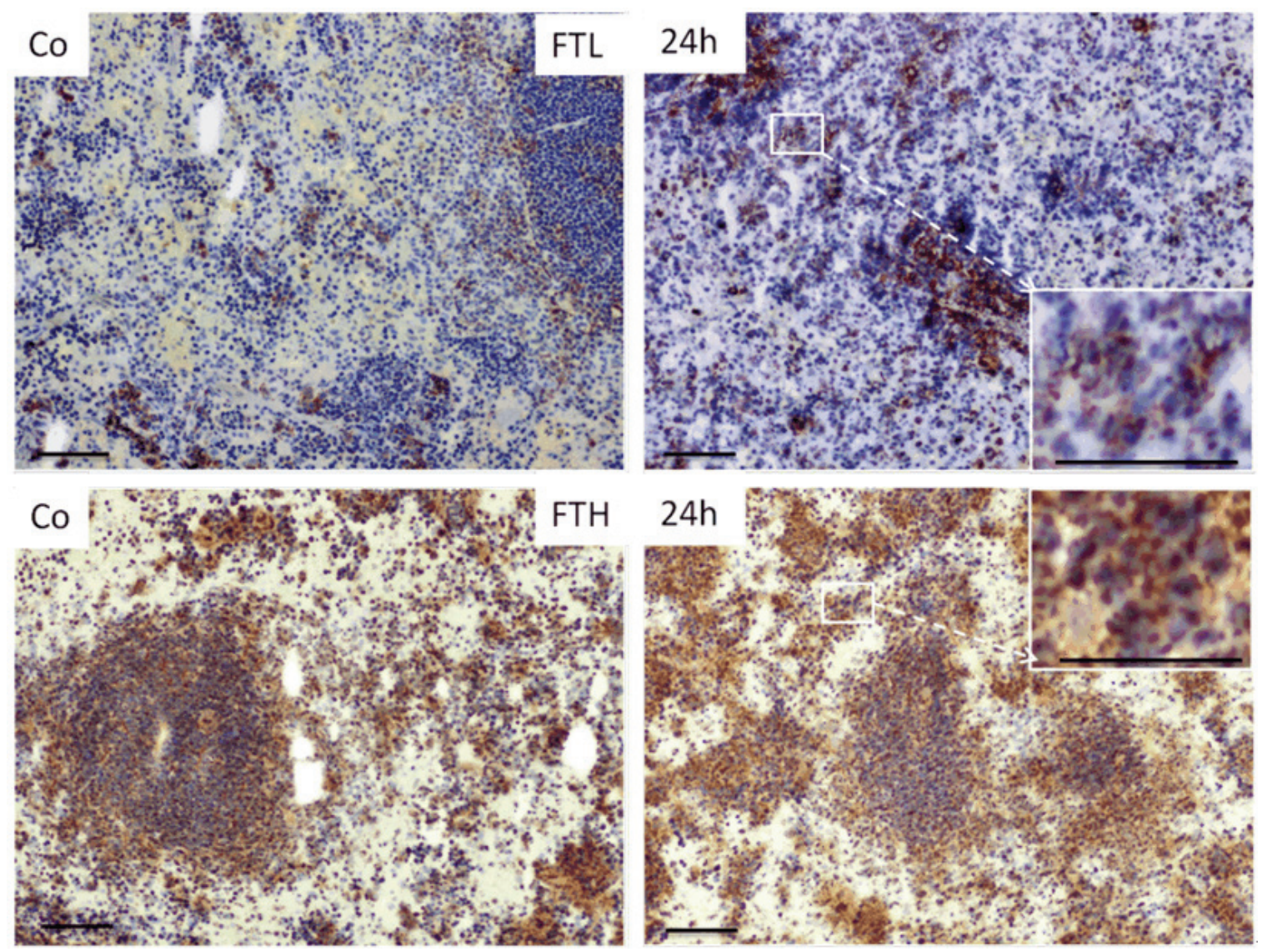

Figure 3. Immunodetection of FTL (upper panel) and FTH (lower panel) on cryostat sections of Rat spleen from control and TO-injected animals utilizing horse reddish peroxidase conjugated secondary antibody. Insets show the enlarged magnification of selected box. Original magnification $100 x$ bar $25 \mu \mathrm{m}$.

cytoplasm of hepatic cells, which kept on increasing in TO treated rats. Intensity of FTL immunoexpression was found to be stronger after TO-injection with an intense expression in hepatocytes (distinguished on visual morphology; Figure 1 enlarged insets). The number of cells positive for FTL cytoplasmic expression was highest at $24 \mathrm{~h}$ after TO-injection. The reaction was negative when the primary antibody was omitted (negative control; Figure 1; upper right panel).

In contrast to FTL immunolocalization, peroxidase staining of FTH showed intense granular positivity in the nucleus of hepatic cells of control and TO-injected rats. Compared to negative controls (primary antibody omission) where nuclei were stained clear blue, liver tissue from control and TO-injected rats showed FTH blotching (brown dots) mainly in the large nuclei of hepatocytes (Figure 1; lower panel).

\section{Localization of FTL and FTH in extra-hepatic organs}

In control heart tissue, the immunodetection of FTL indicated a very weak expression as compared to liver tissue. However, it was localized exclusively within the cytoplasm. The protein expression of FTL showed more intense granular expression in TO-injected animals at $24 \mathrm{~h}$ Figure 2; upper panel). In contrast to FTL expression within the heart tissue, FTH immunodetection was more intense and was spread all over the tissue structure including the cytoplasm and the nuclei of tissue (Figure 2; lower panel).

In control spleen tissue, FTL was detected within the cytoplasm of red pulp and white pulp cell population. This expression was more copious in spleen tissue of TO-injected rats (Figure 3; upper panel). However, within the spleen tissue, FTH protein showed a dual localization. We 

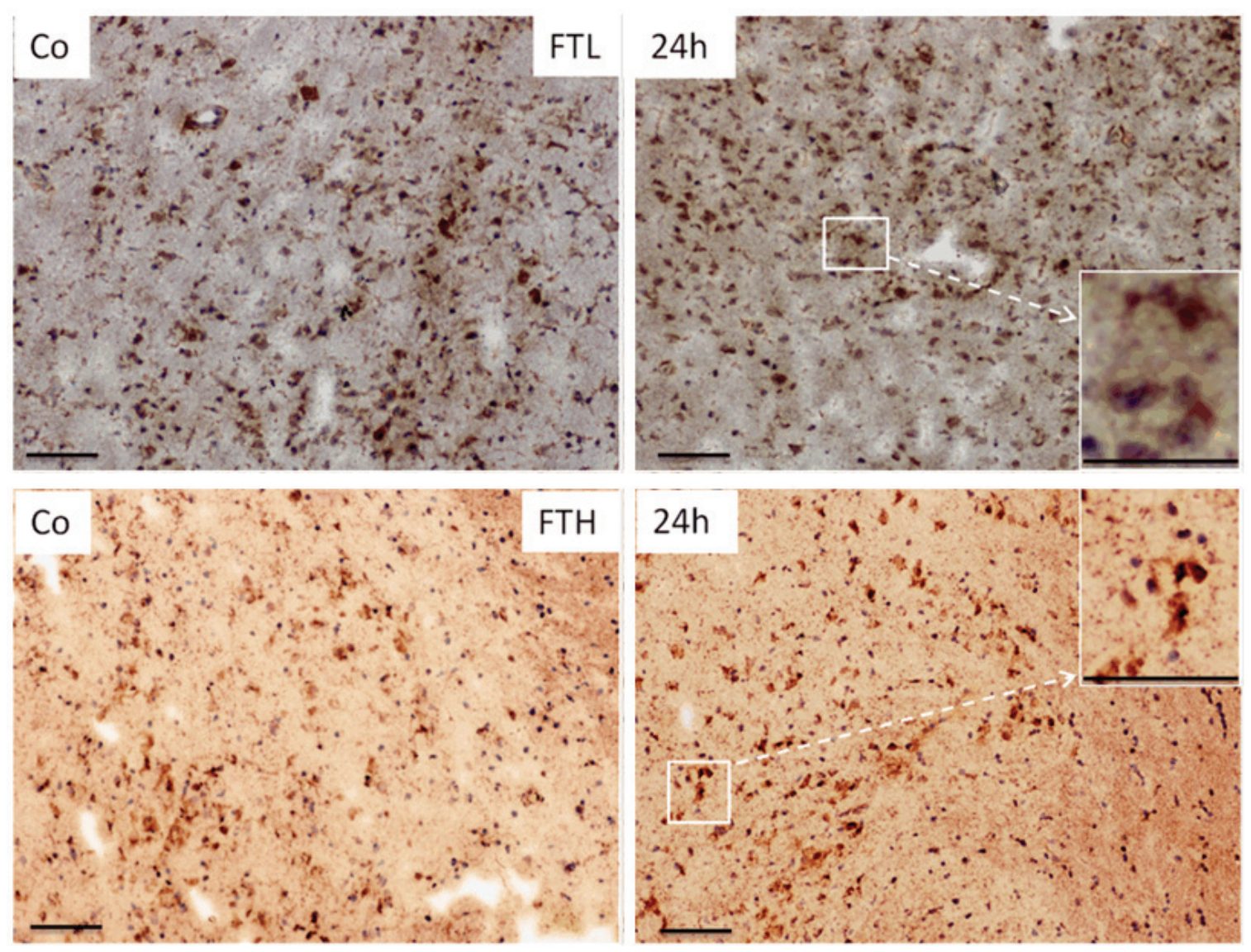

Figure 4. Immunodetection of FTL (upper panel) and FTH (lower panel) on cryostat sections of Rat brain from control and TO-injected animals utilizing horse reddish peroxidase conjugated secondary antibody. Insets show the enlarged magnification of selected box. Original magnification 100x bar $25 \mu \mathrm{m}$.
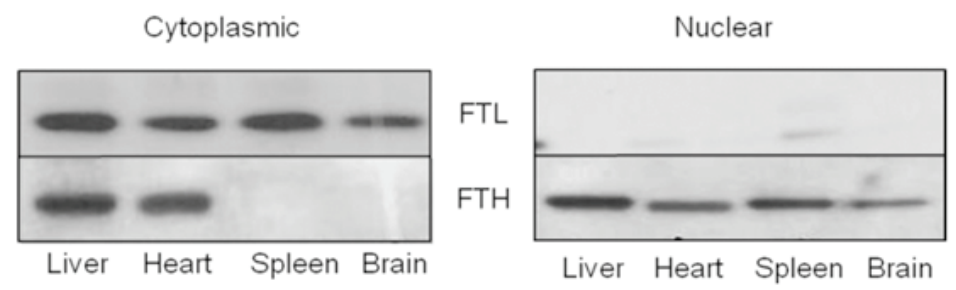

and weakly in the cytoplasm (Figure 4; lower panel).

Western blot analysis of hepatic and extra hepatic protein fractions for FTL and FTH

Figure 5. Western blot analysis of FTL and FTH in protein extracted from nuclear and cytoplasmic fractions of different organs of control animals.

The immunohistochemical data was further confirmed by means of Western blot analysis of cytoplasmic and nuclear fractions proteins

could detect a strong nuclear and comparatively weak cytoplasmic expression of FTH within spleen tissue of control and TO-injected rats (Figure 3; lower panel).

However, within the brain tissue of both control and TO-injected rats, FTL was plentiful in the cytoplasm and a slight nuclear expression was also detected (Figure 4; upper panel). However, in both control and TO-injected animals, FTH was localized strongly within the brain nuclei from hepatic and extra hepatic organs of control animals. Western blot analysis demonstrated mainly cytoplasmic expression of FTL in liver, heart, spleen and brain. FTL was found to be more abundant in liver followed by spleen and then heart and brain. While, only a very slight FTL nuclear expression was found in spleen. FTH was detected mainly in the nuclear fraction of liver, heart, spleen and brain. However, it was also detectable in the liver and heart cytoplasmic fraction (Figure 5). 


\section{Differential localization of ferritin subunits during APR}

\section{Discussion}

To our best knowledge, this is the first attempt to determine the predominantly nuclear localization of FTH in contrast to cytoplasmic expression of FTL under physiological and acute phase conditions. Immunodetection protocols and Western blot analysis showed a strong cytoplasmic and very weak nuclear expression of FTL as compared to the strong nuclear and weak cytoplasmic localization of FTH in hepatic and extra hepatic organs of rat including heart, spleen and brain. Moreover, protein expression was found to be elevated for both FTL and FTH by Immunohistology with the onset of APR.

Ferritin has been investigated as a cytosolic iron storage protein [17]. Its localization within the cell however, is controversially debated. So far, nuclear localization of FTH is reported invitro in human astrocytoma cell line [18], in corneal epithelial cells [19] and in-vitro in mice hepatocytes under iron overload conditions [20]. Indeed, we showed constitutive nuclear FTH detection not only in the hepatic but also in extra-hepatic organs of rat under physiological and acute phase conditions. As increasing amounts of iron seem to be temporarily needed in the nucleus during the APR, therefore, it is not surprising to detect iron storage proteins not only in cytoplasm, but also in the nucleus of the cells.

Nuclear FTH of our current study suggests iron sequestration not only in cytoplasm but also in nucleus of liver cells indicating an important role of iron for nuclear metabolism. It could also suggest that iron may be necessary for the activity of nuclear enzymes for DNA synthesis and repair and/or to regulate the initiation of transcript [21]. Another possibility could be that under acute-phase conditions, extra iron may be needed to satisfy the increased metabolic work of the liver [10].

We previously reported elevated liver iron stores in the same model [13]. Likewise, our previous and current study showed an increased $\mathrm{mRNA}$ and protein expression of FTL and FTH in the liver, in parallel to the increased hepatic uptake of iron during APR [13]. Most of the initial observations reported that the amount of intracellular ferritin could be modified by changes in iron status [17] and accumulation of $\mathrm{H}$-chain $[22,23]$. However, our previ- ous study also showed that gene expression of FTL, FTH and of other iron regulatory genes is modulated also by acute phase cytokines [13, 24]. In other words, the increase in hepatic FTL and FTH expression is not only due to the increase in hepatic iron concentration but it is also due to the direct effect of acute-phase cytokines produced during TO-induced APR.

A previous study [25] reported that FTH is the main iron storage protein in the liver. Depletion of FTH in hepatocytes makes these cells more susceptible to the toxic effect of iron [25]. Moreover, it has been shown that in non-hepatic cell lines (K562 cells) the over-expression of FTH resulted in reduced free iron pool [26]. This may indicate that not only ferritin $L$ but also ferritin $\mathrm{H}$ subunit could be required to reduce free available iron level in the "stressed" hepatocytes during APR.

FTL shares "the iron storage" function in liver tissue and extra hepatic organs (heart, spleen and brain), however the secretory function of liver makes it unique to extra hepatic organs. We reported FTL as a secretory protein (manuscript submitted) so liver should have more FTL as compared to extra hepatic organs.

An earlier study reported evidence of stainable iron within the nuclei of hepatocytes and Kupffer cells in mouse liver under conditions of iron overload [27]. Our current finding supports not only the presence of iron storage protein within the nuclei of liver cells under non-physiological conditions but suggests that nuclear iron is important in the initiation of defense mechanism.

In summary, FTH is localized not only in the cytoplasm but also in the nucleus of liver, heart, spleen and brain cells. This suggests that iron is not only stored in the nucleus but also that nuclei need to be defended from possible dangerous effects of iron overload on DNA as has been hypothesized previously [25]. This might become more important when the metabolic challenges increase during APR.

Address correspondence to: Dr. Ihtzaz Ahmed Malik, Department of Internal Medicine, University Hospital Göttingen, Robert-Koch-Str. 40, 37075 Göttingen, Germany. Phone: 0049 (551) 398902; Fax: 0049 (551) 396921; E-mail: i.malik@med.uni-goettingen. de 


\section{Differential localization of ferritin subunits during APR}

\section{References}

[1] Ganz T, Nemeth E. Iron metabolism: interactions with normal and disordered erythropoiesis. Cold Spring Harb Perspect Med 2012; 2: a011668.

[2] Arosio P, Ingrassia R, Cavadini P. Ferritins: a family of molecules for iron storage, antioxidation and more. Biochim Biophys Acta 2009; 1790: 589-99.

[3] Caskey JH, Jones C, Miller YE, Seligman PA. Human ferritin gene is assigned to chromosome 19. Proc Natl Acad Sci U S A 1983; 80: 482-6.

[4] Worwood M, Brook JD, Cragg SJ, Hellkuhl B, Jones BM, Perera P, Roberts SH, Shaw DJ. Assignment of human ferritin genes to chromosomes 11 and 19q13.3---19qter. Hum Genet 1985; 69: 371-4.

[5] Sammarco MC, Ditch S, Banerjee A, Grabczyk E. Ferritin $\mathrm{L}$ and $\mathrm{H}$ subunits are differentially regulated on a post-transcriptional level. J Biol Chem 2008; 283: 4578-87.

[6] Briat JF, Ravet K, Arnaud N, Duc C, Boucherez J, Touraine B, Cellier F, Gaymard F. New insights into ferritin synthesis and function highlight a link between iron homeostasis and oxidative stress in plants. Ann Bot 2010; 105: 811-22.

[7] Ponka P, Beaumont C, Richardson DR. Function and regulation of transferrin and ferritin. Semin Hematol 1998; 35: 35-54.

[8] Cozzi A, Corsi B, Levi S, Santambrogio P, Biasiotto G, Arosio P. Analysis of the biologic functions of $\mathrm{H}$ - and L-ferritins in HeLa cells by transfection with siRNAs and cDNAs: evidence for a proliferative role of L-ferritin. Blood 2004; 103: 2377-83.

[9] Quinton $\sqcup$, Blahna MT, Jones MR, Allen E, Ferrari JD, Hilliard KL, Zhang X, Sabharwal V, Algül H, Akira S, Schmid RM, Pelton SI, Spira A, Mizgerd JP. Hepatocyte-specific mutation of both NF-kappaB RelA and STAT3 abrogates the acute phase response in mice. J Clin Invest 2012; 122: 1758-63.

[10] Ramadori G, Christ B. Cytokines and the hepatic acute-phase response. Semin Liver Dis 1999; 19: 141-55.

[11] Cairo G, Recalcati S, Mantovani A, Locati M. Iron trafficking and metabolism in macrophages: contribution to the polarized phenotype. Trends Immunol 2011; 32: 241-7.

[12] Malik IA, Naz N, Sheikh N, Khan S, Moriconi F, Blaschke M, Ramadori G. Comparison of changes in gene expression of transferrin receptor-1 and other iron-regulatory proteins in rat liver and brain during acute-phase response. Cell Tissue Res 2011; 344: 299-312.

[13] Naz N, Malik IA, Sheikh N, Ahmad S, Khan S, Blaschke M, Schultze F, Ramadori G. Ferropor- tin-1 is a 'nuclear'-negative acute-phase protein in rat liver: a comparison with other irontransport proteins. Lab Invest 2012; 92: 842-56.

[14] Ramadori P, Ahmad G, Ramadori G. Cellular and molecular mechanisms regulating the hepatic erythropoietin expression during acutephase response: a role for IL-6. Lab Invest 2010; 90: 1306-24.

[15] Laemmli UK. Cleavage of structural proteins during the assembly of the head of bacteriophage T4. Nature 1970; 227: 680-5.

[16] Towbin H, Staehelin T, Gordon J. Electrophoretic transfer of proteins from polyacrylamide gels to nitrocellulose sheets: procedure and some applications. Proc Natl Acad Sci U S A 1979; 76: 4350-4.

[17] Meyron-Holtz EG, Moshe-Belizowski S, Cohen LA. A possible role for secreted ferritin in tissue iron distribution. J Neural Transm 2011; 118: 337-47.

[18] Surguladze N, Patton S, Cozzi A, Fried MG, Connor JR. Characterization of nuclear ferritin and mechanism of translocation. Biochem J 2005; 388: 731-40.

[19] Cai CX, Linsenmayer TF. Nuclear translocation of ferritin in corneal epithelial cells. J Cell Sci 2001; 114: 2327-34.

[20] Smith AG, Carthew P, Francis JE, Edwards RE, Dinsdale D. Characterization and accumulation of ferritin in hepatocyte nuclei of mice with iron overload. Hepatology 1990; 12: 1399405.

[21] Thompson KJ, Fried MG, Ye Z, Boyer P, Connor JR. Regulation, mechanisms and proposed function of ferritin translocation to cell nuclei. J Cell Sci 2002; 115: 2165-77.

[22] Hentze MW, Caughman SW, Rouault TA, Barriocanal JG, Dancis A, Harford JB, Klausner RD. Identification of the iron-responsive element for the translational regulation of human ferritin mRNA. Science 1987; 238: 1570-3.

[23] Goralska M, Holley BL, McGahan MC. Overexpression of $\mathrm{H}$ - and L-Ferritin Subunits in Lens Epithelial Cells: Fe Metabolism and Cellular Response to UVB Irradiation. Invest Ophthalmol Vis Sci 2001; 42: 1721-7.

[24] Sheikh N, Batusic DS, Dudas J, Tron K, Neubauer K, Saile B, Ramadori G. Hepcidin and hemojuvelin gene expression in rat liver damage: in vivo and in vitro studies. Am J Physiol Gastrointest Liver Physiol 2006; 291: G482G490.

[25] Darshan D, Vanoaica L, Richman L, Beermann $\mathrm{F}$, Kuhn LC. Conditional deletion of ferritin $\mathrm{H}$ in mice induces loss of iron storage and liver damage. Hepatology 2009; 50: 852-60.

[26] Picard V, Epsztejn S, Santambrogio P, Cabantchik Zl, Beaumont C. Role of ferritin in the 


\section{Differential localization of ferritin subunits during APR}

control of the labile iron pool in murine erythroleukemia cells. J Biol Chem 1998; 273: 153826.

[27] Magens B, Dullmann J, Schumann K, Wulfhekel U, Nielsen P. Nuclear iron deposits in hepa- tocytes of iron-loaded HFE-knock-out mice: a morphometric and immunocytochemical analysis. Acta Histochem 2005; 107: 57-65. 


\section{DISCUSSION}

This study reports the iron uptake in hepatocytes and changes in gene expression of iron transport (TfR1, TfR2 and LCN-2) and iron storage proteins (FTH, FTL) under the influence of acute phase cytokines. Moreover, it identifies induction of TfR2 and LCN-2 by IL-6 through STAT3 pathway. Furthermore, sub-cellular localization of these proteins in liver in comparison to spleen and heart in acute phase response rat model is described.

\subsection{Iron uptake and regulation of iron transport and iron storage proteins in primary culture of rat hepatocytes: Role of IL-6}

A significant iron uptake was detected in hepatocytes after administration of iron in culture medium. This iron uptake further enhanced when AP-cytokines (mainly IL-6) and iron were ad-

ministrated concomitantly. There was a parallel increase in iron uptake and gene expression of different iron regulatory proteins i.e. iron import proteins (TfR1, TfR2 LCN-2) and iron storage proteins (FTL, FTH). This up-regulation was further induced when AP-cytokines, mainly IL-6, were administrated together with iron. In contrast to TfR2, the amount of TfR 1 was decreased by the addition of IL-6 or iron alone into the culture medium. However, surprisingly this reduction was abrogated when IL-6 was used concomitantly with iron.

Indeed, binding of transferrin to iron keeps iron in a soluble form and acts as major transporter of plasma iron into cells via TfRs. Diferric Tf has a high affinity for the TfRs and this Tf uptake by cells has important implications during physiological conditions (Conner and Schmid, 2003; Frazer and Anderson, 2005;Herbison et al, 2009). Although, it is supposed that TfR1 is inversely regulated by intracellular iron concentration through the posttranscriptional IRE-IRP (iron 
responsive element-iron regulatory protein) mechanism (Levy et al, 1999) but in my study an increase in the TfR 1 protein expression was detected in hepatocytes after concomitant administration of AP-cytokines and iron. This TfR1 up-regulation could be due to activation of IRP-1 or hypoxiainducible factor $1 \alpha$ (HIF-1 $\alpha$ ) (Caltagirone et al, 2001; Malik et al. 2011) which binds to a conserved binding region in TfR1 promoter site (Tacchini et al, 1999) as induction of hepatic HIF-1 $\alpha$ was also reported by us in our model. However TfR2 is known to be positively regulated by cellular iron concentration (Calzolari et al, 2007) which is in accordance with our study.

Furthermore, the existence of non-transferrin-bound iron (NTBI) uptake is now well established (Breuer et al, 2000a). Recent studies have shown that LCN-2 is responsible for transport of iron through this pathway (Kaplan, 2002;Schmidt-Ott et al, 2007). A recent report clearly demonstrated the participation of LCN-2 in iron transportation during kidney damage (Yang et al, 2002). Likewise, a disrupted iron-uptake has been described in LCN-2 knockout mice (Srinivasan et al, 2012).

In fact, this transferrin independent pathway becomes active in iron overload conditions (Chua et al, 2004), because in such conditions plasma iron concentration exceeds the transferrin binding limit. NTBI uptake is known to cause significant iron accumulation in the liver (Breuer et al, 2000a). NTBI uptake mechanisms have been studied in different types of cell lines, (Prus and Fibach, 2011) including hepatocytes also (Chua et al, 2004). Based on experimental observations of current study, it can be proposed that iron transport into hepatocytes can take place by both pathways, the transferrin dependent and the transferrin independent and the latter can be regulated by LCN-2 under the influence of IL-6.

IL-6 is the key regulator of iron metabolism under different inflammatory conditions resulting in iron accumulation. IL-6 causes hypoferremia of inflammation by hepcidin regulatory 
pathway but in a recent study hepcidin independent pathway has been described clearly (Deschemin and Vaulont, 2013). In a mouse of LPS-induced sepsis, LCN-2 played a pivotal role in causing hypoferremia of inflammation (Srinivasan et al, 2012). From experimental data of current study it is speculated that increased uptake of iron in IL-6 stimulated hepatocytes could be another mechanism of hypoferremia of inflammation. Few previous studies clearly reported that amount of intracellular ferritin was regulated by change in iron status (Meyron-Holtz et al, 2011). These observations clearly indicate that not only FTL but also FTH is needed for reduction of free available iron in the stressed hepatocytes during APR. FTL shares "the iron storage" function in hepatic and extra-hepatic tissues (heart, spleen and brain) however, liver is a unique organ due to its secretory function when compared to extra hepatic organs.

Even though human plasma ferritin levels are used to estimate body iron stores (Goralska et al, 2001), this seems not always applicable in humans and animals (Kanra et al, 2006). An increase of iron level is associated with increased serum levels of AP-cytokines such as IL-6, IL-1 $\beta$ and TNF- $\alpha$ (Sheikh et al, 2006). Indeed, we and several previous acute phase studies reported that the liver responded dramatically to elevated levels of IL-6 by releasing acute phase proteins (Naz et al, 2012) which up-regulate gene expression of most of iron regulatory proteins in the liver (and isolated hepatocytes). This indicates a strong correlation of these major AP-cytokines with hepatic expression of iron regulatory proteins. A similar effect can be true in case of LCN-2 in the current study, as the data showed that iron and IL-6 seemed to be the main factors responsible for the dramatically induced LCN-2 gene expression in hepatocytes as has been previously reported (Sultan et al, 2012). Furthermore, a reduced LCN-2 expression was reported in the liver of IL-6 knockout mice during APR (Sultan et al, 2012). 
In fact, most of the serum proteins are synthesized by hepatocytes which play a pivotal role in regulation of in iron metabolism (Arosio et al, 2009; Tran et al, 1997). This study showed that $\mathrm{LCN}-2$ is a secretory hepatocellular protein. A release of $\mathrm{LCN}-2$ into the supernatants of isolated hepatocytes was detected not only by AP-cytokines (mainly IL-6) but also by iron and this release was comparable to that of FTL (iron storage and acute-phase secretory protein). This finding indicates that acute phase cytokines and iron increase the release of LCN-2 probably in a similar way to FTL.

According to the data of current study, IL-6 is the key player of iron uptake in hepatocytes during AP-conditions and LCN-2 behaves as an alternative iron transport protein in addition/ compared to classical iron transport proteins (like TfRs) during AP-conditions whose gene expression is increased by iron and/or AP-cytokines. In addition, $\mathrm{LCN}-2$ is also a secretory acute phase protein whose release from hepatocytes (major cell population of the liver) into the supernatant is controlled by iron and AP-cytokines (mainly IL-6). The results of current study show that change in expression of hepatic iron regulatory genes including $\mathrm{LCN}-2$ is not only because of increase in iron contents of hepatocytes but is also due to the effect of AP-cytokines produced in hepatocytes during acute-phase conditions.

\subsection{Kinetic of acute phase cytokines after turpentine oil induced acute phase response}

In the current study, TO injection in animals was used as a means to induce an APR. After turpentine oil (TO)-administration, a dramatic increase in IL-6 gene expression and a significant up-regulation of IL-1 $\beta$ was detected in the injured muscle. However, the kinetics of IL-1 $\beta$ was quite less than that of IL-6. Furthermore, serum analysis showed a strong up-regulation of IL-6 and IL-1 $\beta$ whereas expression of IL-6 was 9-times higher than that of IL-1 $\beta$ (Sheikh et al. 2007), 
which clearly indicates IL-6 as a major cytokine induced in this study model. This model is of sterile inflammation in which the inflammatory agent (TO), was restricted to a specific area i.e. the muscle. The local inflammation caused by this insult recruits the inflammatory cells at the site of injury (damaged muscle) and up-regulation of IL-6 is also recorded in the injured muscle.

The inflammatory stimulus is localized to specific area so it could not approach the liver to cause the IL-6 up-regulation. TO is a lipophilic substance which readily accumulates in fatty tissues and cannot reach the hepatic tissue. In different studies of TO administration to rats maximum concentration of turpentine was found in perinephric fat and brain (Savolainen and Pfaffli, 1978) which might be a possible cause of local production of acute phase cytokines.

\subsection{Regulation of iron transport proteins after TO-induced acute phase response in rat and mice hepatic tissue}

According to an increase in liver iron level (Naz et al, 2012), an intense increase of iron importer proteins (TfRs and LCN2) within liver under AP conditions was studied. Under iron overload conditions, level of these proteins increase resulting in cellular iron retention (CanonneHergaux et al, 2006). However, the early up-regulation of these transporter proteins could be controlled by the acute-phase cytokines (mainly IL-6) which is released at the site of injury resulting in an APR (Sheikh et al, 2007) confirming the in vitro results which showed a regulative effect of the acute phase cytokine, IL-6, on iron importer proteins.

It further strengthens our hypothesis that liver (and hepatocytes) need iron to respond to APconditions. In order to confirm the direct effect of IL-6 on iron importer proteins and to find out the signaling pathway responsible for these changes during APR, same APR model was established in wild type (WT) and IL-6-KO mice after TO-injection. Similar to what was observed in 
rat APR model, a pattern of increase in TfR1, TfR2 and LCN-2 protein level was observed in the liver of WT-mice with the onset of APR, such an increase was not observed for TfR2 and LCN2 in the liver tissue of IL-6 KO mice. Moreover, IL-6 stimulation leads to the activation and phosphorylation of STAT3 pathway (Taub, 2003). A striking finding of the current study is to detect STAT3 phosphorylation in WT-mice liver after TO-injection which was not observed in IL-6-KO

mice liver, indicating a regulative function of this acute-phase cytokine on TfR2 and LCN-2 during APR.

In contrast, an increase in TfR1 protein level, similar in both WT and IL-6 KO mice during APR may suggest the effects of the other acute phase cytokines such as IL-1 $\beta$ and, to a lesser extent TNF- $\alpha$, which are produced also at the site of tissue injury to control this protein. In fact, an intense up-regulation of IL-1 $\beta$ and TNF- $\alpha$ gene expression is recorded in the injured muscle of IL-6-KO mice than their wild type (Ramadori et al, 2010) indicating that in the absence of IL-6 other cytokines may replace its functional role.

\subsection{The cellular localization of iron transport proteins in rat hepatic and extra-hepatic} tissues

To elucidate which cell types are responsible for the TO-induced iron importer proteins expression in the liver and extra hepatic organs, immunohistochemical analysis of these organs was performed. By means of double immunohistochemical analysis TfR1 showed membranous and cytoplasmic expression whereas TfR2 positivity was mostly in the nuclei of hepatic and spleen cells. In spleen a partial co-expression of TfR 1 and TfR 2 was also observed, both in spleens of control rat and after AP-reaction. A nuclear expression of TfR1 was detected in heart tissue as compared to the liver and spleen where a membranous and cytoplasmic expression was observed. Moreover, 
in rat liver and spleen we clearly showed that TfR2 is exclusively located in the nuclei of the cells whereas, in heart tissues TfR2 showed nuclear positivity mostly with partial membranous and cytoplasmic expression. Transferrin receptors (TfR1 \& TfR2) also expressed a colocalization in heart tissues both in control and TO-administrated rats. In nuclei of some cardiomyocytes, to some extent, co-expression of TfRs was also present. The expression of transferrin receptors (TfR1, TfR2) increased after TO-administration in liver and heart tissues but decreased in spleen. These observations suggest that iron is not only being sequestrated into cytoplasm but also in nuclei of cells as was observed by the increased cytoplasmic and nuclear iron concentrations in liver (Naz et al, 2012). A previous study reported the evidence of stainable iron in the hepatocytes nuclei and kupffer cells of mice liver under iron overload conditions. This finding support not only the presence of iron transport proteins in the nucleus of liver cells under pathological conditions as a defence mechanism (Magens et al. 2005) but also the need of iron for nuclear metabolism. TfR2 nuclear expression has been demonstrated in rat PC12 cells (Roth et al. 2000) and in mice glioblastomas cancer cell lines respectively (Calzolari et al. 2010). However, in contrast to liver and spleen membranous expression, being an iron importer, the nuclear localization of TfR 1 in heart cells needs further insights.

Furthermore, LCN-2 colocalization with TfR1 and TfR2 was detected in liver during physiological and AP-conditions, however after ARP co-expression of LCN-2 and TfRs increased strengthening the hypothesis, LCN-2 transports iron during acute phase conditions. In extra-hepatic tissues (heart, spleen), LCN-2 interaction with transferrin receptors (TfR1, TfR2) was also observed in spleen of control and of TO-rat, however, in heart LCN-2 expression was detected only after AP reaction, appearance of LCN-2 protein in heart only after the generation of AP reaction can be due to stress conditions. We previously reported LCN-2 expression in heart at mRNA 
level in the same settings and a different also study reported LCN-2 production by isolated neonatal cardiomyocytes (Yndestad et al, 2009). To the best of my knowledge the current study is first of a kind to exclusively report colocalization of TfRs in extra-hepatic tissues. My this study also suggests that differential localization of transferrin receptors (TfR1, TfR2) in hepatic and extrahepatic tissues is due to diverse role of these proteins in different tissues under physiological and pathological conditions (AP-conditions).

Although nuclear expression of iron proteins in different organs has already been reported, previously, we and others showed TfR1 nuclear expression in rat brain (Malik et al, 2011), LCN2 nuclear expression in mice brain (Ip et al, 2011), FTH (Ahmad et al, 2013), Fpn1 and DMT-1 nuclear expression in rat liver (Naz et al, 2012), in PC12 cells (Roth et al, 2000) and in mice glioblastoma cell lines respectively (Calzolari et al, 2010). However, colocalization and differential localization of iron importer proteins (TfRs, LCN-2) in hepatic and extra-hepatic tissues (heart and spleen) has never been reported before.

These findings support not only the presence of iron transport proteins within the nuclei to transport more iron in the hepatic cell nuclei under stress conditions but suggests that increased level of nuclear iron may be necessary for the increased activity of nuclear enzymes involved in DNA synthesis, repair and regulation of transcription (Roth et al, 2000).

\subsection{The cellular localization of iron storage proteins (FTH, FTL) in rat hepatic and extra- hepatic tissues}

Similar to iron importer proteins, protein expression of iron storage proteins (FTH and FTL) was also observed by immunohistochemistry. Immunofluorescence staining showed FTH 
localized in nucleus while FTL mostly in cytoplasm under physiological and acute phase conditions. Furthermore, Western blot analysis revealed a FTL expression was strong in cytoplasm and week in the nuclei of cells. In contrast to FTL, FTH expression was stronger in nucleus and weaker in cytoplasm in hepatic and extra-hepatic organs (heart, spleen and brain). After the onset of ARP, protein expression of both ferritin subunits (FTH, FTL) increased. Ferritin is always reported as iron storage protein of cytosol (Meyron-Holtz et al, 2011) and its subcellular localization is controversial. Some previous studies reported presence of FTH in nucleus of human astrocytoma cell line (Surguladze et al, 2005), in corneal epithelial cells (Cai and Linsenmayer, 2001) and in mice hepatocytes during iron overload states (Smith et al, 1990). According to my study, FTH is constitutively expressed in hepatic and extra-hepatic organs during physiological and acute-phase conditions. During ARP, nuclear iron contents increased (Naz et al, 2012) therefore, detection of iron storage proteins in the nucleus of the cells is not surprising. Nuclear expression of FTH like TfR2 further confirms these findings that iron is sequestrated in both cytoplasm and nucleus of hepatic cells for nuclear metabolism. There could be another possibility that during acute-phase conditions, liver needs more iron to combat the increased metabolic work load (Ramadori and Christ, 1999).

Similarly, results of our previous and current study showed a parallel increase in mRNA and protein expression of ferritin subunits (FTH, FTL) and hepatic iron uptake during APR (Naz et al, 2012). Few previous studies clearly reported that amount of intracellular ferritin was regulated by change in iron status (Meyron-Holtz et al, 2011) and accumulation of H-chain (Goralska et al, 2001;Hentze et al, 1987). However, our previous studies reported that modulation in FTH, FTL and other iron metabolism proteins is also due to acute-phase cytokines (Naz et al, 2012; Sheikh et al, 2006). In other words, acute-phase cytokines synthesized during TO-induced 
APR have direct effect on hepatic FTL and FTH up-regulation and this increase in their expression is not only due to the hepatic iron uptake.

A previous study (Darshan et al, 2009) reported FTH as main hepatic iron storage protein and hepatocytes become more susceptible to toxic effects of iron when FTH was depleted in these cells (Darshan et al, 2009). Moreover, over-expression of FTH in K562 cells resulted in reduction of free available iron pool in these cells (Picard et al, 1998). These observations clearly indicate that not only FTL but also FTH is needed for reduction of free available iron in the stressed hepatocytes during APR. FTL shares "the iron storage" function in hepatic and extra-hepatic tissues (heart, spleen and brain) however, liver is a unique organ due to its secretory function when compared to extra hepatic organs.

The nuclear expression of FTH in liver, heart, spleen and brain cells suggests that there is not only iron storage in the nuclei but also nuclei need to be protected from toxic effects of iron on DNA due to iron-overload (Darshan et al, 2009). This function might be more important during APR due to increased metabolic challenges.

\section{CONCLUSION}

In conclusion, I propose that under normal conditions, transferrin bound iron of portal blood is taken up by liver cells through TfRs mediated and non-trasnferrin bound iron uptake by LCN-2 under the influence of IL-6. Once in the cell, it is in part delivered not only to cytoplasmic organelles like mitochondria (Richardson et al, 2010) but also to the nucleus to meet the cellular functional requirements including DNA synthesis and RNA metabolism. As iron is transported into the nucleus, surplus iron in the nucleus is stored within FTH to protect nucleus from oxidative damage. 
Under acute phase conditions, liver behaves as a "sponge" for iron as the decrease in serum iron levels is most probably achieved by increased hepatic uptake of transferrin bound iron by TfR 1 mediated iron transport into the hepatocytes; increased LCN-2 also serves to transport iron into the cell. Furthermore, differential localization pattern of iron regulatory proteins in hepatic and extra-hepatic tissues indicates their diverse role in these tissues during physiological and acute phase conditions. The findings of current suggest that IL-6 causes hypoferremia of inflammation by inducing TfRs (exclusively TfR2) and LCN-2 through STAT3 pathway activation. These findings will help in the implications for further understanding the importance of iron metabolism in iron related disorders. 


\section{SUMMARY}

Acute phase response (APR) is the systemic reaction to tissue injury and inflammation. It is clinically characterized by certain symptoms such as fever, weakness, and anemia, somnolence loss of appetite and cytokines release. In the blood, it results in an increase of positive acute phase proteins (APPs) in plasma, including clotting proteins, transport proteins, anti-proteases, and complement factors, with a concomitant decrease in negative APPs such as albumin. In addition, a decrease of serum iron-levels and consecutive increase of hepatic iron levels is also a hallmark of

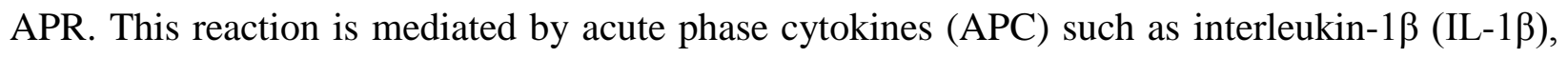
tumor necrosis factor-alpha (TNF- $\alpha$ ) and IL- 6 cytokines through the activation of different transcription factors. The mechanism of liver iron uptake during APR is poorly understood. Therefore, current study aimed to investigate the exact mechanism of iron uptake with relation to iron regulatory proteins and their signaling pathway under the influence of APC in liver and liver cells. Furthermore, sub-cellular localization of these proteins in hepatic and extra-hepatic organs during APR is also examined.

In vitro: primary cultures of rat isolated hepatocytes were stimulated with APC (IL-1 $\beta$, IL-6 and TNF- $\alpha$ ) in the presence/absence of different concentrations of iron $\left(\mathrm{FeCl}_{3}: 0.01 \mathrm{mM}, 0.1 \mathrm{mM}\right)$. APR was induced by injecting turpentine-oil (TO) in hind limbs of rat and mice (wild type and IL6 knock-out). Hepatocytes cell lysates and cell supernatants were prepared for iron measurement, RT-PCR and Western blotting. Tissue samples (liver, spleen and heart) were removed to use for immunobloting and immunohistochemical analysis.

In hepatocytes treated with iron in the presence/absence of cytokines, a significant iron uptake was observed with $0.1 \mathrm{mM}$ iron administration with a maximum at $24 \mathrm{~h}(133 \mu \mathrm{g} / \mathrm{g}$ protein $)$ in comparison to control and other iron concentrations administrated. This iron uptake was further 
enhanced in the presence of acute phase cytokines with a maximum iron uptake $(481 \mu \mathrm{g} / \mathrm{g}$ of protein) after IL-6 and 0.1mM iron concomitant administration. LCN-2 and ferritin subunits (FTH, FTL) gene expression was up-regulated by iron with further induction by acute phase cytokines both, at mRNA and protein level. The maximum increase was seen for the combination of IL-6 with iron. TfR 2 was increased by IL-6 and iron alone, however TfR1 was decreased. Combination of iron and APC abrogated the down-regulation of TfR1. Iron as well as APC stimulation led to LCN-2 release into supernatant, with increased release in the presence of iron and APC (IL-6 mainly) combined.

Similar to in vitro data, liver tissue of rat and wild type mice also showed an increase in iron transport (TfR1, TfR2 and LCN-2) and storage proteins (FTH, FTL) during APR whereas such an increase was not detected for TfR2, LCN-2 and FTH in IL6-KO mice. In parallel to induction of iron transporters, a phosphorylation of STAT3 was also observed in WT-mice however such a change was not noticed in IL-6 KO mice.

Immunohistochemistry of hepatic and extra hepatic tissues indicated organ dependent localization of TfR1 and TfR2. TfR1 was primarily localized in the membrane and cytoplasm of liver, and spleen cells whereas, in both organs, TfR2 showed nuclear expression mostly. However, in heart, both TfR1 and TfR2 were detected to be surplus in membrane, cytoplasm and nucleus. In all the organs studied, TfR1, TfR2 and LCN-2 were colocalized. The iron storage protein FTL was localized in cytoplasm while a strong FTH positivity was observed in the nucleus of liver cells. Similarly, in spleen and heart FTL was mostly localized in the cytoplasm however, an intense nuclear and a weak cytoplasmic expression was evident for FTH. 
By summarizing, results of current study demonstrate that liver behaves as a "sponge" for iron during APR. Iron uptake in hepatocytes is tightly controlled by already present iron and this uptake can be further enhanced by APC, mainly by IL-6. Hepatocytes need more iron to respond the massive increase of protein synthesis under such stress conditions. These changes could explain iron retention in hepatocytes during APR. Furthermore, portal blood iron is taken up by liver cells mostly through importer proteins (TfRs and LCN-2) and these proteins are regulated mainly through IL-6 activated STAT3 pathway. The differential localization pattern of iron regulatory proteins in hepatic and extra-hepatic organs suggests their organ specific diverse role during APR. 
Ahmad, S., Moriconi, F., Naz, N., Sultan, S., Sheikh, N., Ramadori, G. and Malik, I. A. (2013). Ferritin $\mathrm{L}$ and Ferritin $\mathrm{H}$ are differentially located within hepatic and extra hepatic organs under physiological and acute phase conditions. Int. J. Clin. Exp. Pathol. 6, 622-629.

Aisen, P. (2004). Transferrin receptor 1. Int. J. Biochem. Cell Biol. 36, 2137-2143.

Aisen, P., Enns, C. and Wessling-Resnick, M. (2001). Chemistry and biology of eukaryotic iron metabolism. Int. J. Biochem. Cell Biol. 33, 940-959.

Andrews, N. C. (1999). Disorders of iron metabolism. N. Engl. J. Med. 341, 1986-1995.

Andrews, N. C. (2008). Forging a field: the golden age of iron biology. Blood 112, 219-230.

Arosio, P., Ingrassia, R. and Cavadini, P. (2009). Ferritins: a family of molecules for iron storage, antioxidation and more. Biochim. Biophys. Acta 1790, 589-599.

Bali, P. K., Zak, O. and Aisen, P. (1991). A new role for the transferrin receptor in the release of iron from transferrin. Biochemistry 30, 324-328.

Bernstein, S. E. (1987). Hereditary hypotransferrinemia with hemosiderosis, a murine disorder resembling human atransferrinemia. J. Lab Clin. Med. 110, 690-705.

Breuer, W., Hershko, C. and Cabantchik, Z. I. (2000a). The importance of non-transferrin bound iron in disorders of iron metabolism. Transfus. Sci. 23, 185-192.

Breuer, W., Ronson, A., Slotki, I. N., Abramov, A., Hershko, C. and Cabantchik, Z. I. (2000b). The assessment of serum nontransferrin-bound iron in chelation therapy and iron supplementation. Blood 95, 2975-2982.

Briat, J. F., Ravet, K., Arnaud, N., Duc, C., Boucherez, J., Touraine, B., Cellier, F. and Gaymard, F. (2010). New insights into ferritin synthesis and function highlight a link between iron homeostasis and oxidative stress in plants. Ann. Bot. 105, 811-822.

Bridle, K. R., Crawford, D. H. and Ramm, G. A. (2003). Identification and characterization of the hepatic stellate cell transferrin receptor. Am. J. Pathol. 162, 1661-1667.

Cai, C. X. and Linsenmayer, T. F. (2001). Nuclear translocation of ferritin in corneal epithelial cells. J. Cell Sci. 114, 2327-2334.

Cairo, G., Recalcati, S., Pietrangelo, A. and Minotti, G. (2002). The iron regulatory proteins: targets and modulators of free radical reactions and oxidative damage. Free Radic. Biol. Med. 32, 12371243. 
Caltagirone, A., Weiss, G. and Pantopoulos, K. (2001). Modulation of cellular iron metabolism by hydrogen peroxide. Effects of $\mathrm{H} 2 \mathrm{O} 2$ on the expression and function of iron-responsive elementcontaining mRNAs in B6 fibroblasts. J. Biol. Chem. 276, 19738-19745.

Calzolari, A., Larocca, L. M., Deaglio, S., Finisguerra, V., Boe, A., Raggi, C., Ricci-Vitani, L., Pierconti, F., Malavasi, F., De, M. R. et al. (2010). Transferrin receptor 2 is frequently and highly expressed in glioblastomas. Transl. Oncol. 3, 123-134.

Calzolari, A., Oliviero, I., Deaglio, S., Mariani, G., Biffoni, M., Sposi, N. M., Malavasi, F., Peschle, C. and Testa, U. (2007). Transferrin receptor 2 is frequently expressed in human cancer cell lines. Blood Cells Mol. Dis. 39, 82-91.

Camaschella, C. (2013). Iron and hepcidin: a story of recycling and balance. Hematology. Am. Soc. Hematol. Educ. Program. 2013, 1-8.

Camaschella, C., Roetto, A., Cali, A., De, G. M., Garozzo, G., Carella, M., Majorano, N., Totaro, A. and Gasparini, P. (2000). The gene TFR2 is mutated in a new type of haemochromatosis mapping to 7q22. Nat. Genet. 25, 14-15.

Canonne-Hergaux, F., Donovan, A., Delaby, C., Wang, H. J. and Gros, P. (2006). Comparative studies of duodenal and macrophage ferroportin proteins. Am. J. Physiol Gastrointest. Liver Physiol 290, G156-G163.

Caskey, J. H., Jones, C., Miller, Y. E. and Seligman, P. A. (1983). Human ferritin gene is assigned to chromosome 19. Proc. Natl. Acad. Sci. U. S. A 80, 482-486.

Chua, A. C., Olynyk, J. K., Leedman, P. J. and Trinder, D. (2004). Nontransferrin-bound iron uptake by hepatocytes is increased in the Hfe knockout mouse model of hereditary hemochromatosis. Blood 104, 1519-1525.

Cole, E. S. and Glass, J. (1983). Transferrin binding and iron uptake in mouse hepatocytes. Biochim. Biophys. Acta 762, 102-110.

Conner, S. D. and Schmid, S. L. (2003). Differential requirements for AP-2 in clathrin-mediated endocytosis. J. Cell Biol. 162, 773-779.

Cozzi, A., Corsi, B., Levi, S., Santambrogio, P., Biasiotto, G. and Arosio, P. (2004). Analysis of the biologic functions of $\mathrm{H}$ - and L-ferritins in HeLa cells by transfection with siRNAs and cDNAs: evidence for a proliferative role of L-ferritin. Blood 103, 2377-2383.

Darshan, D., Vanoaica, L., Richman, L., Beermann, F. and Kuhn, L. C. (2009). Conditional deletion of ferritin $\mathrm{H}$ in mice induces loss of iron storage and liver damage. Hepatology 50, 852-860.

De, D., I, McVey, W. D. and Kaplan, J. (2008). Regulation of iron acquisition and storage: consequences for iron-linked disorders. Nat. Rev. Mol. Cell Biol. 9, 72-81.

De, D., I, Ward, D. M., Musci, G. and Kaplan, J. (2006). Iron overload due to mutations in ferroportin. Haematologica 91, 92-95. 
Deaglio, S., Capobianco, A., Cali, A., Bellora, F., Alberti, F., Righi, L., Sapino, A., Camaschella, C. and Malavasi, F. (2002). Structural, functional, and tissue distribution analysis of human transferrin receptor-2 by murine monoclonal antibodies and a polyclonal antiserum. Blood 100, 3782-3789.

Decker, K. (1990). Biologically active products of stimulated liver macrophages (Kupffer cells). Eur. J. Biochem. 192, 245-261.

DeMaeyer, E. and Adiels-Tegman, M. (1985). The prevalence of anaemia in the world. World Health Stat. Q. 38, 302-316.

Deschemin, J. C. and Vaulont, S. (2013). Role of hepcidin in the setting of hypoferremia during acute inflammation. PLoS. One. 8, e61050.

Devireddy, L. R., Gazin, C., Zhu, X. and Green, M. R. (2005). A cell-surface receptor for lipocalin 24p3 selectively mediates apoptosis and iron uptake. Cell 123, 1293-1305.

Devireddy, L. R., Hart, D. O., Goetz, D. H. and Green, M. R. (2010). A mammalian siderophore synthesized by an enzyme with a bacterial homolog involved in enterobactin production. Cell 141, 1006-1017.

Dreyfuss, M. L., Stoltzfus, R. J., Shrestha, J. B., Pradhan, E. K., LeClerq, S. C., Khatry, S. K., Shrestha, S. R., Katz, J., Albonico, M. and West, K. P., Jr. (2000). Hookworms, malaria and vitamin A deficiency contribute to anemia and iron deficiency among pregnant women in the plains of Nepal. J. Nutr. 130, 2527-2536.

Eisenstein, R. S. (2000). Iron regulatory proteins and the molecular control of mammalian iron metabolism. Annu. Rev. Nutr. 20, 627-662.

Fleming, R. E., Ahmann, J. R., Migas, M. C., Waheed, A., Koeffler, H. P., Kawabata, H., Britton, R. S., Bacon, B. R. and Sly, W. S. (2002). Targeted mutagenesis of the murine transferrin receptor2 gene produces hemochromatosis. Proc. Natl. Acad. Sci. U. S. A 99, 10653-10658.

Fleming, R. E., Migas, M. C., Holden, C. C., Waheed, A., Britton, R. S., Tomatsu, S., Bacon, B. R. and Sly, W. S. (2000). Transferrin receptor 2: continued expression in mouse liver in the face of iron overload and in hereditary hemochromatosis. Proc. Natl. Acad. Sci. U. S. A 97, 2214-2219.

Flo, T. H., Smith, K. D., Sato, S., Rodriguez, D. J., Holmes, M. A., Strong, R. K., Akira, S. and Aderem, A. (2004). Lipocalin 2 mediates an innate immune response to bacterial infection by sequestrating iron. Nature 432, 917-921.

Frazer, D. M. and Anderson, G. J. (2005). Iron imports. I. Intestinal iron absorption and its regulation. Am. J. Physiol Gastrointest. Liver Physiol 289, G631-G635.

Galaris, D., Mantzaris, M. and Amorgianiotis, C. (2008). Oxidative stress and aging: the potential role of iron. Hormones. (Athens. ) 7, 114-122.

Ganz, T. and Nemeth, E. (2012). Iron metabolism: interactions with normal and disordered erythropoiesis. Cold Spring Harb. Perspect. Med. 2, a011668. 
Goldenberg, H., Seelos, C., Chatwani, S., Chegini, S. and Pumm, R. (1991). Uptake and endocytic pathway of transferrin and iron in perfused rat liver. Biochim. Biophys. Acta 1067, 145-152.

Goralska, M., Holley, B. L. and McGahan, M. C. (2001). Overexpression of H- and L-Ferritin Subunits in Lens Epithelial Cells: Fe Metabolism and Cellular Response to UVB Irradiation. Investigative Ophthalmology \& Visual Science 42, 1721-1727.

Graham, R. M., Morgan, E. H. and Baker, E. (1998). Ferric citrate uptake by cultured rat hepatocytes is inhibited in the presence of transferrin. Eur. J. Biochem. 253, 139-145.

Gruys, E., Toussaint, M. J., Niewold, T. A. and Koopmans, S. J. (2005). Acute phase reaction and acute phase proteins. J. Zhejiang. Univ Sci. B 6, 1045-1056.

Haase, M., Bellomo, R. and Haase-Fielitz, A. (2010). Novel biomarkers, oxidative stress, and the role of labile iron toxicity in cardiopulmonary bypass-associated acute kidney injury. J. Am. Coll. Cardiol. 55, 2024-2033.

Harmatz, P., Butensky, E., Quirolo, K., Williams, R., Ferrell, L., Moyer, T., Golden, D., Neumayr, L. and Vichinsky, E. (2000). Severity of iron overload in patients with sickle cell disease receiving chronic red blood cell transfusion therapy. Blood 96, 76-79.

Harrison, P. M. and Arosio, P. (1996). The ferritins: molecular properties, iron storage function and cellular regulation. Biochim. Biophys. Acta 1275, 161-203.

Hayashi, A., Wada, Y., Suzuki, T. and Shimizu, A. (1993). Studies on familial hypotransferrinemia: unique clinical course and molecular pathology. Am. J. Hum. Genet. 53, 201-213.

Heinrich, P. C., Behrmann, I., Haan, S., Hermanns, H. M., Muller-Newen, G. and Schaper, F. (2003). Principles of interleukin (IL)-6-type cytokine signalling and its regulation. Biochem. J. $374,1-20$.

Heinrich, P. C., Behrmann, I., Muller-Newen, G., Schaper, F. and Graeve, L. (1998). Interleukin-6type cytokine signalling through the gp130/Jak/STAT pathway. Biochem. J. 334 ( Pt 2), 297-314.

Hentze, M. W., Caughman, S. W., Rouault, T. A., Barriocanal, J. G., Dancis, A., Harford, J. B. and Klausner, R. D. (1987). Identification of the iron-responsive element for the translational regulation of human ferritin mRNA. Science 238, 1570-1573.

Hentze, M. W., Muckenthaler, M. U. and Andrews, N. C. (2004). Balancing acts: molecular control of mammalian iron metabolism. Cell 117, 285-297.

Hentze, M. W., Muckenthaler, M. U., Galy, B. and Camaschella, C. (2010). Two to tango: regulation of Mammalian iron metabolism. Cell 142, 24-38.

Herbison, C. E., Thorstensen, K., Chua, A. C., Graham, R. M., Leedman, P., Olynyk, J. K. and Trinder, D. (2009). The role of transferrin receptor 1 and 2 in transferrin-bound iron uptake in human hepatoma cells. Am. J. Physiol Cell Physiol 297, C1567-C1575.

Hider, R. C. (2002). Nature of nontransferrin-bound iron. Eur. J. Clin. Invest 32 Suppl 1, 50-54. 
Hirose-Kumagai, A. and Akamatsu, N. (1989). Change in transferrin receptor distribution in regenerating rat liver. Biochem. Biophys. Res. Commun. 164, 1105-1112.

Hvidberg, V., Jacobsen, C., Strong, R. K., Cowland, J. B., Moestrup, S. K. and Borregaard, N. (2005). The endocytic receptor megalin binds the iron transporting neutrophil-gelatinaseassociated lipocalin with high affinity and mediates its cellular uptake. FEBS Lett. 579, 773-777.

Ip, J. P., Nocon, A. L., Hofer, M. J., Lim, S. L., Muller, M. and Campbell, I. L. (2011). Lipocalin 2 in the central nervous system host response to systemic lipopolysaccharide administration. $J$. Neuroinflammation. 8, 124.

Johnson, M. B., Chen, J., Murchison, N., Green, F. A. and Enns, C. A. (2007). Transferrin receptor 2: evidence for ligand-induced stabilization and redirection to a recycling pathway. Mol. Biol. Cell 18, 743-754.

Johnson, M. B. and Enns, C. A. (2004). Diferric transferrin regulates transferrin receptor 2 protein stability. Blood 104, 4287-4293.

Kalinowski, D. S. and Richardson, D. R. (2005). The evolution of iron chelators for the treatment of iron overload disease and cancer. Pharmacol. Rev. 57, 547-583.

Kanra, G. Y., Ozen, H. and Kara, A. (2006). Infection and anorexia. Turk. J. Pediatr. 48, 279-287.

Kaplan, J. (2002). Mechanisms of cellular iron acquisition: another iron in the fire. Cell 111, 603-606.

Kawabata, H., Yang, R., Hirama, T., Vuong, P. T., Kawano, S., Gombart, A. F. and Koeffler, H. P. (1999). Molecular cloning of transferrin receptor 2. A new member of the transferrin receptorlike family. J. Biol. Chem. 274, 20826-20832.

Kell, D. B. (2009). Iron behaving badly: inappropriate iron chelation as a major contributor to the aetiology of vascular and other progressive inflammatory and degenerative diseases. BMC. Med. Genomics 2, 2.

Koj, A. (1985). Cytokines regulating acute inflammation and synthesis of acute phase proteins. Blut 51, 267-274.

Koppenol, W. H. (1993). The centennial of the Fenton reaction. Free Radic. Biol. Med. 15, 645-651.

Lee, A. W., Oates, P. S. and Trinder, D. (2003). Effects of cell proliferation on the uptake of transferrin-bound iron by human hepatoma cells. Hepatology 38, 967-977.

Levy, J. E., Jin, O., Fujiwara, Y., Kuo, F. and Andrews, N. C. (1999). Transferrin receptor is necessary for development of erythrocytes and the nervous system. Nat. Genet. 21, 396-399.

Lewis, D. K., Whitty, C. J., Walsh, A. L., Epino, H., Broek, N. R., Letsky, E. A., Munthali, C., Mukiibi, J. M. and Boeree, M. J. (2005). Treatable factors associated with severe anaemia in adults admitted to medical wards in Blantyre, Malawi, an area of high HIV seroprevalence. Trans. R. Soc. Trop. Med. Hyg. 99, 561-567. 
Loreal, O., Gosriwatana, I., Guyader, D., Porter, J., Brissot, P. and Hider, R. C. (2000). Determination of non-transferrin-bound iron in genetic hemochromatosis using a new HPLCbased method. J. Hepatol. 32, 727-733.

Lu, J. P., Hayashi, K. and Awai, M. (1989). Transferrin receptor expression in normal, iron-deficient and iron-overloaded rats. Acta Pathol. Jpn. 39, 759-764.

Malik, I. A., Naz, N., Sheikh, N., Khan, S., Moriconi, F., Blaschke, M. and Ramadori, G. (2011). Comparison of changes in gene expression of transferrin receptor-1 and other iron-regulatory proteins in rat liver and brain during acute-phase response. Cell Tissue Res. 344, 299-312.

Meyron-Holtz, E. G., Moshe-Belizowski, S. and Cohen, L. A. (2011). A possible role for secreted ferritin in tissue iron distribution. J. Neural Transm. 118, 337-347.

Morgan, E. H. (1991). Specificity of hepatic iron uptake from plasma transferrin in the rat. Comp Biochem. Physiol A Comp Physiol 99, 91-95.

Morgan, E. H., Smith, G. D. and Peters, T. J. (1986). Uptake and subcellular processing of 59Fe-125Ilabelled transferrin by rat liver. Biochem. J. 237, 163-173.

Mori, K., Lee, H. T., Rapoport, D., Drexler, I. R., Foster, K., Yang, J., Schmidt-Ott, K. M., Chen, X., Li, J. Y., Weiss, S. et al. (2005). Endocytic delivery of lipocalin-siderophore-iron complex rescues the kidney from ischemia-reperfusion injury. J. Clin. Invest 115, 610-621.

Moshage, H. (1997). Cytokines and the hepatic acute phase response. J. Pathol. 181, 257-266.

Mullner, E. W. and Kuhn, L. C. (1988). A stem-loop in the 3' untranslated region mediates irondependent regulation of transferrin receptor mRNA stability in the cytoplasm. Cell 53, 815-825.

Napier, I., Ponka, P. and Richardson, D. R. (2005). Iron trafficking in the mitochondrion: novel pathways revealed by disease. Blood 105, 1867-1874.

Naz, N., Malik, I. A., Sheikh, N., Ahmad, S., Khan, S., Blaschke, M., Schultze, F. and Ramadori, G. (2012). Ferroportin-1 is a 'nuclear'-negative acute-phase protein in rat liver: a comparison with other iron-transport proteins. Lab Invest 92, 842-856.

Ohgami, R. S., Campagna, D. R., Greer, E. L., Antiochos, B., McDonald, A., Chen, J., Sharp, J. J., Fujiwara, Y., Barker, J. E. and Fleming, M. D. (2005). Identification of a ferrireductase required for efficient transferrin-dependent iron uptake in erythroid cells. Nat. Genet. 37, 12641269.

Olsson, K. S. and Norrby, A. (2008). Comment to: Hepcidin: from discovery to differential diagnosis. Haematologica 2008; 93:90-7. Haematologica 93, e51.

Picard, V., Epsztejn, S., Santambrogio, P., Cabantchik, Z. I. and Beaumont, C. (1998). Role of ferritin in the control of the labile iron pool in murine erythroleukemia cells. J. Biol Chem. 273, 15382-15386.

Pietrangelo, A. (2010). Hereditary hemochromatosis: pathogenesis, diagnosis, and treatment. Gastroenterology 139, 393-408, 408. 
Ponka, P., Beaumont, C. and Richardson, D. R. (1998). Function and regulation of transferrin and ferritin. Semin. Hematol. 35, 35-54.

Prus, E. and Fibach, E. (2011). Uptake of non-transferrin iron by erythroid cells. Anemia. 2011, 945289.

Ramadori, G. and Christ, B. (1999). Cytokines and the hepatic acute-phase response. Semin. Liver Dis. 19, 141-155.

Ramadori, G., Sipe, J. D. and Colten, H. R. (1985). Expression and regulation of the murine serum amyloid A (SAA) gene in extrahepatic sites. J. Immunol. 135, 3645-3647.

Ramadori, P., Ahmad, G. and Ramadori, G. (2010). Cellular and molecular mechanisms regulating the hepatic erythropoietin expression during acute-phase response: a role for IL-6. Lab Invest 90, 1306-1324.

Richardson, D. R., Lane, D. J., Becker, E. M., Huang, M. L., Whitnall, M., Suryo, R. Y., Sheftel, A. D. and Ponka, P. (2010). Mitochondrial iron trafficking and the integration of iron metabolism between the mitochondrion and cytosol. Proc. Natl. Acad. Sci. U. S. A 107, 10775-10782.

Robb, A. and Wessling-Resnick, M. (2004). Regulation of transferrin receptor 2 protein levels by transferrin. Blood 104, 4294-4299.

Robb, A. D., Ericsson, M. and Wessling-Resnick, M. (2004). Transferrin receptor 2 mediates a biphasic pattern of transferrin uptake associated with ligand delivery to multivesicular bodies. Am. J. Physiol Cell Physiol 287, C1769-C1775.

Roth, J. A., Horbinski, C., Feng, L., Dolan, K. G., Higgins, D. and Garrick, M. D. (2000). Differential localization of divalent metal transporter 1 with and without iron response element in rat PC12 and sympathetic neuronal cells. J. Neurosci. 20, 7595-7601.

Rouault, T. A. (2006). The role of iron regulatory proteins in mammalian iron homeostasis and disease. Nat. Chem. Biol. 2, 406-414.

Rowell, D. L., Eckmann, L., Dwinell, M. B., Carpenter, S. P., Raucy, J. L., Yang, S. K. and Kagnoff, M. F. (1997). Human hepatocytes express an array of proinflammatory cytokines after agonist stimulation or bacterial invasion. Am. J. Physiol 273, G322-G332.

Sammarco, M. C., Ditch, S., Banerjee, A. and Grabczyk, E. (2008). Ferritin L and H subunits are differentially regulated on a post-transcriptional level. J. Biol. Chem. 283, 4578-4587.

Savolainen, H. and Pfaffli, P. (1978). Effects of long-term turpentine inhalation on rat brain protein metabolism. Chem. Biol. Interact. 21, 271-276.

Schmidt-Ott, K. M., Mori, K., Li, J. Y., Kalandadze, A., Cohen, D. J., Devarajan, P. and Barasch, J. (2007). Dual action of neutrophil gelatinase-associated lipocalin. J. Am. Soc. Nephrol. 18, 407413.

Sheikh, N., Batusic, D. S., Dudas, J., Tron, K., Neubauer, K., Saile, B. and Ramadori, G. (2006). Hepcidin and hemojuvelin gene expression in rat liver damage: in vivo and in vitro studies. Am. J. Physiol Gastrointest. Liver Physiol 291, G482-G490. 
Sheikh, N., Dudas, J. and Ramadori, G. (2007). Changes of gene expression of iron regulatory proteins during turpentine oil-induced acute-phase response in the rat. Lab Invest 87, 713-725.

Sibille, J. C., Octave, J. N., Schneider, Y. J., Trouet, A. and Crichton, R. (1986). Subcellular localization of transferrin protein and iron in the perfused rat liver. Effect of Triton WR 1339, digitonin and temperature. Eur. J. Biochem. 155, 47-55.

Smith, A. G., Carthew, P., Francis, J. E., Edwards, R. E. and Dinsdale, D. (1990). Characterization and accumulation of ferritin in hepatocyte nuclei of mice with iron overload. Hepatology 12, $1399-1405$

Srinivasan, G., Aitken, J. D., Zhang, B., Carvalho, F. A., Chassaing, B., Shashidharamurthy, R., Borregaard, N., Jones, D. P., Gewirtz, A. T. and Vijay-Kumar, M. (2012). Lipocalin 2 deficiency dysregulates iron homeostasis and exacerbates endotoxin-induced sepsis. J. Immunol. 189, 1911-1919.

Stein, J., Hartmann, F. and Dignass, A. U. (2010). Diagnosis and management of iron deficiency anemia in patients with IBD. Nat. Rev. Gastroenterol. Hepatol. 7, 599-610.

Stoltzfus, R. J., Chwaya, H. M., Montresor, A., Albonico, M., Savioli, L. and Tielsch, J. M. (2000). Malaria, hookworms and recent fever are related to anemia and iron status indicators in 0- to 5-y old Zanzibari children and these relationships change with age. J. Nutr. 130, 1724-1733.

Streetz, K. L., Wustefeld, T., Klein, C., Manns, M. P. and Trautwein, C. (2001). Mediators of inflammation and acute phase response in the liver. Cell Mol. Biol. (Noisy. -le-grand) 47, 661673.

Sultan, S., Pascucci, M., Ahmad, S., Malik, I. A., Bianchi, A., Ramadori, P., Ahmad, G. and Ramadori, G. (2012). LIPOCALIN-2 is a major acute-phase protein in a rat and mouse model of sterile abscess. Shock 37, 191-196.

Surguladze, N., Patton, S., Cozzi, A., Fried, M. G. and Connor, J. R. (2005). Characterization of nuclear ferritin and mechanism of translocation. Biochem. J. 388, 731-740.

Tacchini, L., Bianchi, L., Bernelli-Zazzera, A. and Cairo, G. (1999). Transferrin receptor induction by hypoxia. HIF-1-mediated transcriptional activation and cell-specific post-transcriptional regulation. J. Biol. Chem. 274, 24142-24146.

Taub, R. (2003). Hepatoprotection via the IL-6/Stat3 pathway. J. Clin. Invest 112, 978-980.

Tavassoli, M., Kishimoto, T., Soda, R., Kataoka, M. and Harjes, K. (1986). Liver endothelium mediates the uptake of iron-transferrin complex by hepatocytes. Exp. Cell Res. 165, 369-379.

Thorstensen, K. and Romslo, I. (1984). Uptake of iron from transferrin by isolated hepatocytes. Biochim. Biophys. Acta 804, 200-208.

Thorstensen, K. and Romslo, I. (1990). The role of transferrin in the mechanism of cellular iron uptake. Biochem. J. 271, 1-9. 
Tran, T. N., Eubanks, S. K., Schaffer, K. J., Zhou, C. Y. and Linder, M. C. (1997). Secretion of ferritin by rat hepatoma cells and its regulation by inflammatory cytokines and iron. Blood 90, 4979-4986.

Trinder, D., Fox, C., Vautier, G. and Olynyk, J. K. (2002). Molecular pathogenesis of iron overload. Gut 51, 290-295.

Trinder, D. and Morgan, E. (1997). Inhibition of uptake of transferrin-bound iron by human hepatoma cells by nontransferrin-bound iron. Hepatology 26, 691-698.

Trinder, D., Morgan, E. and Baker, E. (1986). The mechanisms of iron uptake by fetal rat hepatocytes in culture. Hepatology 6, 852-858.

Trinder, D., Morgan, E. H. and Baker, E. (1988). The effects of an antibody to the rat transferrin receptor and of rat serum albumin on the uptake of diferric transferrin by rat hepatocytes.

Biochim. Biophys. Acta 943, 440-446.

Vogel, W., Bomford, A., Young, S. and Williams, R. (1987). Heterogeneous distribution of transferrin receptors on parenchymal and nonparenchymal liver cells: biochemical and morphological evidence. Blood 69, 264-270.

Wallander, M. L., Leibold, E. A. and Eisenstein, R. S. (2006). Molecular control of vertebrate iron homeostasis by iron regulatory proteins. Biochim. Biophys. Acta 1763, 668-689.

Walters, T. D. and Griffiths, A. M. (2009). Mechanisms of growth impairment in pediatric Crohn's disease. Nat. Rev. Gastroenterol. Hepatol. 6, 513-523.

Wang, W., Grier, D. D., Woo, J., Ward, M., Sui, G., Torti, S. V., Torti, F. M. and Beaty, M. W. (2013). Ferritin $\mathrm{H}$ is a novel marker of early erythroid precursors and macrophages.

Histopathology 62, 931-940.

Watkins, J. A., Altazan, J. D., Elder, P., Li, C. Y., Nunez, M. T., Cui, X. X. and Glass, J. (1992). Kinetic characterization of reductant dependent processes of iron mobilization from endocytic vesicles. Biochemistry 31, 5820-5830.

Worwood, M., Brook, J. D., Cragg, S. J., Hellkuhl, B., Jones, B. M., Perera, P., Roberts, S. H. and Shaw, D. J. (1985). Assignment of human ferritin genes to chromosomes 11 and 19q13.3---19qter. Hum. Genet. 69, 371-374.

Yang, J., Goetz, D., Li, J. Y., Wang, W., Mori, K., Setlik, D., Du, T., Erdjument-Bromage, H., Tempst, P., Strong, R. et al. (2002). An iron delivery pathway mediated by a lipocalin. Mol. Cell 10, 1045-1056.

Yang, J., Mori, K., Li, J. Y. and Barasch, J. (2003). Iron, lipocalin, and kidney epithelia. Am. J. Physiol Renal Physiol 285, F9-18.

Yndestad, A., Landro, L., Ueland, T., Dahl, C. P., Flo, T. H., Vinge, L. E., Espevik, T., Froland, S. S., Husberg, C., Christensen, G. et al. (2009). Increased systemic and myocardial expression of neutrophil gelatinase-associated lipocalin in clinical and experimental heart failure. Eur. Heart J. 30, 1229-1236. 
Zhang, A. S., Xiong, S., Tsukamoto, H. and Enns, C. A. (2004). Localization of iron metabolismrelated mRNAs in rat liver indicate that HFE is expressed predominantly in hepatocytes. Blood 103, 1509-1514. 


\section{ACKNOWLEDGEMENTS}

To begin with the name of ALLAH Almighty who revealed through his beloved prophet Muhammad (PBUH) Read! In the Name of your Lord, Who has created (all that exists).

I feel enormous intensity of obligation and heights of gratefulness to my learned supervisor Prof. Dr. Giuliano Ramadori for his valuable guidance, positive criticism, stimulating ideas and extreme patience with my work which proved to be a panacea in the completion of this dissertation. I deeply appreciate the time he spent supervising and teaching me. I express my particular gratitude to my scientific supervisors; Prof. Dr. Gregor Eichele and Prof. Dr. Lutz Walter for their outstanding supervision, support and contribution to my success. Their constructive cricism and suggestions are highly appreciated.

My sincere thanks to my co-guide Dr. Ihtzaz Malik for his practical advices and the time he spent for time to time discussion, valuable suggestions to my work and Prof. Tilman Sauerbruch for his support to complete my project.

I am very grateful for all other colleagues Dr. Sadaf Sultan, Dr. Naila Naz, Dr. Silke Cameron, Dr. Sajjad Khan and Gesa Martius in the department for providing me nice and friendly working atmosphere. I am also grateful to the technical personnel of the department, especially S. Zachmann, C. Dunaiski and E. Neumann for their significant help during these years.

A special thanks to my brother Shaukat Ali without whom I could never think to conquer this entire break, a special gratitude to him. Words are inadequate to convey sincere gratitude to my friends Dr. Saima Zafar, Dr. Ghayyor ahmad, Ibrahim Sheikh, Waqas Tahir and Mohsin Shafiq who were always there to build up my hope and courage whenever I felt down to earth. My kind regards for Mr. Muhammad Haroon for helping me out during my stay in Goettingen.

Last but not the least; I must not miss the opportunity to acknowledge the role of my parents and family in my success. Without their support it would have been a dream which became a reality today and I finished my Ph.D. Thank you all.

Shakil Ahmad 
Dedication

Q dedicate my thesis to my elder brother
QShaukat $\mathcal{A l i}$ 


\section{CURRICULUM VITAE}

$\begin{array}{ll}\text { Family Name } & \text { Ahmad } \\ \text { First name } & \text { Shakil } \\ \text { Date of birth } & 05.12 .1981 \\ \text { Place of birth } & \text { Lahore, Pakistan } \\ \text { Nationality } & \text { Pakistani }\end{array}$

\section{Academic Information:}

Oct-2010-Jan- 2014:

$2008-2010$ :

$2002-2004:$

$2000-2002:$

$2000:$

1995 - 1997:
PhD (Biology)

Department of Gastroenterology and Endocrinology,

University Medical Center, Georg-August University,

Goettingen, Germany

Title: "Effect of acute phase cytokines on iron uptake in hepatocytes and differential localization of Lipocalin-2 and Transferrin receptors in rat hepatic and extra hepatic organs".

Master of Philosophy (Molecular Cell Biology)

King Edward Medical University, Lahore, Pakistan

Title: "Detection of polymorphism in bovine (Bos indicus)

DGAT1 (Diacylglycerol o-acyltransferase) gene.”

Master of Science (Zoology)

University of the Punjab, Lahore, Pakistan

Bachelor of Science

Forman Christian College, Lahore, Pakistan

F.Sc (Pre-medical)

Lahore, Pakistan

Matric, Lahore, Pakistan 


\section{$\underline{\text { Research Skills }}$}

Molecular Biology \& Biotechnology

DNA \& RNA Purification, Gel Electrophoresis, PCR

\section{Cell Biology}

Cell Isolation (expertise in Rat \& Mice Hepatocytes and Kupffer Cells Isolation) \& Culture Maintenance, Tumor Cell Lines Culture, Gene Knockdown Techniques

\section{Protein Chemistry \& Biophysics}

Standard Protein Purification Techniques, Co-immunoprecipitation, 1-D and 2-D Electrophoresis and Blotting Techniques, Micro-HPLC, Capillary Electrophoresis, Confocal Microscopy,

\section{Histochemistry}

Tissue Microtomy (Paraffin and cryostat sectioning), Immunostainings (Immunofluorescence, Peroxidase), APAAP , TUNEL and H \& E Staining,

\section{Microbiology \& Parasitology}

Isolation, Identification, Culture maintenance of Bacteria and Fungi

\section{Bioinformatics}

Primer Designing, Blast2Sequence, Sequence alignment, Cluster analyses, 32 Karat software, Graphpad prism, Excel, Image J. SPSS

\section{Instrumental Expertise}

PCR (Conventional and Real Time), Spectrofluorometer, Spectrophotometer, Electrophoresis and Blotting systems, Ultra-centrifuge, Microscopes, Confocal Microscope, Lypholizer, HPLC

\section{Awards/Scholarships:}

1. PhD Stipend from Gastroenterology and Endocrinology department of UniversitäteMedizin, GeorgAugust University Goettingen, Germany, 2010-2013

2. Post-graduate (M.Phil) Stipend from Pakistan Medical and Dental Council (PMDC) 2008-2010 


\section{$\underline{\text { Research and Teaching Experience: }}$}

1. Visiting Lecturer in King Edward Medical University, Lahore Pakistan, from January 2010 to June 2010.

2. Research Officer in Parasitology Lab of Zoology Department at Punjab University, Lahore, Pakistan, for one year (2005-06) and developed a pregnant mice model to study the adverse effects of antimalarial drugs in different tissues.

\section{$\underline{\text { Publications }}$}

1. Ahmad S, Sultan S, Naz N, et al; 2013. Regulation of iron uptake in primary culture rat hepatocytes: The role of acute phase cytokines: Shock.

2. Ahmad S, Moriconi F, Naz N, et al; 2013. Ferritin L and Ferritin H are differentially locat-ed within hepatic and extra hepatic organs under physiological and acute phase conditions: Int J Clin Exp Pathol. 6(4):622-9.

3. N. Naz, S. Ahmad, S. Cameron, et al; 2013. Differential regulation of ferritin subunits and other iron regulatory proteins - an effect of targeted hepatic X-irradiation: Biomed. Res. Int.

4. Alwahsh SM, Xu M, Seyhan HA, Schaefer I, Ahmad S, et al; 2013. Diet high in fructose leads to an overexpression of lipocalin-2 in rat fatty liver model: World J Gastroenterol.

5. Birlea SA, Ahmad FJ, Uddin RM, Ahmad S, et al; 2013. Association of Generalized Vitili-go with MHC Class II Loci in Patients from the Indian Subcontinent: $J$ Invest Dermatol. 133(5):1369-72.

6. Uddin RM, Babar ME, Nadeem A, Hussain T, Ahmad S, Munir S, Ahmad FA. 2013. Ge-netic Analysis of the Prolactin gene in Pakistani cattle: Mole Biol Rep.

7. Rave-Fränk M, Malik IA, Christiansen $\mathrm{H}$, Naz N, Sultan S, Amanzada A, Blaschke M, Cameron S, Ahmad S, Hess CF, Ramadori G, Moriconi F. 2013. Rat model of fractionat-ed (2 Gy/day) 60 Gy irradiation of the liver: long-term effects: Radiat Environ Biophys. 52(3):321-38.

8. Naz N, Moriconi F, Ahmad S, et al; 2013. Ferritin L is The Sole Serum Ferritin Constituent and a Positive Hepatic Acute Phase Protein: Shock. 39(6):520-6. 
9. N. Naz, IA. Malik, N. Sheikh, S. Ahmad, et al; 2012. Ferroportin-1 is a 'nuclear'negative acute-phase protein in rat liver: a comparison with other iron-transport proteins: Lab Invest. 92(6):842-56.

10. Sultan S, Cameron S, Ahmad S, et al; 2012. Serum Lipocalin-2 is a potential Biomarker of Liver irradiation damage. Liver Intl 33(3):459-68.

11. Sultan, S., M. Pascucci, S. Ahmad, et al; 2012. LIPOCALIN-2 is a major acute-phase protein in a rat and mouse model of Sterile Abscess: Shock. 37(2):191-6.

\section{Abstracts and Posters presented}

1. S. Ahmad, N. Naz, F. Moriconi, IA. Malik. Differential localization of transferrin receptors and lipocalin-2 in rat hepatic and extra-hepatic organs during acute phase response. J Gastro-enterol 2014; 52 - P_3_07 (DOI: 10.1055/s-0033-1360926)

2. S. Ahmad, N. Naz IA. Malik, P. Ramadori, A. Amanzada, G. Ramadori, F. Moriconi. Role of the hypoxia inducible factors during hepatic repair in a rat model of thioacetamide (TAA)-induced chronic liver damage and cholangiocarcinoma. J Gastroenterol 2014; 52 - P_1_34 (DOI: 10.1055/S-0033-1360878)

3. N. Naz, S. Ahmad and IA. Malik. Ferroportin-1 is a'nuclear' -negative acute-phase protein in rat liver. EASL Conference April 2013 Amsterdam, Nederland

4. S. Ahmad, S. Sultan and G. Ramadori. Iron Uptake in cultured rat primary hepatocytes: A Role of Lipocalin-2. APASL-2013, Singapore. Hepatology International 06/2013; 7(Suppl 1):S2. (DOI 10.1007/s12072-013-9429-0)

5. S. Ahmad, S. Sultan, N. Naz, G. Ramadori and IA. Malik Erythropoietin (EPO) gene expression and regulation in rat liver after X-irradiation. APASL-2013, pore. Hepatology International 06/2013; 7(Suppl 1):S36. (DOI 10.1007/s12072-013-9429$0)$

6. N. Naz, S. Ahmad, N. Sheikh and Malik IA. Ferritin L and Ferritin H are differentially located within hepatic and extra hepatic organs under physiological and acute phase conditions: APASL-2013, Singapore

7. Naz N, Ahmad S, Sheikh N, and Malik IA. Differential localization of iron transport proteins in rat liver and slpeen during acute phase response. GASL-Conference 2013, Hannover, Germany 
8. S. Sultan, S. Ahmad and S. Cameron. Expression of Lipocalin2 in upper and lower parts of the liver after lung irradiation. Falk Workshop, Targeted Therapies in Hepatology, January 24-25, 2013 Hannover Germany

9. Ahmad S, Sultan S, Naz N, Malik IA and Ramadori G. Lipocalin-2 role in transferrin receptor 1 dependent and independent iron uptake in cultured rat primary hepatocytes. 2nd World Congress on Cell Science \& Stem Cell Research, J Cell Sci Ther 2012, 3:8, November 12-14, 2012 San Antonio, USA (DOI:10.4172/2157-7013.S1.021)

10. Naz N., Ahmad S., Sheikh N., Mihm S., Ramadori G. and Malik I.A. Ferritin L is the sole serum ferritin constituent and a positive hepatic acute phase protein. 2nd World Congress on Cell Science \& Stem Cell Research, J Cell Sci Ther 2012, 3:8, November 12-14, 2012 San Antonio, USA (DOI:10.4172/2157-7013.S1.021)

11. Sultan S, Ahmad S, Pascucci M, Ramadori G. Changes of LCN-2 gene expression in different organs in a rat model of tissue damage. GASL-Conference 2012, Hamburg, Germany

12. Sultan S, Cameron S, Ahmad S, Malik IA, Ramadori G. Serum Lipocalin-2 (LCN-2) is a potential Biomarker of Liver irradiation. ASCO-annual meeting, J Clin Oncol 30, 2012 (suppl; abstr e13039), Chicago, Illinois, USA

\section{Computer and Software Skills:}

Microsoft office, Operation of Windows XP, Vista, 7, 8 and 8.1, Graphpad prism 4 and 5, Axio-vision 4 software, ABI Prism 7000 system, Step one software, Reference manager, Adobe pho-toshop, Adobe acrobat professional, 32 Karat Software 